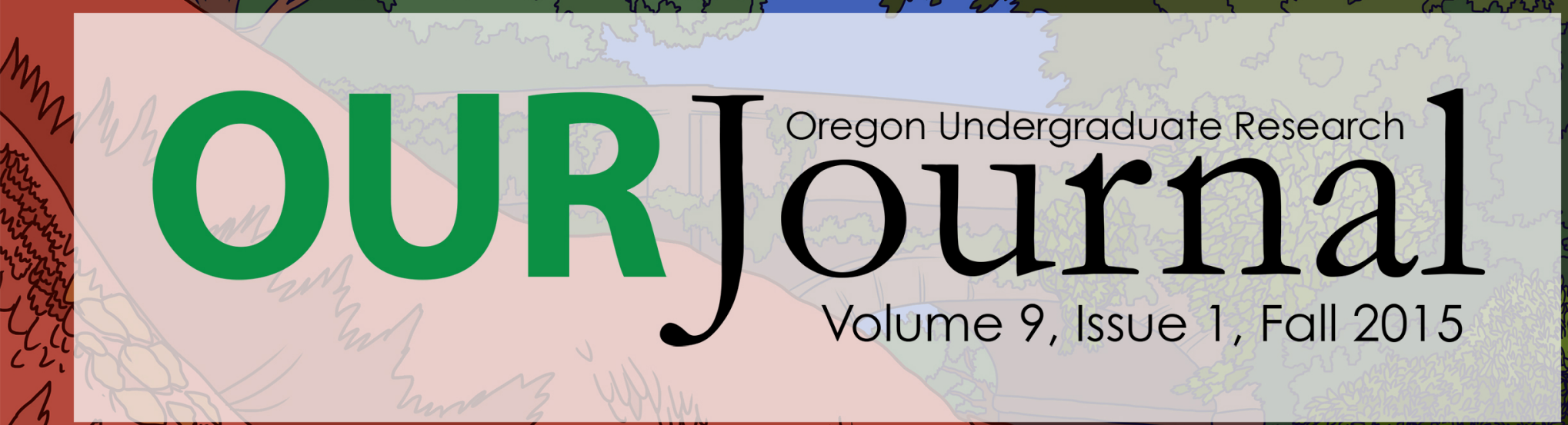

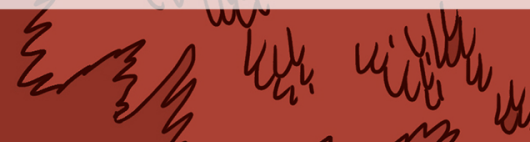
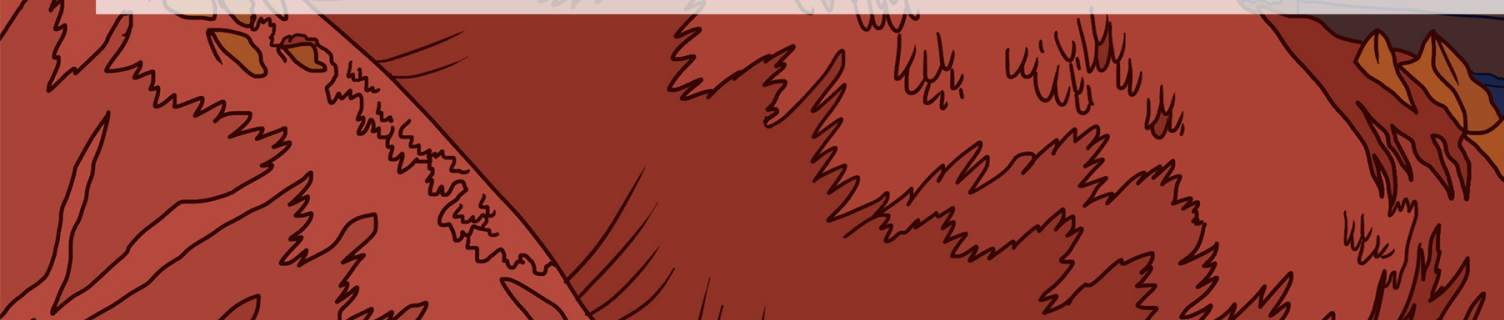

$\mathrm{m}^{2} \mathrm{O}^{2}$

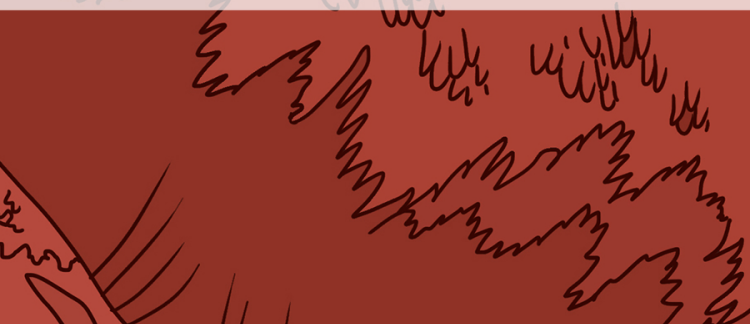


(c) (7)

\section{Volume 9, Issue 1, Fall 2015}

\section{TABLE OF CONTENTS}

\section{WELCOME}

Letter from the Editor

Artist's Statement

Basil Price

Guest Editorial

\section{ARTICLES}

Sexuality, Gender, and US Imperialism after Philippine

Bible Reveal about Yahweh's Nature?

Jonathan Faris

Searching for the Nearest Extragalactic Binary Black Hole: A

Spectroscopic Study of NGC 4736

\section{Annika Gustafsson}

Adamov's Alienation Effect: Showing the Absurdist Slant of the

Epic Theatre Aesthetic

Nicholas Maurer

GPU-Imogen: An Astrophysical Hydrodynamic Code 


\section{Letter from the Editor}

\section{Aidan Grealish, Digital Arts and Clark Honors College*}

Fall at the University of Oregon is a time of transition, and this issue is no exception. As a publication staffed entirely by and focused on undergraduates, we as a journal must adapt in order to keep up with the constant flow of undergraduate research and innovation. Naturally, this often means that Editors come and go as they graduate and move on to bigger and better things. Our superb former Editor-in-Chief, Charlotte Rheingold, graduated this past spring and is now living and working in France post-graduation; we truly wish her all the best and are thankful for all the work she did for the OUR Journal. Along with a new Editor-in-Chief, we are also welcoming an almost entirely new Editorial Board. I am excited to help usher in a new era of the OUR Journal as one that will foster truly interdisciplinary, creative scholarship through our growing relationship with the Undergraduate Symposium and the Undergraduate Research Opportunity Program.

As we reflect on the foundation laid by former Editors and look toward the future, I would like to express my gratitude to the faculty and staff that make our publication possible. I would like to thank Karl Reasoner in particular, who we have featured as the writer of this issue's guest editorial. He is one of the greatest proponents of undergraduate research here at the University of Oregon and he has offered us a perspective on the importance of research on the future of both scholarship and society. As the program manager of the Undergraduate Research Opportunity Program, he has a hand in directly encouraging research through stipends and networking opportunities; I hope that we will soon see the results of that support in the form of manuscripts that we can publish in OUR Journal. As ever, I would also like to acknowledge the support of our wonderful faculty mentors: Barbara Jenkins of UO Libraries and Kevin Hatfield of the Department of History and the Clark Honors College. Their help and guidance in this transitional time has been invaluable, and I cannot fully express my gratitude for their patience and assistance as we move forward into a new era of the Oregon Undergraduate Research Journal.

Fall 2015 is a new start for us, and I am thrilled to present the ninth issue of the Oregon Undergraduate Research Journal and my first as Editor-in-Chief. The Editorial Board and I are very happy to showcase a selection of some of the most diverse and interesting research projects conducted here at the University of Oregon. From black holes to absurdist theatre, we truly have a wide range of departments and subjects to highlight in this issue.

Thank you so much for celebrating undergraduate research with us. Enjoy!

\footnotetext{
*Aidan Grealish is a third year Digital Arts and General Science double major in the Clark Honors College. As a researcher in the Page lab in the Center for Sustainable Materials Chemistry, a peer tutor in the Art Department, and an OURJ editor, she works within a diverse range of subjects. Her research interests include human-centered design, digital humanities, and data ethics. Please direct correspondence to aidang@uoregon.edu.
} 


\section{(7)}

\section{Artist's Statement: “Line”}

\section{Basil Price, Department of Art}

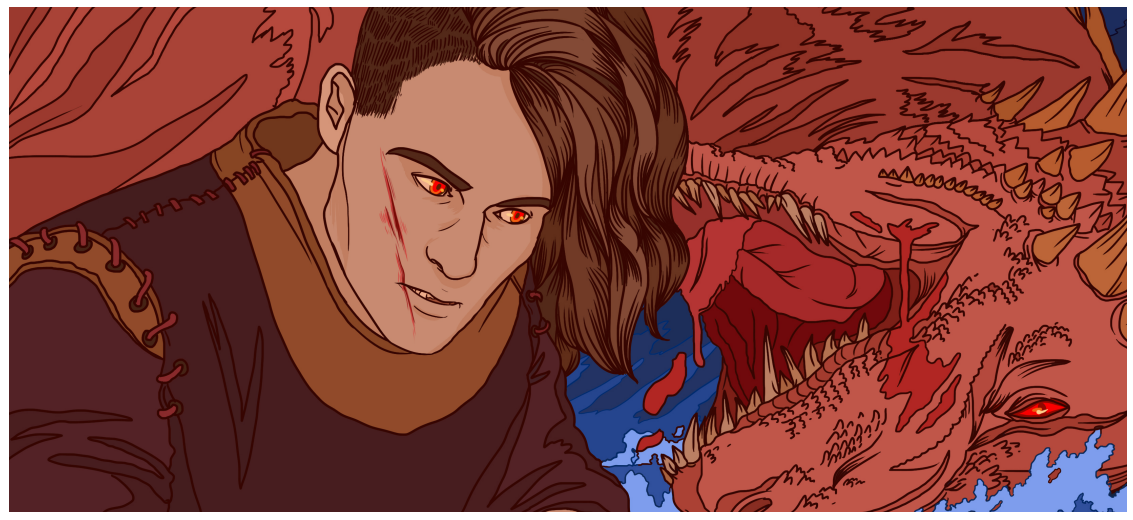

"Line" evokes, at the most surface level, the act of markmaking itself - the pen across the page. However, the word "line" evokes an image similar to that of a single "strand" - something fibrous, drawn, and done with full intent. The narrative is comparable to this interpretation of line; and when faced with the prospect of defining "line" in an image, its difficult for me to consider illustrating the idea of line without tapping into the much longer tradition of the line of narrative, the strands of story and verse. Old Norse's word for saga, derived from the verb "seigr" comes from an even older Indo-European form, which etymologically means a line or strand. Narrative was attached to line, and now - lines are narrative themselves.

Therefore, I attempt to utilize line as a means to tell a narrative, while reflecting upon the origins of my subjects - subjects that have ranged from medieval literary characters to 1970 s sword and sorcery characters. Although I work as a digital illustrator, the digital interface rarely inspires my work. Rather, I draw upon the rich history of medieval artwork, such as manuscript illumination to inform the style of my work. By utilizing bold lines, bright colors, and iconographic elements, the guiding style of my work is the notion of a manuscript come to life.

While my subjects are usually historical or fantastic figures, I often find myself lost in selfportraiture, reflecting upon my own role within both modern culture, and how I look back at my historical interests. I believe that it is important to not only think about one's relationship with the past and present, but also to consider why these stories, these sagas, and the "line" in general, are so enduring. Thus, much of what my artwork explores is how I, working and learning in the 21st century, can find so much common ground with stories that come from the 12th century. I don't yet have an answer to this question. What I do know is that by walking with one foot in the modern world, and one foot in the heroic past, I am able to explore complex themes of self identify, narratology, and folkloric practice within my work. 


\section{Guest Editorial}

\section{Karl Reasoner, Program Manager, Undergraduate Research Opportunities Program*}

During your undergraduate education many people will talk to you about why you should conduct research or creative scholarship and all of their reasoning will be solid. "Do research because it's at the core of a liberal arts education," harkens the endowed professor. "Do research because you will gain important skills and learn to think more critically," implores the academic adviser. "Do research so you can build up your credentials and make yourself more marketable," suggests the career adviser. I am guilty of using all of these reasons to encourage undergraduates to conduct research or creative scholarship. I don't feel guilty about it because there is a bevy of evidence that supports these assertions. Undergraduate research is the quintessential high impact learning practice, resulting in positive gains in important indicators of student success from persistence to skill acquisition to increased interest in academic pursuits to critical thinking. But that evidence has been around for decades now, and despite its appeal, participation in undergraduate research is still relatively low when viewed in contrast to its benefits. So I am going to try and appeal to a different motivating factor. I'm not going to say you should do research or creative scholarship to benefit yourself, I'm going to encourage you to conduct research and explore all forms of creative scholarship so you can save the world.

It is no secret that there is a general feeling of uneasiness about the future amongst millennials. The current generation of college students faces what appears to be an array of diverse, complex and wicked problems, including everything from climate change to pandemics to college debt and underemployment to extreme poverty and homelessness. And while sitting through lectures, earning good grades and receiving a baccalaureate degree will help prepare you to enter the work force as an effective professional, that qualification alone is not enough to tackle the issues you will face. The world needs ambitious thinkers and innovators. It needs big data explorers and disrupters. It needs compassionate and creative organizers, planners, and designers. And it needs learned public servants and nuanced policy makers. In short, the world needs people with a researcher's mentality and tenacity. So the next time you experience that intellectual itch during a class or while reading a text, consider exploring it further. Begin now to foster an inquiring mind; it will reap benefits down the road that you cannot currently conceptualize.

From this perspective, when your network of faculty mentors, instructors and advisors suggest that you should consider conducting research or creative scholarship, they are asking you, in part and implicitly, to be selfless. They are encouraging you to pursue your interests while considering the greater good. And they are urging you to make discoveries that can improve the human condition. If you want to prepare yourself to save the world, conducting

*Please direct inquiries to kreasoner@uoregon.edu. 
research and creative scholarship is as good of a place as any to start. We are all depending on it.

Fortunately, at the University of Oregon, there are many opportunities to get involved in research; whether it is in a lab, in the studio, at an archive, out in the field, at an incubator or in a study carrel at the library. There is also a suite of resources available to support your research activities. You can apply for an Undergraduate Research Opportunity Program (UROP) Minigrant to obtain up to $\$ 1,000$ in financial support for materials, supplies and/or travel that is necessary to conduct research or creative scholarship. You can also apply for the Vice President for Research and Innovation (VPRI) Fellowship and receive a \$5,000 stipend to conduct research or creative scholarship over the summer. Both of these programs are open to students from every academic discipline on campus.

There are also research programs that are more discipline specific, such as the Presidential Undergraduate Research Scholars program for students majoring in chemistry, physics, geological sciences and mathematics, or the Humanities Undergraduate Research Fellowship program for students conducting humanities related research. These programs only scratch the surface of the list of opportunities available to you at the University. On campus there are over twenty research programs to apply to and there are hundreds more open to you at institutions in the United States and around the world. You are only limited by your ambition and your time here, so make it count. 


\title{
Sexuality, Gender, and US Imperialism after Philippine Independence: An Examination of Gender and Sexual Stereotypes of Pilipina Entertainment Workers and US Servicemen
}

\author{
Paulla Santos, History*
}

\begin{abstract}
This paper examines the continuation of United States imperialism in the Philippines after Philippine Independence in 1946 through the gendered and sexual stereotypes of US men and Philippine women. These perceptions of the women as submissive and dependent were constructed through women's interactions with US military men, who were present due to growing US concern of eastern communist influence in the second half of the $20^{\text {th }}$ century. Evidence from these rest and recreation areas near the bases during this time suggests US servicemen were seen as powerful and wealthy, while the Philippines appeared submissive and dependent on US power, as represented by Philippine women's behavior towards the servicemen. The Philippine presidencies of Ferdinand Marcos and Corazon Aquino also transformed identities particularly of Philippine women. These ranged from the support and promotion of Pilipina entertainment workers to condemning and imprisoning them. However, this paper illuminates instances of Pilipina agency that show how many Pilipinas were not simply victims to US power within these entertainment districts, but also sought employment opportunities in order to benefit from the circumstances created by US presence and provide for themselves, their families, and their country. This paper then connects the events around US military bases at that time to present-day stereotypes associated with Asian-born women married to US men in the United States, as well as the current discussions of reopening of the US military bases in the Philippines.
\end{abstract}

\section{INTRODUCTION}

With the end of the Spanish-American War, the 1898 Treaty of Paris officially started the legacy of US imperialism in the Philippines. Prior to US colonial rule, Spain controlled the islands for approximately 300 years. Despite the establishment of a government by Philippine nationalist Emilio Aguinaldo after the US and Philippine military forces defeated the Spanish, US presence remained in the Philippines. Although a small population of Pilipino elites saw the

\footnotetext{
* Paulla Santos is a junior history major in the McNair Scholars Program at the University of Oregon. She was a Drum Major for the University of Oregon Marching Band, played for the University of Oregon Women's rugby team, and is currently a Program Coordinator for the campus organization Intercultural Mentoring Program Advancing Community Ties (IMPACT). Her research interests include the history of gender and sexuality, the Philippines, Filipino Americans, and immigration. Paulla plans to attend graduate school after leaving the University of Oregon in order to pursue a career in academia. Please direct correspondence to paullasantos23@gmail.com.
} 
personal socioeconomic benefits of working with US officials in the colonial government, Pilipino nationalists were once more disheartened by the inability to determine their own destiny through self-governing. ${ }^{1}$ When US politicians discussed whether the US should continue its possession over the Philippines in 1903, President William McKinley supported the US presence by stating that God himself told him that it was the role of the US "to educate the Filipinos, and uplift and civilize and Christianize them."2 Although Christianity was already prevalent in the Philippines because of Spanish rule, this attitude led to continued US involvement in the Philippines that would heavily impact Pilipino culture and the perception of the Philippine people, even after the country achieved independence in 1946.

Despite the Philippines attaining sovereignty in the mid-20 ${ }^{\text {th }}$ century, a new form of US imperialism emerged with the passage of the Military Bases Agreement on March 14, 1947. To the dismay of Philippine nationalists who pushed for complete separation from the US, many Philippine officials and even some US politicians desired a connection between the two nations for economic and political reasons. A struggling agricultural-centric Philippine economy and the US-envisioned growing threat of communism in Asia were both critical factors that justified the passage of the agreement. ${ }^{3}$ Officials from both sides saw a potential symbiotic relationship between the two countries. However, it was a relationship where the US was dominant, wealthy, and played the role of the protector, while the Philippines was weak, dependent, and in need of support. The bases agreement between the two nations permitted the presence of US military bases in the Philippines with a tenure of approximately one hundred years, which added to the already existing Philippine military bases. ${ }^{4}$ Rather than the direct rule previously enforced over the Philippines by the US, the presence of US servicemen stationed at US military bases such as Clark Air Base and Subic Bay Naval Base inadvertently shifted social and economic spheres of Philippine society, especially in regard to the lives of Philippine women.

During their time in the Philippines, US servicemen would enter surrounding cities such as Angeles and Olongapo for leisure in "rest and recreation" (R\&R) establishments, places which changed over time to cater to their evolving social and sexual needs. These developments included hotels, bars, brothels, gambling dens, and other nightlife venues. ${ }^{5}$ Many of these spaces offered alternative employment options to Pilipinas that would otherwise be faced with limited lower paying agricultural jobs. ${ }^{6}$ According to sociologist Kathleen Barry, the underdevelopment of the Philippine economy was due to its exposure to warfare, which pushed women to the life of prostitution and other jobs.7 Although an "underdeveloped" Philippine economy and warfare may have caused many women to labor as sex workers, it was not the primary form of work for most women. Jobs ranged from sexual services such as prostitution and exotic dancing to gender-oriented services that resembled traditional US notions of women's roles. For example, Pilipinas working as waitresses and bar girls acted in a demeanor that was stereotypically feminine-subservient and dependent-qualities that were displayed to fulfill the desires of servicemen and make money. Although popularly seen as exploitive, these jobs did enable them to better provide for themselves through the opportunity created by the presence of US servicemen. The relationship between US servicemen and Pilipinas was one that cannot simply be defined as US men taking advantage of a poor Philippine economic situation, but rather was a form of symbiotic exploitation. In other words, both groups found benefits from the situation, 
despite each of them being taken advantage of in some way. These relationships created and perpetuated stereotypes based on gender, sexuality, and even nationality, which created power imbalances between the two countries.

Despite US power over the Philippine population, to say Pilipinas were simply victims of US influence risks omitting part of their history. Pilipina agency also contributed to the molding of these gender and sexual stereotypes. To make a living in these industries, a Pilipina abided by these US-preferred female characteristics to financially provide for herself and her family. Although the new form of US imperialism heavily influenced these actions, Pilipinas also sought out the opportunities that arose from growing $R \& R$ industries for their own personal benefit.

Scholars who have studied the rest and recreation industries around US military bases have primarily focused on the colonization of Philippine women through prostitution and sexual violence by US servicemen. Bananas, Beaches, and Bases by Cynthia Enloe, The Prostitution of Sexuality by Kathleen Barry, and Sex, Money, and Morality by Tranh-Dam Truong are prime examples. Although they provide insight to an understudied subject, there is still a lack of examination into the everyday and intimate relations between US servicemen and Pilipinas around US military bases outside of prostitution. Fortunately, a rising consciousness among the suppressed groups of the world and the scholars within these factions continue to unearth and analyze the stories of Philippine women working in these industries. ${ }^{8}$ Therefore, to contribute to existing knowledge, I provide specific examples of continued US imperialism after Philippine Independence in 1946 in the form of the gendered and sexual associations between US servicemen and Pilipinas. By examining the early development of servicemen's perspectives of Pilipinas and vice versa after World War Two, the Vietnam War period, and the Philippine presidencies of Ferdinand Marcos and Corazon Aquino, it can be observed that interactions both intimate and casual between US servicemen and Pilipinas portrayed servicemen as powerful, dominant, and wealthy-the embodiment of the US- and Pilipinas reflected the Philippines as submissive, controllable, and dependent on US power.

\section{THE POWER OF THE EXOTIC: EARLY DEVELOPMENT OF THE PILIPINA IMAGE}

Before the Military Bases Agreement in 1947, US involvement in the Philippines during World War Two helped form US perceptions of Pilipinas that continued even after Philippine independence. These views of Pilipinas stemmed from US servicemen's fascination with the "exotic". Former professor of English and Comparative Literature at Columbia University Edward Said argues that Americans generally did not view Asia or the "Orient" the same way as Europeans, who saw it as "a place of romance, exotic beings, haunting memories and landscapes, [and] remarkable experiences."9 However, many US servicemen found Philippine women sexually attractive because they possessed a sense of otherness- a culture different from their own. The oriental exoticism of Pilipinas by US servicemen after World War Two was facilitated by US music and through photographs taken in the Philippines that were shared amongst servicemen. 
Furthermore, music written about US servicemen and Pilipina interactions reflected the relationship between the imperial US and the Philippine colony: Pilipinas were dependent, beautiful, and possessable, while US servicemen became the caretakers and dominant figures in the relationship. For example, on September 17, 1946, US country singer Ernest Tubb released the song Filipino Baby. This song communicated the sadness among US servicemen as they left their Pilipina sweethearts to return to the US after World War Two. When describing the Pilipinas, Tubb sang:

\section{[Chorus]}

She's my Filipino baby

She's my treasure and my pet

Her teeth are bright and pearly

And her hair is black as jet

Oh, her lips are sweet as honey

And her heart is true I know

She's my darlin' little Filipino Baby. ${ }^{10}$

This song by Ernest Tubb spread these objectifying images of Pilipinas through servicemen and prompted a focus on the physical qualities of the women. In another portion of the song, Tubb sang, "When up steps a little sailor with his bright eyes all aglow, sayin' 'Take a look at my gal's photograph.' Then the sailors gathered round him just to look upon her face and he said, 'I love my Filipino baby." 11 The sailor showing off a photo of his Pilipina sweetheart reinforced notions of patriarchy and the infatuation with the exotic. The repetitive use of the word "my" indicates possession of Pilipinas, for they were objects to be had. The line "gathered round him just to look upon her face" suggests the men primarily desire to see a beautiful and attractive woman, neglecting to learn this woman's character. This song demonstrates how servicemen were eager to discuss their experiences in the Philippines and encounters with Philippine women, and it is this open dialogue which further spread a patriarchal exotic fantasy revolved around Philippine woman.

After the passage of the Military Bases Agreement and the evolution of the gendered and sexual stereotypes associated with Pilipinas through music, word of mouth, and photographs, new waves of servicemen entered the islands with this sexualized, exotic fantasy in mind. An online gallery composed of photographs submitted by former US servicemen who spent some period of time in and around the Subic Bay Naval base before the closure of all US bases in 1991 displays a trend that portrays Pilipinas as submissive to US servicemen. The website is designed and managed by former US Marine Sgt. Howard James Holub. One particular photograph titled, "Beach Party at Subic Bay 1954" (Fig. 1) conveys the romanticized life similar to the one portrayed in Tubb's song. ${ }^{12}$ 


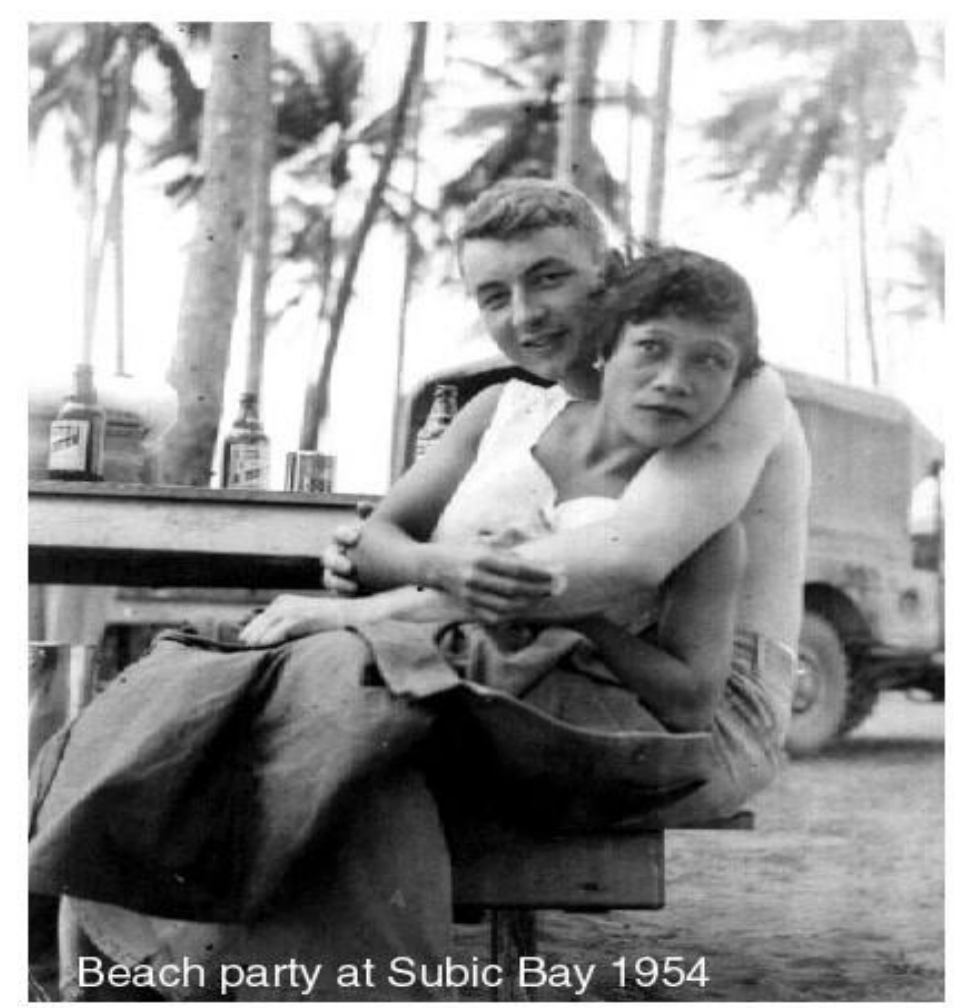

Figure 1

The body language within the photograph reveals the power dynamics between the US servicemen and Pilipinas as well as US-Philippine relations. As the title indicates, the serviceman sits at a beach picnic table with a grin on his face while holding a Pilipina close. He appears to be enjoying himself as the dominant person in the situation with a "Filipino baby" on his lap and in his arms. At the same time, the woman appears to express discomfort. One could argue that she may have been unprepared for the photo, but her absent smile and strained facial expression suggests otherwise. Furthermore, her gaze is off to the side, which could stem from a resistance to participate, and indicates a level of overall dissatisfaction with the situation. The Pilipina's body looks awkward and tense and is supported by the serviceman's embrace, suggesting her comfort was not a priority. This photograph gives insight into the everyday interactions between US servicemen and Pilipinas, which exhibit US imperialism over the Philippines at a personal level.

The dissemination of the Pilipina exotic fantasy through music, photographs and word of mouth between US servicemen reinforced prior notions of the submissiveness and helplessness of Pilipinas that developed during the colonial era and gained strength during the World War Two. These forms of communication contributed to the already-present perceptions US servicemen held of Philippine women in $R \& R$ industries. These perceptions were based on dominant-submissive power dynamics, which were a reflection of the traditional heteronormative narrative between US men and Pilipinas. These power dichotomies prompted 
the early transformation of US imperialism in the post-independence Philippines to one of intercultural dominance over the Pilipinas at a community level.

\section{THE VIETNAM WAR AND HEIGHTENED DEMAND FOR RECREATIONAL SERVICES}

The increase of US servicemen in the Philippines during the Vietnam War period (19641973) catalyzed the rapid growth of R\&R districts, which perpetuated the exotic fantasy among servicemen by exposing larger numbers of servicemen to the image of Pilipina submission. The increase of US military in the Philippines was caused by the US' fear of growing communist sentiments in Southeast Asia, and the Philippines provided strategic positioning if conflicts arose in the region. ${ }^{13}$ Sociologist Leopoldo M. Moselina stated that in 1964 there were approximately 98 US ships that entered Subic Bay for maintenance and to provide rest for sailors. In 1966, the number of ships arriving in Subic Bay grew to $193 .{ }^{14}$ With this rapid increase of military personnel in US bases, it is unsurprising that the number of R\&R establishments in entertainment districts rapidly increased to keep pace with the demands of the increasing population of US servicemen who were eager to spend their wages. ${ }^{15} \mathrm{R} \& \mathrm{R}$ development further supported perceptions of the US' dominance and wealth through the US servicemen's consumerism and the profit Pilipinas received by catering to servicemen's needs through gender-oriented labor.

Throughout rest and recreation districts, US consumerism dictated what services wereprovided. While examining another online photo gallery titled, "Olongapo 1965", one can see the numerous comments left by former US servicemen. A majority of the comments consist of these men reminiscing about their time in Olongapo. One specific post stated:

Hostesses populated every club providing drinks and companionship to sailors whose diet had been deficient in both...The American sailors found what they wanted in this combination of rock and roll, women, and San Miguel. ${ }^{16}$

There is an endearing tone in his poetic comment, which bears fond memories of his life in Olongapo. It was not only the food and drinks that the Pilipina waitresses provided, but also companionship that fulfilled US servicemen's social and sexual "diets." US servicemen sought Pilipinas, music, and alcohol to fulfill their needs, and Philippine businesses found profits in providing these "commodities".

Many Pilipinas who worked in these bars portrayed themselves in ways that would persuade US servicemen to spend more of their money. Women incorporated various strategies such as dressing in very little clothing, performing in musical groups (Fig. 2), and acting in a flirty demeanor. ${ }^{17}$ 


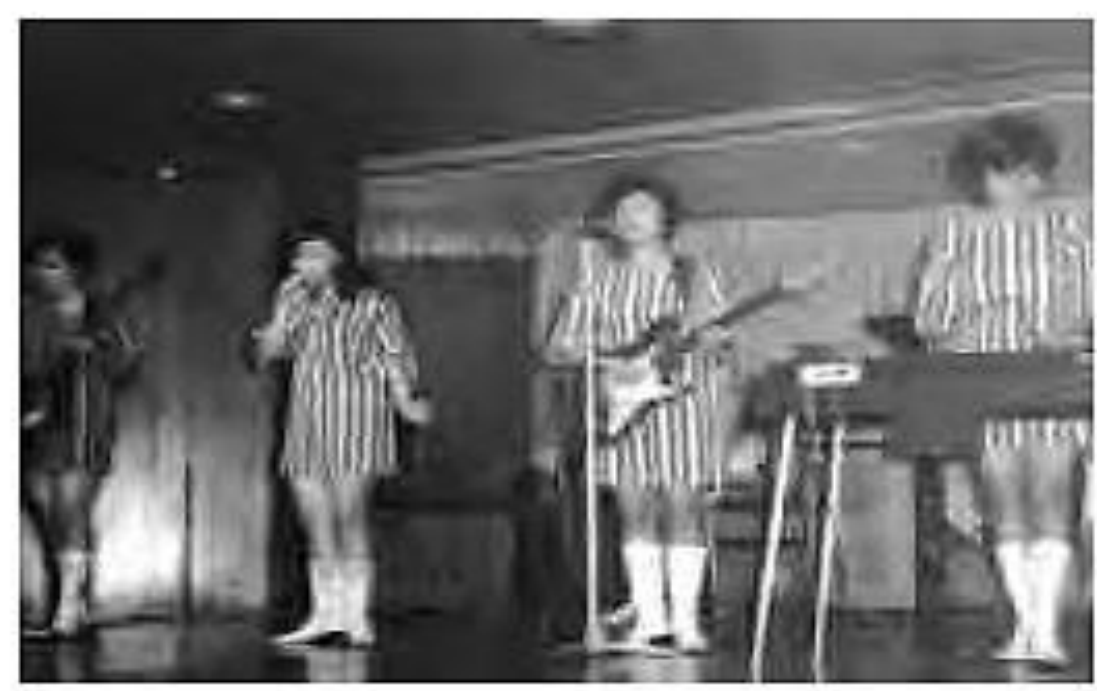

Figure 2

These strategies may be viewed in various ways. One may see Pilipinas controlled by US power, put on display for the pleasure of servicemen. A different interpretation is that Pilipina agency led these women to embrace their jobs and sexuality to deceive servicemen for their money. In other words, the US servicemen with obvious power were actually the victims of subtle manipulation by the seemingly powerless Pilipinas. Among the photographs on subicbaypi.com are numerous images of Pilipinas proudly posing while they work. Discussions of embraced sexuality tend to be silenced and covered by the stories of exploitation of Pilipinas. The latter is a critical factor in the history of many women who worked in R\&R industries after the Military Bases Agreement because it exposes the injustices that many Filipinas faced while working within these districts. However, the stories of triumph and success of the women who worked the system for their own benefit should also be acknowledged because they provide a more complete history of the experiences of these women.

The growing number of US servicemen during the Vietnam period ultimately broadened the exotic fantasy before and shortly after World War Two, which contributed to the rapidly increasing number of entertainment businesses, along with the volume of employment opportunities for Pilipinas. Given the struggling agricultural-centric economy throughout the majority of the Philippines during this time, Pilipinas made the most of these employment opportunities by profiting monetarily and, in some cases, embracing their sexualities, even though their jobs catered to the needs of their former colonizers, therefore extending US imperialism past its officially recognized end. ${ }^{18}$ Additionally, US' power to create a booming job market illuminated the continued dependency of the Philippine people in their time of need.

\section{PHILIPPINE PRESIDENTS AND THE PILIPINA IMAGE}

The Philippine presidencies of Ferdinand Marcos (1965-1986) and Corazon Aquino (19861992) respectively portrayed representations of Pilipina entertainment workers as national 
breadwinners of the Philippine economy or as threats to the Philippine national identity. According to Tranh-Dam Truong, Marcos' presidency encouraged Philippine sex-industries to utilize Pilipina sexuality to advance their national economy. ${ }^{19}$ Tourism, specifically sex-tourism, allowed higher valued foreign currency to enter the Philippines, despite continuing to place the Philippine people in a subservient position to the US. However, this economic ideology changed when Corazon Aquino entered office following Marcos in 1986. According to feminist scholar Cynthia Enloe, Aquino was not considered a feminist and found the prostitution of Pilipinas a deterioration of Philippine dignity. ${ }^{20}$ Rather than viewing prostitution as a potentially regulated and profitable profession, she sought to end it because of its perceived immorality. Ultimately, $\mathrm{R} \& \mathrm{R}$ businesses responded to Marcos' pro- sex tourism stance by implementing business strategies such as live music and business cards that highlighted Pilipina sexuality and upheld the exotic fantasy. However, with her stance on prostitution as well as the introduction of AIDS and HIV in the Philippines, Aquino mandated police raids of entertainment establishments, which stigmatized Pilipina entertainment workers as criminals instead of national breadwinners, and provoked backlash from Philippine feminist organizations who sought to better the conditions of Pilipina workers, especially when AIDS and HIV entered the Philippines. Both presidential positions were influenced by the results of US military presenceanother example of how the US continued to influence the minds and bodies of the Philippine people.

With the support of the Marcos government, R\&R businesses on the ground level implemented various business strategies such as live music containing sexual representations of Pilipinas in order to encourage profits. Music played within entertainment establishments not only created welcoming atmospheres for clients, but also reinforced notions of the exotic Pilipina fantasy already circulating the US bases. Similar to Tubb's Filipino Baby in 1946, Ballad of Subic Bay by the late 1960's-created Philippine band Eddie Tallada and Company, contains themes of US servicemen masculinity and sexuality. ${ }^{21}$ Tallada and Company sung:

Horny sailors, all are we for we must sail the seven seas.

One thousand miles we steamed today to see our girls in Subic Bay.

Silver dollar on my girl's breast, she's gone short time with America's best.

One hundred men she laid today, but only three in a normal way. ${ }^{22}$

The song is a parody of US singer Barry Sadler's Ballad of the Green Berets, which lauded the masculine, heroic and patriotic lives of servicemen from the US Special Forces, the Green Berets. ${ }^{23}$ Ballad of Subic Bay, set to the melody of widely popular Ballad of the Green Berets, reminded US servicemen of themes that were conveyed in the latter song. The song's melody added a familiar aspect to entertainment establishments aimed to attract servicemen to a space that appeared welcoming. The imagery of sailing "the seven seas" and travelling "one thousand 
miles" in one day for the sake of seeing the women in Subic Bay conveyed messages of romanticized perceptions of foreign adventure and virile masculinity. ${ }^{24}$ The second stanza objectifies Pilipinas. The lyrics connect masculinity with sexual prowess while promoting Pilipinas as commodities in the entertainment districts marketed toward US servicemen. Placing a silver dollar on the breast of a Pilipina signified the simplicity of acquiring whatever one desired, as if to say that if you have money to spend, you could purchase a wide range of services from the bars, restaurants, and especially from the women of the Philippines. This is further supported with the lyrics stating "One hundred men she laid today, but only three in a normal way.” 25 The Pilipina's sexual services were touted as highly accessible and serviced, to the extent that a hundred men were able to pay for them daily. Other music similar to the Ballad of Subic Bay conveyed messages of bravery and manliness associated with control over Pilipinas; this in turn heightened the appeal of R\&R establishments to US servicemen as they raced to fulfil this view, at the same time reinforcing the subservient characteristics of Pilipinas to US power.

Business cards distributed by R\&R businesses reveal the Pilipina services that made them servile to US servicemen. Although business cards were used prior to the Marcos period, Marcos' pro-tourism platform increased support for business strategies such as business cards that advertised Pilipina sexuality and would result in more revenue for the Philippine economy. The sexual services advertised on the business cards suggested a separation between women and their bodies. ${ }^{26} \mathrm{~A}$ Pilipina's body, as advertised, was not her own, but a sex toy ready for purchase by a US serviceman. A business card posted by an ex-serviceman in an online archive within a firearm club website reveals the various services Pilipina workers were expected to perform at “Marilyn's Super Inn” (Fig. 3) near Subic Naval Base. ${ }^{27}$

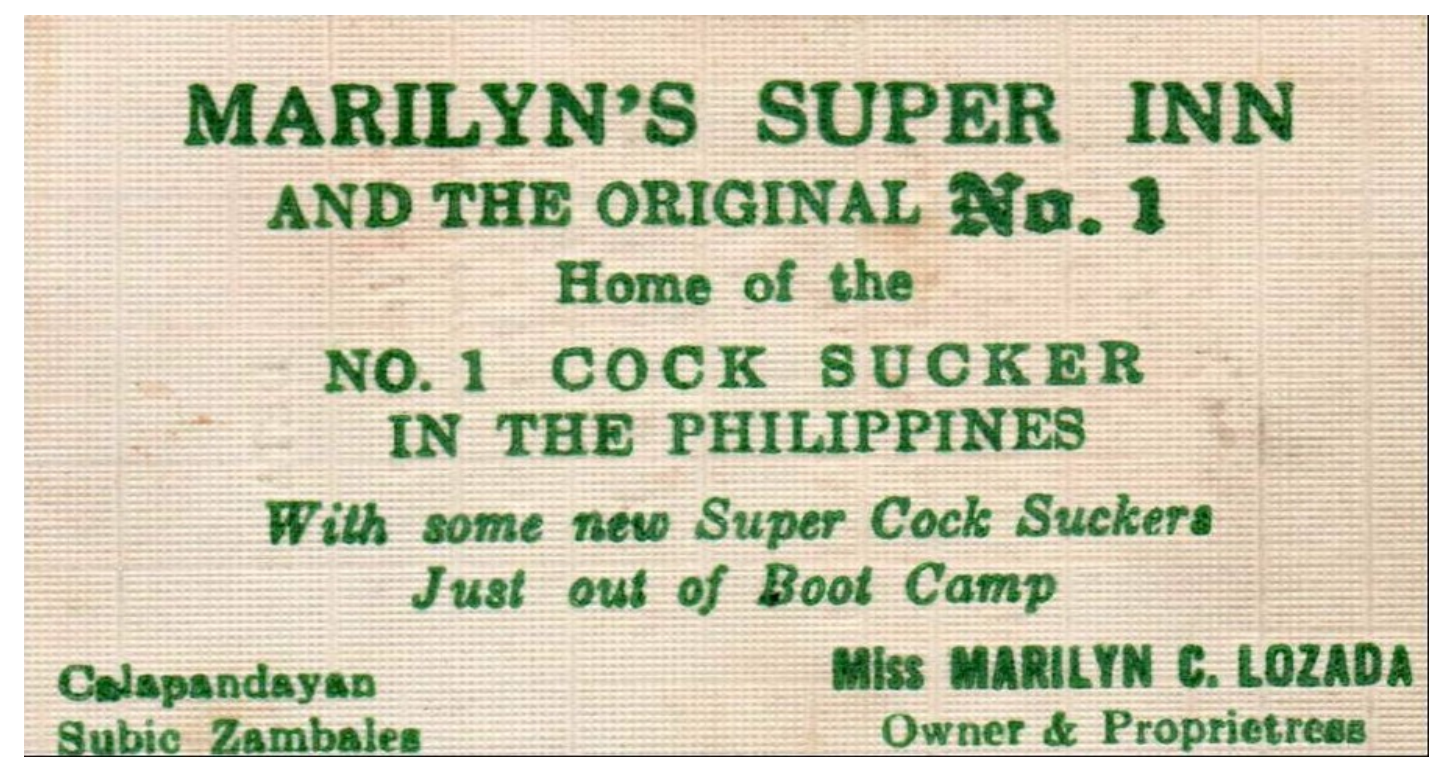

Figure 3

Figure 3 reveals the front of the business card. It advertises the "No. 1 Cock Sucker in the Philippines" as well as "some new Super Cock Suckers Just out of Boot Camp." The first claim 
dehumanizes the Pilipina and places her in the same category as a sex toy. The second line draws a connection between the Pilipina and the US servicemen. Like servicemen, these "cock suckers" right out of training are eager and willing to serve their commanders to the fullest, mimicking military command structure and appealing to the naval culture that the servicemen participated in. Marcos' pro-tourism economic strategy resulted in a recorded 150,000 foreign tourists in 1971, and nine years later that number was over one million. From 1974 to 1980, there was also an increase from 93 to 225 cocktail lounges in the Philippines. ${ }^{28}$ Under the presidency of Marcos, many Pilipinas were serving their country with their bodies while neglecting their inherent humanity.

Despite the growing amounts of revenue from tourism, President Corazon Aquino mandated police raids that transformed the Pilipina entertainment image from national provider to criminal. As stated earlier, Aquino was not a feminist, and primarily concentrated on the betterment of the Philippine national image rather than the well-being of Pilipinas. Despite this vision, her raids, most notably the raids that were conducted on dance-halls in Manila's entertainment district Ermita, stigmatized Pilipina women within the Philippines and even the US. In 1988, Aquino permitted a two-week long raid on the district, which resulted in the arrest of many Pilipina entertainment workers, but rarely were any male pimps or clients arrested. ${ }^{29}$ Pilipinas, as the majority of individuals arrested, showed that their sexual and gendered associations were also tied to crime. This situation was noticed by US news sources. A Los Angeles Times article conveyed:

The purpose of the two-week long police operation is to shut down the district forever- flowers, women, bars and all- an unprecedented effort to destroy Manila's international image as the "sin capital" of the Orient. ${ }^{30}$

In this US article, Pilipina entertainment workers were to be "shut down." They were viewed as criminals and needed to be eradicated with everything else associated with the Ermita entertainment district and other entertainment districts in the Philippines. Under the Aquino administration, these women were no longer viewed as economic assets by the Philippine government and were left with even fewer options to make a living.

Aquino's primary concentration on the Philippine national image, instead of the wellbeing of Pilipinas, prompted Pilipina Feminist organizations' attempts to better the lives of Pilipinas on the ground level. As examples of Pilipina agency, women took it upon themselves to create women's groups such as Gabriela, Women's Education, Development, Productivity and Research Organization (WEDPRO), and Katipunan ng Kababaihan para sa Kalayaan (KALAYAAN), which advocated for programs that would allow Pilipinas to gain skills and resources to pursue alternative employment. ${ }^{31}$ Rather than advocating for the incarceration of Pilipina entertainment workers in hopes of changing their ways, the organizations aimed to better the lives of these women by advocating for services that could better their lives. A survey report conducted by WEDPRO and KALAYAAN stated: 
Prostituted women have been denied so many things rightfully due them such as education, parental care and attention, justice for when she was abandoned with a child, battered or raped, health facilities, living wages, humane working conditions, dignity- the list is long and seemingly endless. ${ }^{2}$

The women in the two organizations argued that the wellbeing and dignity of Pilipina entertainment workers, not the nation, were most important when improving the image of the Philippines.

The introduction of AIDS and HIV into the Philippine islands in 1987 also added to the activism of these organizations and put the US presence in the spotlight among many Pilipinos. Philippine nationalists who desired the expulsion of the US bases blamed US servicemen presence as the cause of Philippine exposure to AIDS/HIV. The arrival of AIDS and HIV gave further reason to fight for complete separation from their former colonizer and attain Philippine sovereignty. 33 This brought a change to the US servicemen image that perceived them as unclean and dangerous. Although Pilipinas were always at risk of sexual violence, objectification, and sexually transmitted diseases, the introduction of AIDS/HIV presented another threat-one's permanent inability to financially provide for herself and for family members, since an infected individual would often be denied work. In an interview with a former bargirl, who is referred to as "Rose," she states: "It's just you know, my parents are just farmers. I'm sorry [apologizing for beginning to cry], it's a very very hard life...I know my parents could not afford to send me to college...So I tried to move hoping that one of these days I could have a better life." 34 Many of the individuals who worked as entertainers in these districts came from rural and economically depressed regions with few local opportunities for employment, and the contraction of HIV/AIDS eliminated one of their only hopes for a steady wage.

The presidencies of Ferdinand Marcos and Corazon Aquino provided two different political environments that affected the status of Pilipina entertainment workers. Whereas Marcos lifted up these women as the ultimate patriots and brought them to the forefront of Philippine economic development, Aquino denounced their economic and cultural contributions to the Philippines as immoral, indecent, and illegal, taking the steps she saw appropriate to dismantle the entire industry. The introduction of AIDS and HIV further stigmatized Pilipina sex workers, prompting many non-profit feminist organizations to step in and provide aid to these women. Philippine nationalists pushed for the separation of their country from such heavy US influence, after realizing the devastating effects of this continued form of US imperialism and the gendered and sexual stereotypes it brought along with it.

\section{RECENT IMPERIALISM}

The transformation of US imperialism in relation to Philippine people continues today. While examining the various exhibits at the Wing Luke Museum within the Chinatown International District of Seattle, one can find a long, white dress with large red postal stamps reading "fragile" and "return to sender" along the dress. ${ }^{35}$ It is a Wal-Mart mail order bride 
Halloween costume that sold in the early 2000s. It is a reminder of the legacy of power dichotomies between US men and Philippine women, epitomizing relationships with imperialistic qualities. "Fragile" upholds the belief that Asian women are weak, submissive, and in need of a protector. "Return to sender" signifies the women as commodities that are easily accessible and disposable when one is no longer satisfied with them. Further research needs to examine current marriages between Pilipinas and US men to understand how the aforementioned imperialistic power dynamics in the past have affected their daily lives in the US.

Although the Military Bases Agreement ended in 1991, there are currently discussions between the US and Philippine officials that would permit three to five US bases in the Philippines because of rising tensions with China's expansionist policies. Most notably, Subic Naval Base and Clark Air Base could potentially be reestablished. ${ }^{36}$ With the continued struggle of the Philippine economy and a quarter of the Philippine population in poverty from overpopulation and the lack of resources to support the impoverished, it would not be surprising to see the reemergence of the bustling rest and recreation districts. 37 The potential rebirth of the $\mathrm{R} \& \mathrm{R}$ districts could possibly revive the exotic fantasy and colonization of the minds and bodies of the Philippine people, especially those of Pilipinas.

\section{ACKNOWLEDGEMENTS}

I would like to thank Professor April Haynes for introducing me to the history of sexuality and inspiring me to pursue a career in academia. Special thanks to my mentor, Professor Julie Weise for her suggestions, enthusiasm, and encouragement throughout the writing process. Thank you to my girlfriend, Kim Bowen, who read numerous drafts and provided great insights in order to better my paper. Lastly, I would like to thank my mother, Annabelle Santos, for sharing her life with me. Her experiences in the Philippines and the United States are my inspiration for researching and writing the untold stories of Filipinos and Filipino-Americans.

\section{ENDNOTES}

1. Glenn May, "Philippine-American War 1899-1902” (lecture, University of Oregon, Eugene, OR, April 22, 2015).

2. General James Rusling, "Interview with President William McKinley," The Christian Advocate 22 January 1903, 17. Reprinted in Daniel Schirmer and Stephen Rosskamm Shalom, eds., The Philippines Reader (Boston: South End Press, 1987), 22-23.

3. Alexander R. Magno, "Cornucopia or Curse: The Internal Debate on the US Bases in the Philippines,” Kasarinlan: Philippine Journal of Third World Studies, no. 3 (1988): 8.

4. Setsu Shigematsu, Keith L. Camacho, and Cynthia Enloe, Militarized Currents: Toward a Decolonized Future in Asia and the Pacific (Minneapolis: University of Minnesota Press, 2010), 65 . 
5. Kathleen Barry, The Prostitution of Sexuality (New York: New York University Press, 1995), 123.

6. Cynthia Enloe, Bananas, Beaches and Bases (Berkeley: University of California Press, 1990), 86.

7. Barry, The Prostitution, 52.

8. Edward Said, Orientalism (New York: Vintage Books, 1979), 371.

9. Said, Orientalism, 28-29.

10. Ernest Tubb, Filipino Baby, (Decca, 1946), vinyl, from authentichistory.com, WWII In American Music: Wartime Romance, MP3 sound, 2 minutes and fifty-one sec., http://www.authentichistory.com/1939-1945/3-music/12-

Wartime_Romance/19460917_Filipino_Baby-Ernest_Tubb.html.

11. Ernest Tubb, Filipino Baby.

12. Sgt. Howard James Holub, "Nothing More Beautiful, Nothing More Fine," Subic Bay PI, accessed May 21, 2015, http://www.subicbaypi.com/town_photo_girls.htm.

13. Leopoldo M. Moselina, “Olongapo's Rest and Recreation Indsutry: A Sociological Analysis of Institutionalized Prostitution-With Implications for a Grassroots-Oriented Sociology," Philippine Sociological Review 27 (1979): 183.

14. Ibid., 183.

15. Barry, The Prostitution, 138.

16. Ron, September 25, 2014 (5:16 p.m.), comment on Carl Harstad, “Olongapo 1965," pbase.com, accessed May 21, 2015. http://www.pbase.com/charstad/olongapo\&page=1.

17. Sgt. Howard James Holub, "Nothing More Beautiful, Nothing More Fine," Subic Bay PI, accessed May 21, 2015, http://www.subicbaypi.com/sub_girls60_003.htm.

18. Barry, The Prostitution, 52.

19. Thanh-Dam Truong, Sex, Money, and Morality: Prostitution and Tourism in South-east Asia (London: Zed Books, 1990), 128.

20. Enloe, Bananas, 39 .

21. Eddie Tallada and Company, Ballad of Subic Bay, (OG's Records, late 1960s), record, from La Salle University Special Archives, Vietnam on Record Discography and youtube.com, 
audio, 3 minutes and 20 sec., http://speccoll.lasalle.edu/items/show/553, https://www.youtube.com/watch?v=2ca4FHwsLr4.

22. Barry, The Prostitution, 52.

23. Thanh-Dam Truong, Sex, Money, and Morality: Prostitution and Tourism in South-east Asia (London: Zed Books, 1990), 128.

24. Enloe, Bananas, 39.

25. Eddie Tallada and Company, Ballad of Subic Bay, (OG's Records, late 1960s), record, from La Salle University Special Archives, Vietnam on Record Discography and youtube.com, audio, 3 minutes and 20 sec., http://speccoll.lasalle.edu/items/show/553, https://www.youtube.com/watch?v=2ca4FHwsLr4.

26. Kathleen Barry, The Prostitution, 30.

27. Member HD357, “House of Repute III. How Many Remember This Place,” Archives, http://www.ar15.com/forums/t $15 / 1647810$ House of Ill Repute How many reme mber this place. html\&page $=1$.

28. Daniel B. Schirmer and Stephen Rosskam Shalom, The Philippines Reader: A History of Colonialism, Neocolonialism, Dictatorship, and Resistance (USA: South End Press, 1987), 182-183.

29. Enloe, Bananas, 39.

30. Mark Fineman, "Manila Tries to Shed Its Image as Sin City," Los Angeles Times, April 11, 1988, http://articles.latimes.com/1988-04-11/news/mn-631_1_sin-city.

31. Enloe, Bananas, 39. Virginia A. Miralao, Celia O. Carlos, and Aida Fulleros Santos, "Women Entertainers in Angeles and Olongapo: A Survey Report," Women's Education, Development, Productivity and Research Organization (WEDPRO) and Katipunan ng Kababaihan para sa Kalayaan (KALAYAAN), August 1990, 52.

32. Miralao, "Women’s Entertainers in Angeles and Olongapo: A Survey Report," 51.

33. Enloe, Bananas, 86.

34. Rose, in person interview by author, May 2, 2015.

35. Athima, Chansanchai, "Shedding Light on Exploitation," from Seattle Post Intelligencer in Wing Luke Museum Online Library (2005): 
http://db.wingluke.org/document.php?cat=library\&id=1900.4807.

36. Manuel Mogato, "Philippines to Give US Forces Access to up to Five Military Bases," Reuters, May 2, 2014, http://www.reuters.com/article/2014/05/02/us-philippines-usaidUSBREA4107020140502.

37. Philippine Statistics Authority-National Statistical Coordination Board, Poverty Incidence among Filipinos Registered at 25.8\%, as of First Semester of 2014-PSA, March 6, 2015, http://www.nscb.gov.ph/poverty/.

\section{REFERENCES}

Barry, Kathleen. The Prostitution of Sexuality. New York: New York University Press, 1995.

Chansanchai, Athima. "Shedding Light on Exploitation." From Seattle Post Intelligencer in Wing Luke Online Library (2007):

http://db.wingluke.org/document.php?cat=library\&id=1900.4807.

Enloe, Cynthia. Bananas, Beaches and Bases. Berkeley: University of California Press, 1990.

Fineman, Mark. "Manila Tries to Shed Its Image as Sin City." Los Angeles Times. April 11, 1988. http://articles.latimes.com/1988-04-11/news/mn-631 1 sin-city.

Holub, Sgt. Howard James. "Nothing More Beautiful, Nothing More Fine.” Welcome to the Former Subic Bay Naval Base: Republic of the Philippines. Accessed May 4, 2015. http://www.subicbaypi.com/town_photo_girls.htm.

May, Glenn. "Philippine-American War 1899-1902." Lecture, University of Oregon, Eugene, OR, April 22, 2015.

Magno, Alexander R. "Cornucopia or Curse: The Internal Debate on the US Bases in the Philippines." Kasarinlan: Philippine Journal of Third World Studies 3, no. 3 (1988): 718. http://journals.upd.edu.ph/index.php/kasarinlan/article/view/616/613.

Member HD357. "House of Repute III. How Many Remember This Place." Archives, http://www.ar15.com/forums/t_1_5/1647810_House_of_Ill_Repute_How_many_re member_this_place_html\&page $=1$.

Miralao, Virginia A., Celia O. Carlos, and Aida Fulleros Santos, "Women Entertainers in Angeles and Olongapo: A Survey Report.” Women's Education, Development, Productivity and Research Organization and Katipunan ng Kababaihan para sa Kalayaan. 1990. 
Mogato, Manuel. "Philippines to Give US Forces Access to up to Five Military Bases.” Reuters, May 2, 2014. http://www.reuters.com/article/2014/05/02/us-philippines-usaidUSBREA4107020140502.

Moselina, Leopold M. “Olongapo’s Rest and Recreation Industry: A Sociological Analysis of Institutionalized Prostitution-With Implications for a Grassroots-Oriented Sociology.” Philippine Sociological Review 27, no. 3 (1979): 181-193. http://www.jstor.org/stable/23892390.

Philippine Statistics Authority-National Statistical Coordination Board. Poverty Incidence among Filipinos Registered at 25.8\%, as of First Semester of 2014-PSA. March 6, 2015. http://www.nscb.gov.ph/poverty/.

Ron, September 25, 2014 (5:16 p.m.). Comment on Carl Harstad, “Olongapo 1965.” pbase.com. Accessed May 21, 2015. http://www.pbase.com/charstad/olongapo\&page=1.

Rusling, General James. “Interview with President William McKinley.” The Christian Advocate 22 January 1903. Reprinted in The Philippine Reader. Daniel Schirmer and Stephen Rosskamm Shalom. Boston: South End Press, 1987.

Said, Edward. Orientalism. New York: Vintage Books, 1979.

Sadler, Barry. Ballad of the Green Berets. RCA Victor Records, 1963, sheet music. From University of Illinois Archives. The Sousa Archives and Center for American Music. Print. http://archives.library.illinois.edu/archon/?p=digitallibrary/digitalcontent\&id=7801.

Schirmer, Daniel B. and Stephen Rosskamm Shalom. The Philippines Reader: A History of Colonialism, Neocolonialism, Dictatorship, and Resistance. Brooklyn: South End Press, 1987.

Shigematsu, Setsu, Keith L. Camacho, and Cynthia Enloe, Militarized Currents: Toward a Decolonized Future in Asia and the Pacific. Minneapolis: University of Minnesota Press, 2010.

Tallada, Eddie and Company. Ballad of Subic Bay. OG's Records, late 1960s, record. From youtube.com and La Salle University Special Collections. Vietnam on Record Discography. https://www.youtube.com/watch?v=2ca4FHwsLr4 and http://speccoll.lasalle.edu/items/show/553.

Truong, Thanh-Dam. Sex, Money, and Morality: Prostitution and Tourism in South-east Asia. London: Zed Books, 1990.

Tubb, Ernest. Filipino Baby. Billy Cox and Clarke Van Ness. Decca 46019 A, 1946, vinyl. 


\title{
Xylaria Primers for Phylogenetic Reconstruction
}

\author{
Alicia Ly, Environmental Studies*
}

\begin{abstract}
Xylaria is a genus of Ascomycete fungi that is comprised of an estimated 400 species. These species are important to the ecosystems in which they inhabit because they contribute to the decomposition of wood, which recycles lignin and cellulose. Though the morphological traits of this genus have been widely studied over the years, their molecular phylogenetics have not been extensively explored due to the historical unavailability of species genomes. Now that complete genomes have become available, there have been an increasing number of ribosomal Internal Transcribed Spacer (ITS) sequence studies in recent years. However, ITS is too variable to consistently construct accurate phylogenetic trees, so Xylaria phylogeny is still being researched. This study explores the use of single-copy genes as an alternative to ITS methods. Here we present three primer pairs for different single-copy genes for use during future phylogenetic evaluation of Xylaria. These primers, Splicing Factor PRP43 F1054/R1691, MCM5 F409/R1059 and 40S Ripro S3Ae F47/R605, are more reliable than ITS sequences for deeper levels of analysis due to less variability in their sequences. This study focuses on Xylaria, while utilizing related species within in the Xylariaceae and Sordariaceae families, providing a promising start to the complete reconstruction of the Xylaria phylogenetic tree.
\end{abstract}

\section{INTRODUCTION}

Xylaria, the type genus of the family Xylariaceae (Xylariales, Sordariomycetes), consists of hundreds of species from around the world (Rogers 2000). Ascomycetes contribute to the decomposition of wood and are important to the natural recycling of lignin and cellulose in many ecosystems (Whalley 1996). Species are often found living on dead angiospermous wood, but have also been discovered on other substrates, including gymnosperms, non-woody angiosperms, living hosts, soil, litter and stool, and among insects (Peláez et al. 2008). A number of the species are common endophytes, which flourish in the foliage of trees and shrubs (Davis et al. 2003; Peláez et al. 2008). Although they are distributed worldwide, Xylaria have been observed most abundantly in tropical zones (Rogers 2000; Whalley 1996). There are also sizeable areas of the world that have not been surveyed for Xylaria (Stadler 2010). Further exploration of such areas could lead to great advancements in the understanding of the genus.

\footnotetext{
*Alicia Ly graduated with honors from the Environmental Science program at the University of Oregon. Her research interests include ecology and species conservation, as well as sustainable technologies. She hopes to contribute to finding creative solutions to environment issues worldwide. Please direct correspondence to alicial@uoregon.edu.
} 


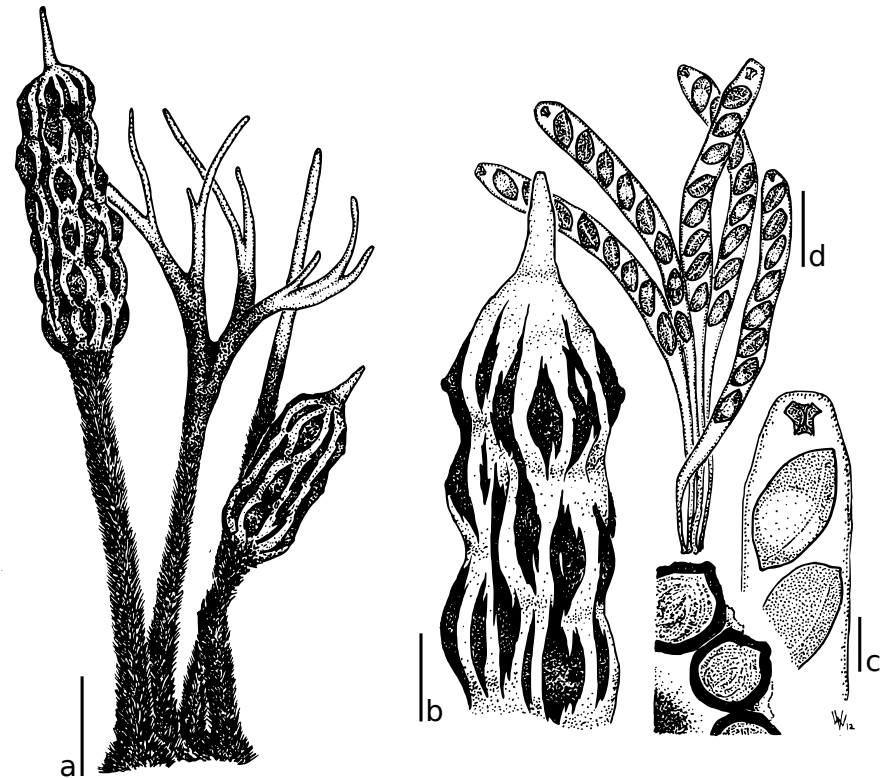

Figure 1. Drawing of one of the target species in this study, Xylaria apiculata, by Roo Vandegrift. (Bars: $a=2 \mathrm{~mm} ; \mathrm{b}=1 \mathrm{~mm}$ (including stromatal section); $\mathrm{c}=10 \mu \mathrm{m} ; \mathrm{d}=50 \mu \mathrm{m}$ ).

Basic characteristics that most Xylaria exhibit include perithecial (flask-shaped) ascomata and generally erect stromata (Lee et al. 2000; Rogers 2000), shown in the drawing of Xylaria apiculata in Figure 1. They also have dark ascospores with a hyaline germination slit and cylindrical, monoseriate asci that have an amyloid apical ring (Lee et al. 2000). However, there is an enormous range of variation between other characteristics of the species (Rogers 2000; Whalley 1996). Though there are diverse traits, there are also a number of species that are virtually indistinguishable using only their gross morphologies (Rogers 1979). Due to this unreliability of gross morphology, many specimens have been identified incorrectly and evaluation of species' relationships has proven to be difficult (Rogers 1979, 2000). In fact, there are approximately 700 named Xylaria species, but probably only about 400 genuine species, due to the re-description based on variation in non-informative characters (Ju, personal communication). Unfortunately, the genus has never been monographed. Characterization based solely on morphology has led to irregular, incorrect, and wholly artificial groupings of species within Xylaria (Dennis 1956), as well as the family Xylariaceae (Whalley 1996). These challenges indicate the need for identification and evaluation of species' relationships on a molecular level, in addition to studies of morphology.

Xylariaceae also includes, but is not limited to, the widely accepted genera Daldinia, Hypoxylon, Nemania and Kretzschmaria (Tang et al. 2009). This study focuses on Xylaria, but utilizes species from all of these genera to consider evolutionary history. The analysis also makes use of species from the genus Neurospora, another Sordariomycete, but from a different family and order (Sordariaceae, Sordariales) (Cai 2006; Tang et al. 2009). Past studies of Xylaria suggest it is a large and complex genus (Hsieh et al. 2010; Peláez et al. 2008), indicating the need for the inclusion of many species in an analysis of phylogenetic relationships. In fact, 
previous studies have shown that Xylaria is a paraphyletic genus, meaning it is not inclusive of all descendants of a single common ancestor (Hsieh et al. 2010). A number of species, including some Kretzschmaria and Nemania species, have been observed amongst groups of Xylaria in past phylogenetic studies (Hsieh et al. 2010; Stadler 2013). There is a great need to clarify these relationships to properly delineate the genus.

The use of DNA sequences of ribosomal genes is now crucial to confirming the identification of a species (Dentinger et al. 2010). Examining genetic variation of these sequences can allow the differentiation between species that look almost exactly the same. Additionally, sequences of DNA allow the consideration of evolutionary histories more accurately, because they utilize huge data sets of characters for analysis (Lee et al. 2000). By studying the history of speciation, the precise processes of evolution can be assessed and relative time estimates of evolutionary events can be formulated. Findings such as these could lead to important advancements in mycology and evolutionary biology, which has pushed scientists to utilize DNA sequences for most current taxonomic and phylogenetic studies. More informative loci (DNA sequences) for Xylaria were never examined previously, because their genomes were not available (Lee et al. 2000). Now that relevant genomes have been published, primer pairs can be designed and used to amplify specific DNA sequences. Primers, unpaired strands of DNA, serve as starting points for DNA synthesis during polymerase chain reactions. Polymerase chain reaction (PCR) is a method that rapidly alternates heating and cooling cycles to amplify a specific DNA sequence (Dentinger et al. 2010; Folmer 1994).

Recently, the use of the nuclear ribosomal DNA internal transcribed spacer (ITS) region has been quite popular for species analysis (Larena et al. 1999). Numerous prominent scientific papers have been published primarily or exclusively using ITS data (Sánchez-Ballesteros 2000; Triebel et al. 2005; Peláez et al. 2008). In fact, a paper by Schoch et al. (2012) claimed it should be "the universal DNA barcode marker for fungi". However, the variability within ITS, which includes intraspecific variation, inhibits this approach from being entirely reliable for phylogenetic inferences (Álvarez and Wendel 2003; Kiss 2012). Furthermore, the variability of the ITS region makes it difficult or impossible to align accurately. This variation has developed because ITS is a freely evolving intron. Although the use of ITS sequences has been very useful for species identification, other methods should be explored for phylogenetic analyses (Álvarez and Wendel 2003). Of the additional primers that have been developed for other Ascomycetes, those that have been tried with Xylaria were not successful. For example, $\beta$-tubulin was used throughout the studies of Hypoxylon species conducted by Hsieh et al. (2005), but $\beta$-tubulin is often ineffective with Xylaria species because two active copies of the gene are present. It is not possible to consistently sequence the same copy each time it is tested. Therefore, accurate comparisons between genes of different species cannot be made.

An alternative to ITS and other methods is the use of single-copy nuclear genes (Álvarez and Wendel 2003; Salvador et al. 2014). Single-copy genes streamline homologous comparisons, have codons that minimize ambiguities in alignments, and can supply copious amounts of data based on $3^{\text {rd }}$ position variability (Álvarez and Wendel 2003). Plus, they have lower likelihood of homoplasy (characteristics that species share, but did not evolve from a common ancestor) than 
ITS data (Álvarez and Wendel 2003). Several scientists argue that single-copy genes are the most accurate way to analyze species' histories and are the future of phylogenetic reconstruction (Álvarez and Wendel 2003; Capella-Gutierrez et al. 2014).

Now that Xylaria genomic sequences are available, there is an opportunity to design primer pairs specifically for single-copy Xylaria genes. With this advancement, my team composed primer pairs using all available Xylariaceae genomes. During this study, these primers were tested on a panel of Xylaria and related species in order to determine if any would be informative for accurate evaluation of Xylaria evolutionary relationships and reconstruction of their phylogenetic tree.

\section{METHODS}

\subsection{DESIGNING AND TESTING PRIMER SETS}

A preliminary list of potential primer sets was assembled using all available Xylariaceae genomes. These included published genomes (three Hypoxylon, one Daldinia; data provided by the Joint Genomics Institute) and one unpublished genome, Xylaria hypoxylon, supplied by Dr. Joseph Spatafora, a professor at Oregon State University. Though no specific formula was used for selection, many factors were considered when designing the primers. Primer pairs that produced long sequences, comprised of approximately 600-700 base pairs, with no significant gaps were selected. Primers possessing more guanine and cytosine bases at the 3 ' end of the strand were considered advantageous, because they bind more securely to DNA than adenine and thymine. In addition, low levels of degeneracy were selected for. Degenerate sequences contain multiple potential bases at some positions (Compton 1990). Degeneracy in primers increases the likelihood of binding at sites that differ between genomes, but consequently reduces the specificity of the primer. Lastly, potential for binding among/within primers of a single pair was avoided when possible. Considering all of these factors, a list of 30 possible primer pairs that had potential to work with Xylaria was created. The list of all primer pairs tested can be found in Table 2, in the appendix.

We began initial tests of these 30 primer pairs using a set of genomic DNA from 4 Xylaria species: $X$. fabelliforme (cubensis), $X$. anisopleura, an undescribed species from Taiwan herein denoted as $X . s p$. nov. 1, and $X . s p .77080301$. PCRs were run to examine the ability of each primer set to successfully amplify their target genes. These four species were selected because previous studies showed that they were significantly different from one another at the ITS locus. The list of primer pairs that had potential was quickly narrowed down based on these preliminary tests. We then expanded the panel of genomic DNA for the effective primer pairs to include 17 species of Xylaria and their relatives. After many PCRs, the primer pairs that yielded the most promising results were selected. A 96-well plate of these samples was sent to Functional Biosciences (Madison, WI) for sequencing. 


\subsection{SEQUENCE DATA ANALYSIS}

Sequences were analyzed (forward and reverse) for 6 single-copy genes from the majority of the trial species. The raw sequences were imported into the program Geneious (Biomatters, Ltd.), where most sequence editing and phylogenetic analysis was conducted. The forward and reverse sequences were trimmed and aligned using the default Geneious alignment, which automatically determines sequence directions. Minor edits were made manually and consensus sequences (with 100\% threshold) were subsequently created for each species at each locus. Generating the consensus sequences served as a data checking method to ensure the sequences were as accurate as possible. Many of the MCM7 F9 (forward) sequences were not viable (likely due to the nature of the primer), so the reverse sequences alone were relied on for the analyses.

\subsection{PHYLOGENETIC TREES}

All of the consensus sequences for each gene were aligned. MUSCLE alignments were used for all multiple alignments, which required me to manually reverse-complement the reverse sequences. These 6 alignments all involved 13-17 species sequences, depending on the success of the amplification and sequencing. We collected additional sequences from published species genomes in order to accurately root the resulting gene trees. A Daldinia, 3 Hypoxylons and 3 Neurosporas were added (data provided by JGI). These references were added to the alignment of the genes that had been sequenced. Then, phylogenetic trees were made from the resulting alignments. The three Neurospora species served as the root for all trees created, just as they did in the Xylariaceae phylogenetic studies conducted by Peláez et al. (2008). This outgroup method was also used in the study by Walker et al. (2010). Neurospora serves as an ideal outgroup, because they always cluster independently of Xylaria species (because they do not belong to the Xylariaceae family), yet still have deep evolutionary relationships with them (Cai et al. 2005).

The phylogenetic trees were constructed using both maximum likelihood (ML) and neighbor-joining (NJ) methods. Maximum likelihood models are regarded as amply robust, because they employ all sequence information and evaluate all different tree topologies (Huelsenbeck 1995). Maximum likelihood trees are built to illustrate the topology that has the highest probability of resulting throughout numerous re-samplings. NJ trees are considered less reliable by much of the scientific community, since the bottom-up clustering method can reduce sequence information. NJ trees were created for comparison, but ML trees were used in later analyses. All 12 of the phylogenetic trees (ML and NJ for all 6 genes) are displayed in Figures 819 , in the appendix.

For all of the maximum likelihood trees generated in this study, 500 bootstrap samples were used; all phylogenetic trees present bootstrap values at the branch nodes (Figures 8-19). Bootstrap values can be defined as the percentage of times the same node is produced throughout resampling (Felsenstein 1985). The scale for each of the trees is in substitutions per site. In phylogenetic trees such as these, branch lengths represent an amount of genetic change (Sanderson 2002). 
To create a single phylogenetic tree based on all of the genetic data, we concatenated (linked together in succession) all sequences and built an alignment. We did this first with all 6 genes that were sequenced, in 17 total species. Later, we created a concatenated alignment using only 4 genes (from 21 species). From these concatenated alignments, we generated new, composite ML trees, which were used in the analysis of the primers' phylogenetic informativeness.

\subsection{ANALYSIS OF PHYLOGENETIC INFORMATIVENESS}

In order to evaluate phylogenetic informativeness of the primer pairs, the trees had to be converted to ultrametric trees (Walker et al. 2012). These have equal path lengths from the root to the branch tips of the tree. Consequently, the trees represent relative evolutionary time, rather than a relative measure of evolutionary change. The relative timescale is calculated based on the assumption of a constant mutation rate. A nonparametric rate smoothing method (Sanderson 1997) was conducted in the program R (version 3.0.1), to create the ultrametric trees.

The resulting ultrametric trees, along with their corresponding sequence alignments, were input into PhyDesign to assess phylogenetic informativeness of the sequences generated from each primer pair (Lopez-Giraldez and Townsend 2011; Walker et al. 2012; http://phydesign.townsend.yale.edu/). Each output provided a graph of phylogenetic informativeness positioned below an ultrametric tree; these graphs matched directly with the relative time-correlated measure of the ultrametric trees. Phylogenetic informativeness is a unitless measure of the amount of information per base pair contributing to the overall ultrametric tree. Useful primer pairs provide a large amount of information for the ultrametric tree, so the graphs produced show broad curves with high levels of phylogenetic informativeness, especially towards the species level.

\section{RESULTS}

\subsection{PCR AMPLIFICATION}

Of the original 30 primer pairs tested, 10 were abandoned promptly after they proved to be unsuccessful at amplifying 3 of the 4 test species' genes. Meanwhile, 9 primer pairs successfully amplified genes in all test species without any modification. The remaining 11 primer pairs showed potential to be successful after adjustments to the PCR process. After increasing the panel of DNA to 17 species for all of the potentially successful primers, we focused further on only 6 primer pairs that produced the most effective results (Table 1). Each primer set amplified genes in at least 15 of the 17 species. The species that did not amplify were primarily not Xylaria, but one of the related species. 
Table 1. Top 6 primer pairs that produced the highest amount of amplification of the test species' genes and were selected to be evaluated for their phylogenetic informativeness.

\begin{tabular}{|l|c|c|}
\hline Primer & Forward & Reverse \\
\hline 40S Ripro S3Ae & 47 & 605 \\
\hline MCM5 & 409 & 1059 \\
\hline Splicing Factor PRP 43 & 1054 & 1691 \\
\hline MCM7 & 665 & 1209 \\
\hline MCM7 & 9 & 595 \\
\hline MCM5 & 1188 & 1970 \\
\hline
\end{tabular}

\subsection{PHYLOGENETIC ANALYSIS}

Comparison of the maximum likelihood and neighbor-joining trees did not show significant conflicts in the relationships between species. We found that neighbor-joining trees showed significantly more polytomy, or unresolved branches. Consequently, the trees would have been difficult to use for further analyses, because their inferences were imprecise. ML trees often resolved many of the nodes, though it is important to note that lower bootstrap values sometimes resulted. We accepted nodes with bootstrap support of $50 \%$ or greater. Due to the knowledge of their robust statistical process and the observations of more resolved branches, ML trees were relied on for additional analyses.

\subsection{PHYLOGENETIC INFORMATIVENESS}

The results from PhyDesign provided a well-defined graph, displaying phylogenetic informativeness levels of each primer pair. The first graph, assessing all 6 sequences from 17 species' genes, showed an unexpected spike towards the tips of the tree (shown in Figure 7, in the appendix). By examining the sequences in Geneious, the team realized that the loci targeted by the two primer pairs showing this irregularity both contained introns. Introns are noncoding regions that are spliced out of mRNA. Thus, those regions can have a huge range of variability, since countless mutations could have surfaced over the course of history without affecting organisms. The variability makes them difficult to align accurately and consistently. The spike in the graph reinforced the conclusion that there was a tremendous amount of variation in the sequences. Though the sequences seemed to indicate a high level of informativeness at the species-level, it was uncertain whether they would remain useful for deeper-level analyses. 
The intron sections were removed from the sequences in Geneious and a new alignment and tree was created to repeat the evaluation in PhyDesign. There was a significant reduction in the spike at the branch tips after intron removal (Figure 2). Though the spike was not completely smoothed out, the reduction allowed for a better observation of the shape of an overall broad curve, as expected. The $40 \mathrm{OS}$ Ripro S3Ae sequences became significantly less informative with the intron removed. However, the intron constituted over $20 \%$ of the entire sequence. Thus, removing the intron significantly shortened the sequence, reducing the amount of information it could provide. Additional evaluation demonstrated that it actually has a much higher level of informativeness when the intron was not removed from the sequence. 


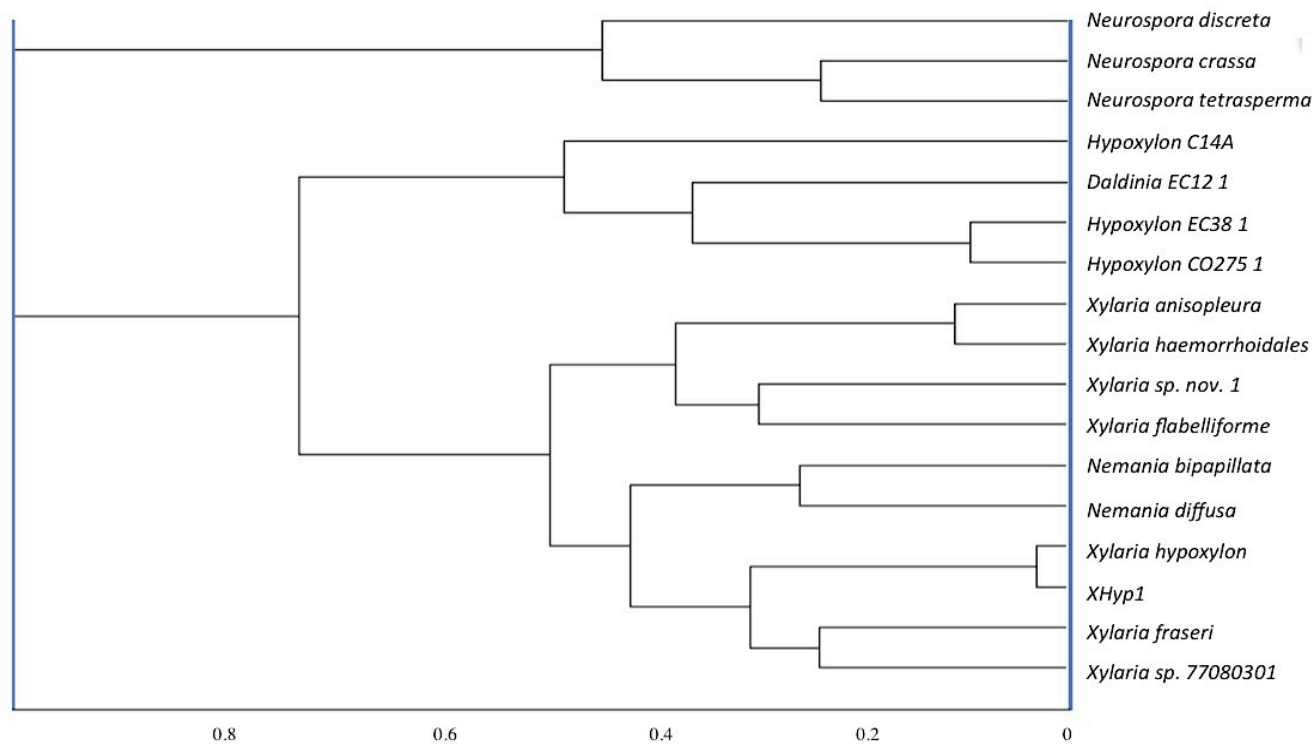

40SRipros3Ae

MCM7_F9

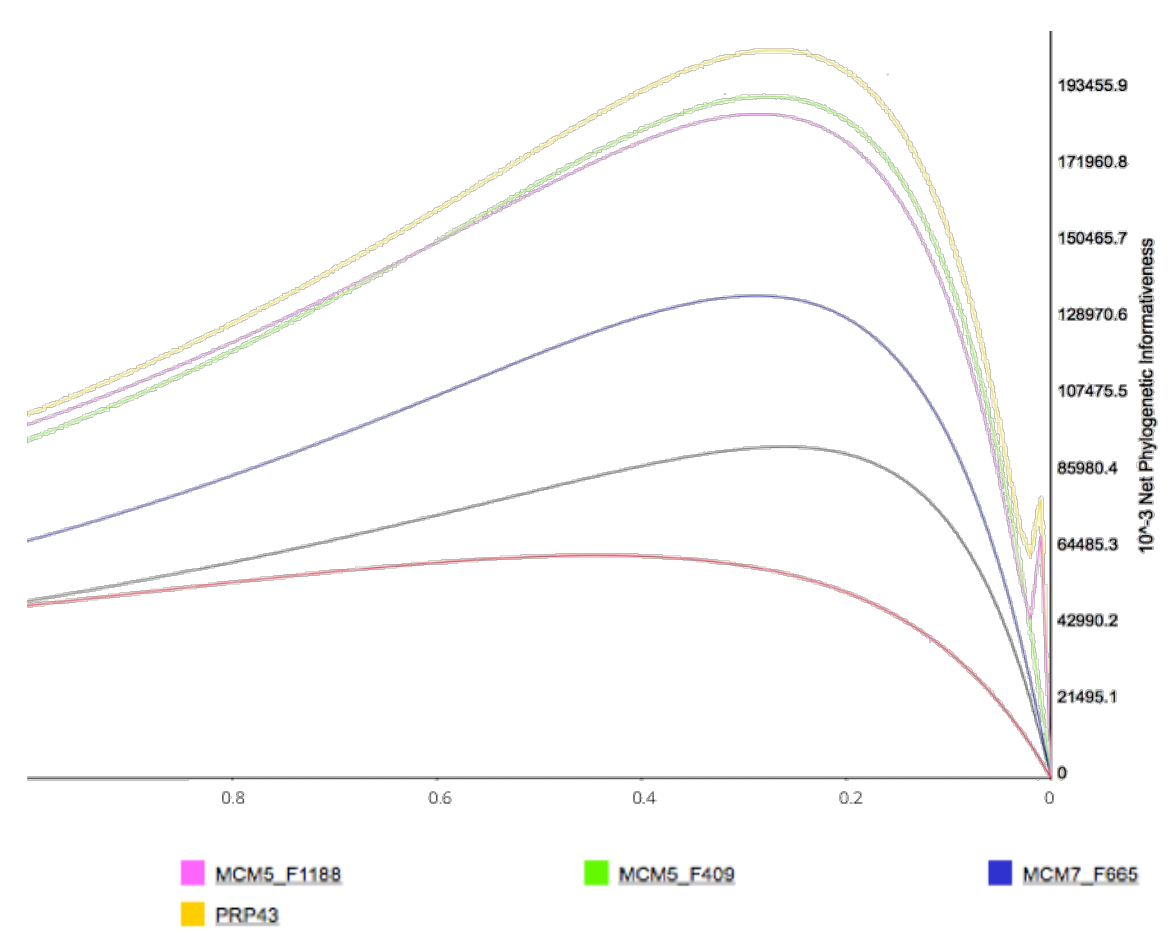

Figure 2. Ultrametric tree (above) and phylogenetic informativeness graph (below) created for all 6 primer pairs with the introns removed from MCM5 F1188/R1970 and 40S Ripro S3Ae F47/R605.

The same method was employed with the 4 primer pairs that were most successful at sequencing genes. This analysis included genes from 21 species (Figure 3). The graph resulted in a broad curve, with no significant irregularities and the general results were unchanged in both analyses. The Splicing factor PRP 43 F1054/R1691 was the most phylogenetically informative primer pair of those tested. The second most informative primer pair was MCM5 F409/R1059. 


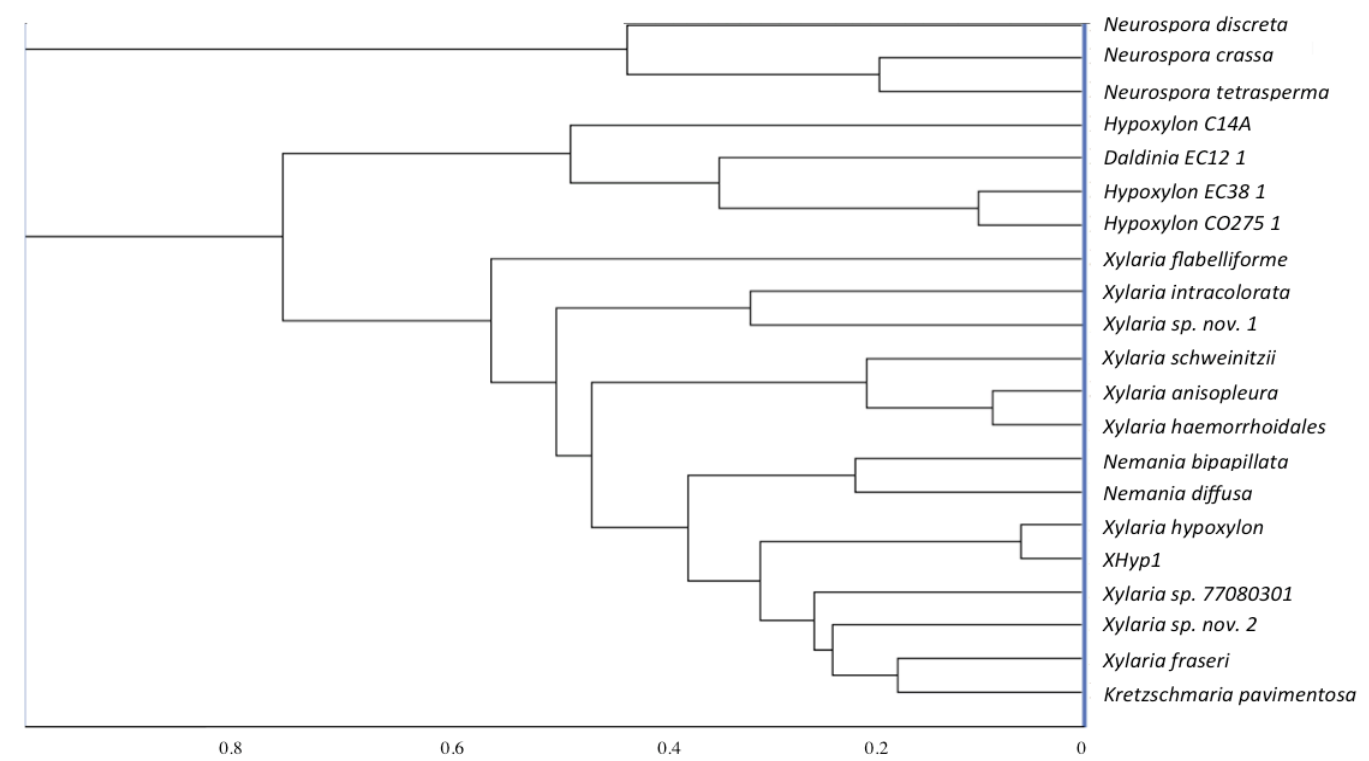

40SRiproS3Ae

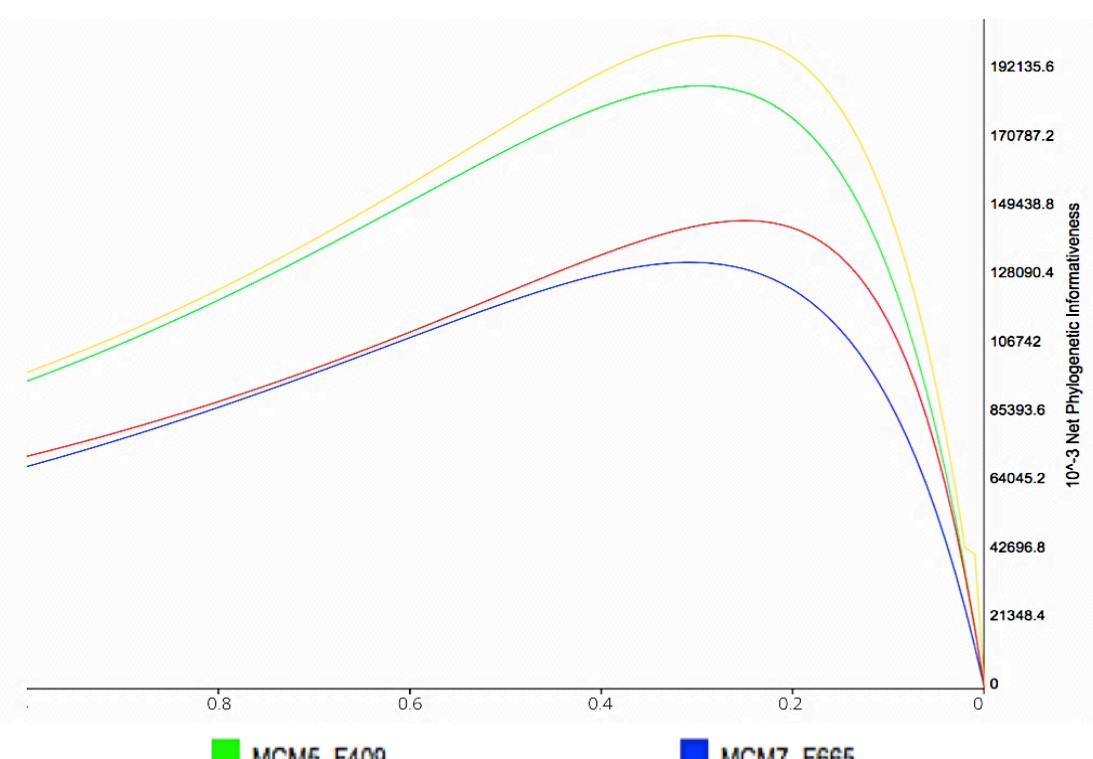

Figure 3. Ultrametric tree (above) and phylogenetic informativeness graph (below) of 4 primer pairs, created with sequences from 21 species' genes.

\section{DISCUSSION}

Many past studies have relied on ITS sequences for phylogenetic analyses, which have proven to be extremely variable. However, the recent availability of published Xylariaceae genomes has opened up opportunities to test and develop methods for phylogenetic analysis using single-copy genes. This study developed primer pairs for single-copy genes and proposes them for use during future Xylaria phylogenetic analysis. 


\subsection{PRIMERS ANALYSIS}

Pairing the graph with the ultrametric trees provided an opportunity to examine where each primer set provided the most information, corresponding to the depth of branching within the tree. The top primer pairs were informative over a long range, corresponding to majority of the phylogenetic tree. The top primers had broad curves, with peaks around 0.25 on the relative time-correlated $\mathrm{x}$-axis. In comparison, the primer pairs that contained introns originally produced a curve that had a single large spike at the tips of the branches. This reinforces the concept that introns, which are noncoding and highly variable, can be very informative for species-level analyses, but not for deeper inference.

The primer pair for the Splicing Factor PRP 43 gene (F1054: RCTYATCGAGCAGACTTAYCC; R1691:YACCTGCATGAAGAAGCC) resulted in the most successful and informative sequence of all those tested in this study. There was successful amplification in all 17 of the species that we sequenced. It consistently produced the highest curve on the phylogenetic informativeness graphs. The curve also showed that this primer pair provided a wide range of information across the full depth of the tree. We propose this Splicing Factor PRP 43 primer pair as a leading primer set for future Xylaria phylogenetic analysis. Examination of the gene's function reveals that the Splicing Factor PRP 43 gene codes for a protein associated with mRNA and is involved in the production of alternative splicing.

The second primer set we present is a section of MCM5 (F409:

TGATCAAGTACCTGTVGGAGAGC; R1059:TCTCGCATCTTGTCGAACTCG), which also showed high levels of phylogenetic informativeness. The primer pair produced the second highest curve on the informativeness graph across multiple analyses (Figures 2 and 3). We were able to collect sequences from 15/17 test species. The MCM5 protein is part of the mini-chromosome maintenance complex, which was named from a study that focused on fungal minichromosomes. However, it is not limited to mini-chromosomes, as many fungi do not actually have them. MCM5 has a broad, important function within DNA replication in all eukaryotic cells, including human cells (Lei 2005).

The ribosomal associated protein 40S Ripro S3Ae (F47: GCGAACGAYGCCCTCAAGG; R605:TTGACCTTGCGGATGTGAACC) primer pair is the third primer set that is advocated. The sequence contains an intron and removing it greatly reduced the information it provided in the other analysis. This intron, where alignable, appears to provide excellent phylogenetic information towards the tips of the tree, as well as providing some deeper information. It effectively sequenced 15/17 species in the study. The 4OS Ripro S3Ae is considered to be an effective primer pair, though further testing is encouraged.

\subsection{TREE PRODUCT}

A recommended phylogenetic tree was constructed for the species tested in this study. The tree includes sequences from 14 species that were amplified in the lab and 7 species sequences from published works. There were 4 genes that contributed to the creation of the trees. The 
phylogenetic and ultrametric versions are depicted in Figure 4. It is important to note that this composite, phylogenetic tree displays higher bootstrap values than many of the trees made by individual genes, because it utilized information from 4 genes sequences, rather than just one.

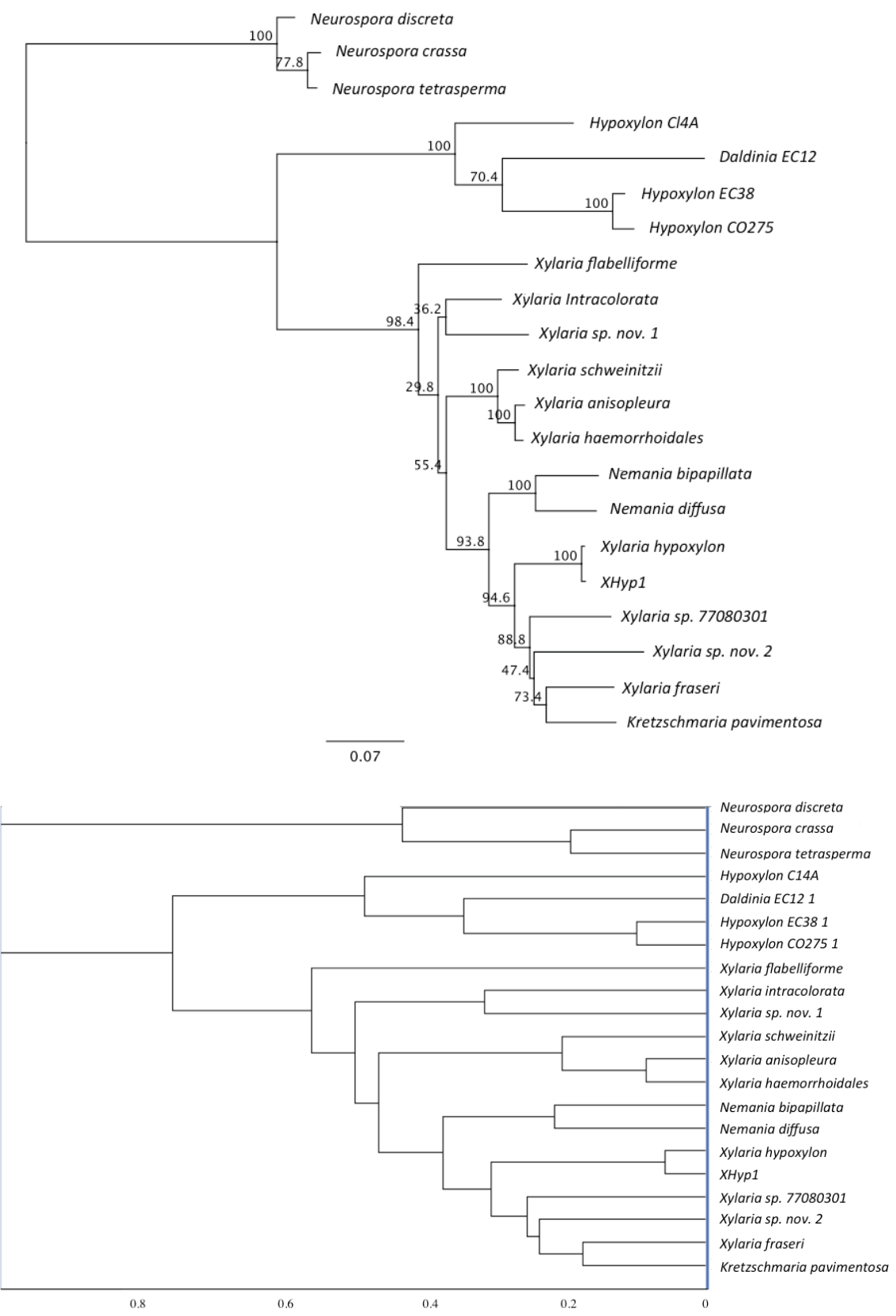

Figure 4. Proposed phylogenetic (above) and ultrametric trees (below) for the tested species. These were created with sequences from 4 genes in 21 Xylaria and related species. 
Most of the relationships these trees display seem to be supported by past reports. However, one relationship that does not match previous studies is the nesting of the Daldinia between Hypoxylon species. Earlier studies have consistently found Hypoxylon and Daldinia species in separate groups (Triebel et al. 2005; Hsieh et al. 2005). But, in this study, the Hypoxylon Cl4A sequence came from a reference, which was known only by endophyte culture and ITS sequences. Samples were never collected from a fruiting body, during which its identification could be confirmed. Thus, we cannot accurately conclude what species it really is. Therefore, our results do not necessarily contradict or disprove any previous studies.

\subsection{RECOMMENDATIONS FOR FURTHER STUDY}

This project has opened up many opportunities for further study. First, the primer sets proposed should be tested further on additional Xylaria species. These primer sets have potential to become widely used gene markers for Xylaria and may even work favorably with related species. By testing the top primer pairs further, more sequence data will be collected as well. This sequence data could be used to build larger, wide-ranging phylogenetic trees for the genus or family. Our lab has the potential to add over 20 additional species from Ecuador to the phylogenetic tree built. In addition, we have reached out to other scientists working with Xylaria about the project. Their contributions could provide unique species from Taiwan and Gabon. We aim to facilitate a collaborative project to build a robust phylogenetic tree that includes Xylaria species from across the world. Dr. George Carroll has designed many more potential primer pairs for Xylaria as well. This study could be replicated to search for additional potential primer sets.

\subsection{RELATION TO ENVIRONMENTAL SCIENCE}

Xylaria species are quite important to the environments in which they inhabit, making further study of the genus valuable to mycology, environmental science, and many other related fields. Their roles as decomposers contribute to the recycling of lignin and cellulose throughout the ecosystems in which they are found. In addition, they play a role in the carbon cycle, because they recycle carbon dioxide back into the atmosphere during their life processes. Studies that investigate the evolutionary history of such an important genus can provide insight into many scientific questions. We can gain a better understanding of the relative ages of the species, diversity within the genus, and patterns of evolution of species that are supported by the decomposition of wood by Xylaria. Especially in a world that is currently experiencing major changes in the environment, understanding the diversity within the genus could be vital to preserving Xylaria species and other organisms supported by them in the future.

\subsection{CONCLUSION}

In this study, three primer pairs were proposed for future use during phylogenetic evaluation of Xylaria. The methods used to develop and evaluate these can be replicated for many other groups of organisms. Studies of numerous fungi, not just Xylaria, have relied solely on ITS data over the years. Finding primers that could be used for single-copy genes in other 
organisms could significantly enhance the study of their species relationships. Use of these methods could lead to greater confidence in numerous phylogenetic analyses conducted in the future.

\section{APPENDIX}

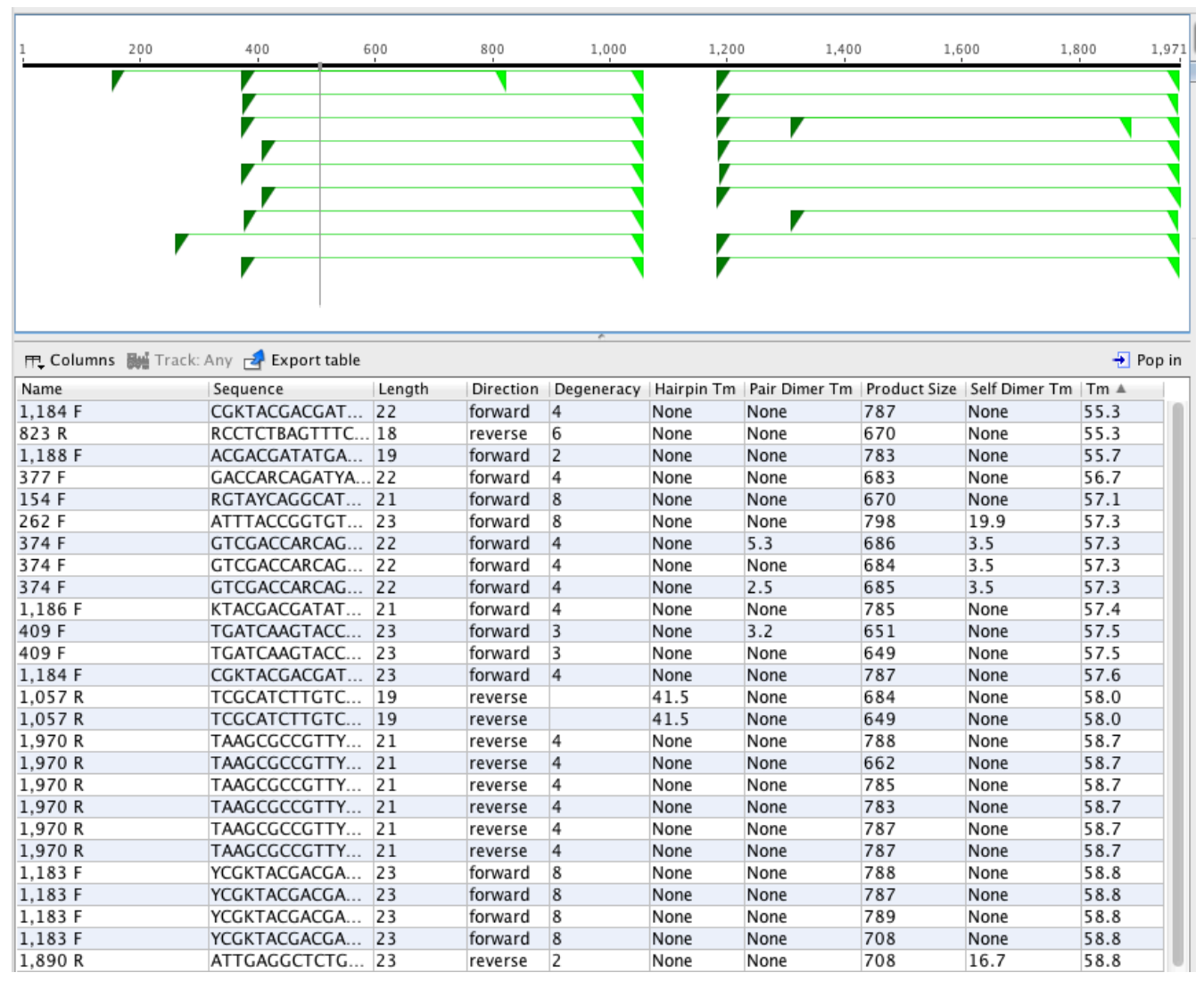

Figure 5. Image showing the selection of primer pairs in Geneious.

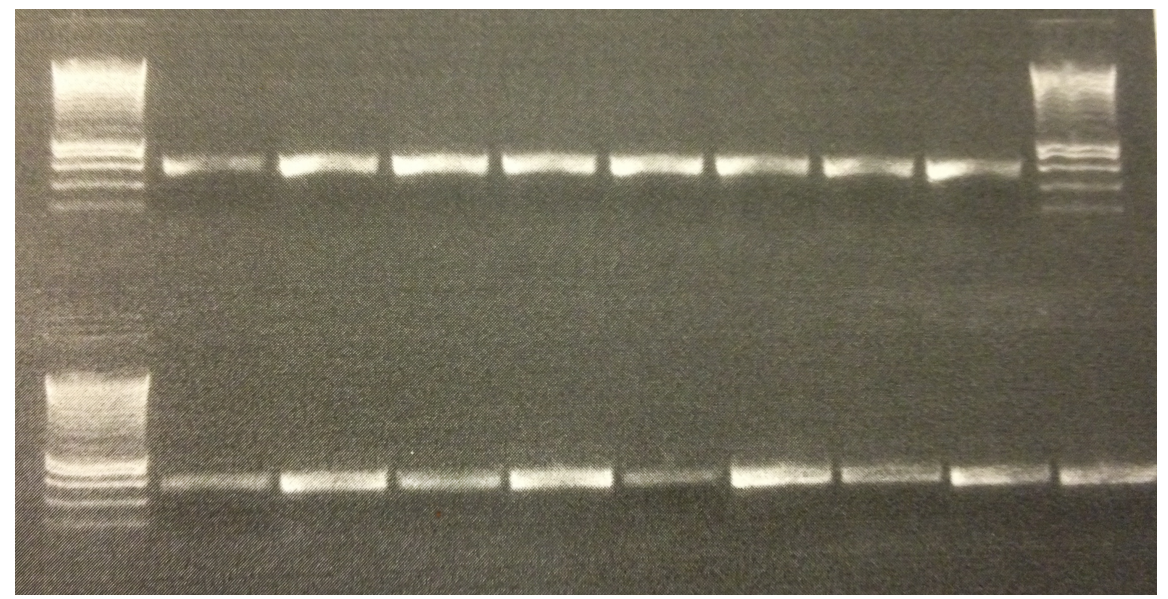

Figure 6. Sample Gel, showing result of gel electrophoresis of PRP 43 F1054/R1691 primer pair. 
Table 2. List of all potential primer pairs tested in this study.

\begin{tabular}{|c|c|c|}
\hline Primer & Forward & Reverse \\
\hline Phosphatidylinositol UDP-GlcNAc transferase PIG-A & 88 & 761 \\
\hline Phosphatidylinositol UDP-GlcNAc transferase PIG-A & 500 & 1299 \\
\hline Transcription regulatory protein pro 1 & 711 & 1324 \\
\hline $\mathrm{MCM} 2$ & 599 & 1249 \\
\hline DNA helicase RAD3 & 938 & 1656 \\
\hline RNA helicase PRP 16 & 1007 & 1756 \\
\hline Splicing factor PRP 43 & 127 & 776 \\
\hline $\mathrm{MCM}_{5}$ & 154 & 823 \\
\hline DNA polymerase gamma & 1618 & 2275 \\
\hline $\mathrm{MCM}_{7}$ & 9 & 595 \\
\hline Transcription regulatory protein pro 1 & 1168 & 1917 \\
\hline $\mathrm{MCM} 2$ & 1291 & 1930 \\
\hline DNA helicase RAD3 & 82 & 683 \\
\hline RNA helicase PRP 16 & 372 & 1081 \\
\hline RNA helicase PRP 16 & 1732 & 2518 \\
\hline $\mathrm{MCM}_{5}$ & 1188 & 1970 \\
\hline DNA polymerase gamma & 106 & 852 \\
\hline DNA polymerase gamma & 938 & 1707 \\
\hline $\mathrm{MCM}_{7}$ & 200 & 961 \\
\hline Transcription regulatory protein pro 1 & 381 & 1020 \\
\hline $\mathrm{MCM} 2$ & 32 & 644 \\
\hline Splicing factor PRP 43 & 900 & 1595 \\
\hline Splicing factor PRP 43 & 1054 & 1691 \\
\hline GTP-binding-protein YPT1 & 16 & 727 \\
\hline $\mathrm{MCM}_{5}$ & 409 & 1059 \\
\hline $\mathrm{MCM} 7$ & 665 & 1209 \\
\hline Nucleosome assembly protein & 150 & 817 \\
\hline Nucleosome assembly protein & 478 & 1221 \\
\hline $40 \mathrm{~S}_{\text {ripro }} \mathrm{S}_{3} \mathrm{Ae}$ & 47 & 605 \\
\hline $40 \mathrm{OS}$ ripro $\mathrm{S}_{3} \mathrm{Ae}$ & 187 & 707 \\
\hline
\end{tabular}


Table 3. Specifications for Splicing Factor PRP 43 primer pair.

\begin{tabular}{|c|c|c|c|c|c|c|c|c|c|}
\hline Name & Sequence & Dir. & Prod. Size & Length & Degen. & Tm & Hrpn Tm & Pri-dm & Slf-dm \\
\hline $1,054 \mathrm{~F}$ & RCTYATCGAGCAGACTTAYCC & $\mathrm{F}$ & 638 & 21 & 8 & 57 & None & None & None \\
\hline $1,691 \mathrm{R}$ & YACCTGCATGAAGAAGCC & $\mathrm{R}$ & 638 & 18 & 2 & 60 & None & None & None \\
\hline
\end{tabular}

Table 4. Specifications for MCM5 primer pair.

\begin{tabular}{|c|c|c|c|c|c|c|c|c|c|}
\hline Name & Sequence & Dir. & Prod. Size & Length & Degen. & Tm & Hrpn Tm & Pri-dm & Slf-dm \\
\hline $409 \mathrm{~F}$ & TGATCAAGTACCTGTVGGAGAGC & $\mathrm{F}$ & 651 & 23 & 3 & 58 & None & 3 & None \\
\hline $1,059 \mathrm{R}$ & TCTCGCATCTTGTCGAACTCG & $\mathrm{R}$ & 651 & 21 & & 61 & 42 & 3 & None \\
\hline
\end{tabular}

Table 5. Specifications for $40 \mathrm{OS}$ Ripro $\mathrm{S}_{3} \mathrm{Ae}$ primer pair.

\begin{tabular}{|c|c|c|c|c|c|c|c|c|c|}
\hline Name & Sequence & Direction & Product Size & Length & Degeneracy & $\mathrm{Tm}$ & Hairpin $\mathrm{Tm}$ & Primer-dimer $\mathrm{Tm}$ & Self dimer $\mathrm{Tm}$ \\
\hline $47 \mathrm{~F}$ & GCGAACGAYGCCCTCAAGG & forward & 559 & 19 & 2 & 59 & 40 & None & None \\
\hline $605 \mathrm{R}$ & TTGACCTTGCGGATGTGAACC & reverse & 559 & 21 & & 61 & None & None & None \\
\hline
\end{tabular}



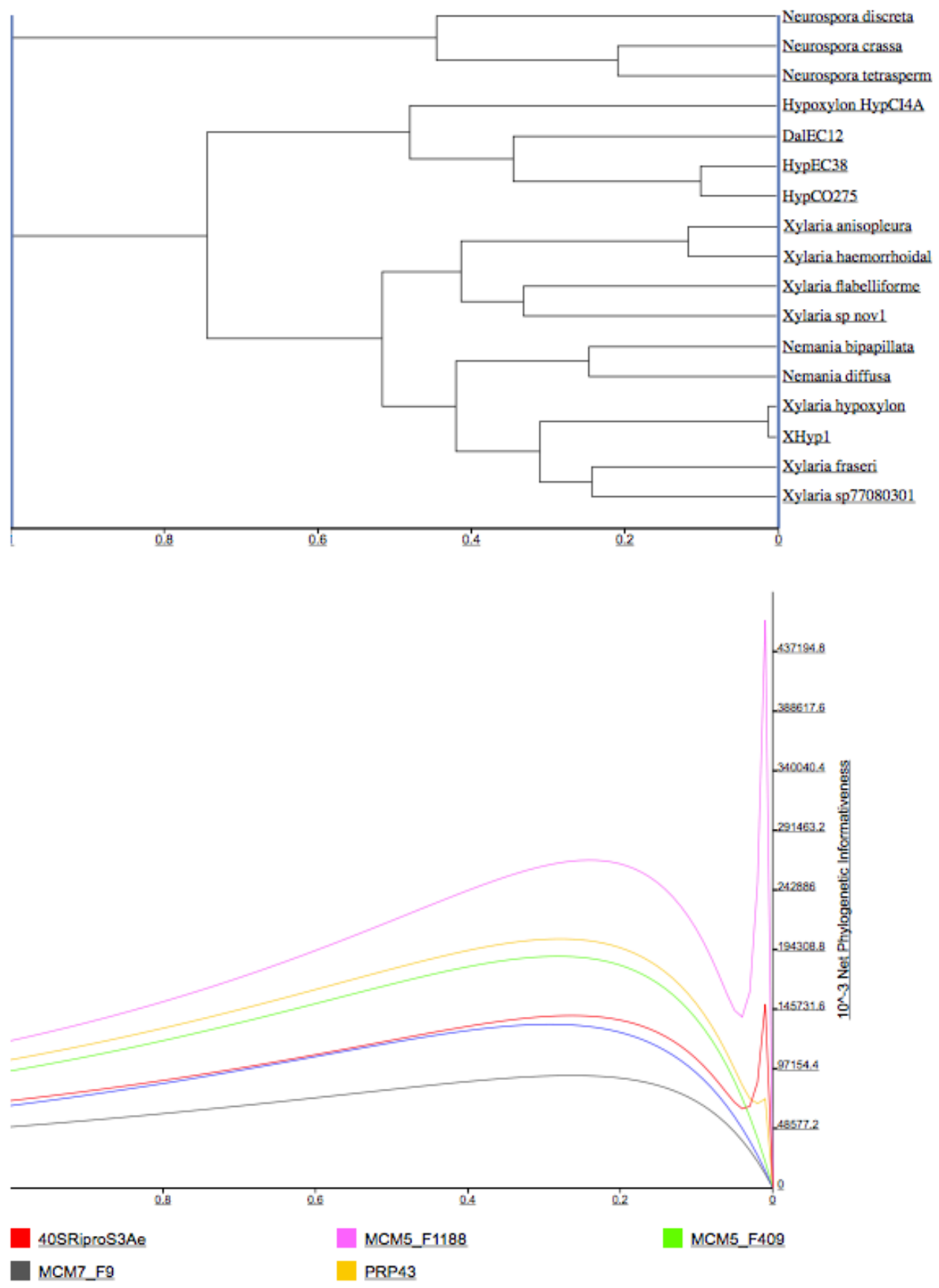

Figure 7. Ultrametric tree (above) and phylogenetic informativeness (below) of 6 Primer Pairs (with introns present). 


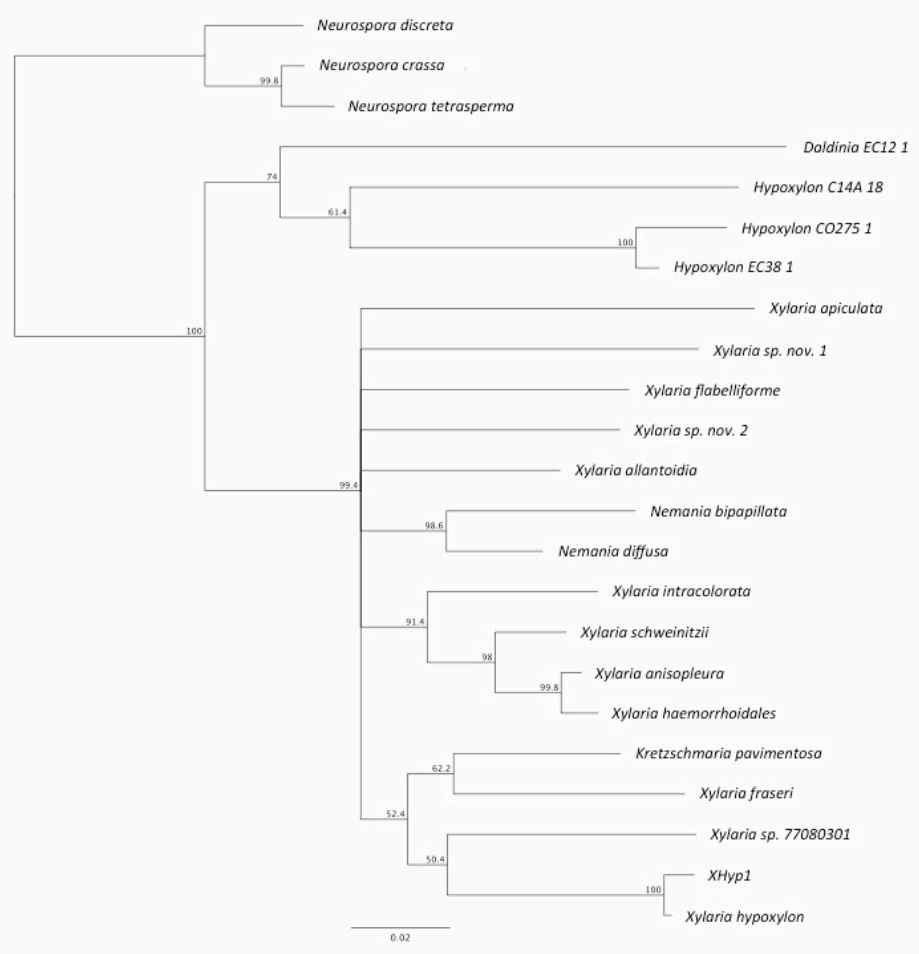

Figure 8. 40S Ripro S3Ae F47/R595 Neighbor-Joining Tree

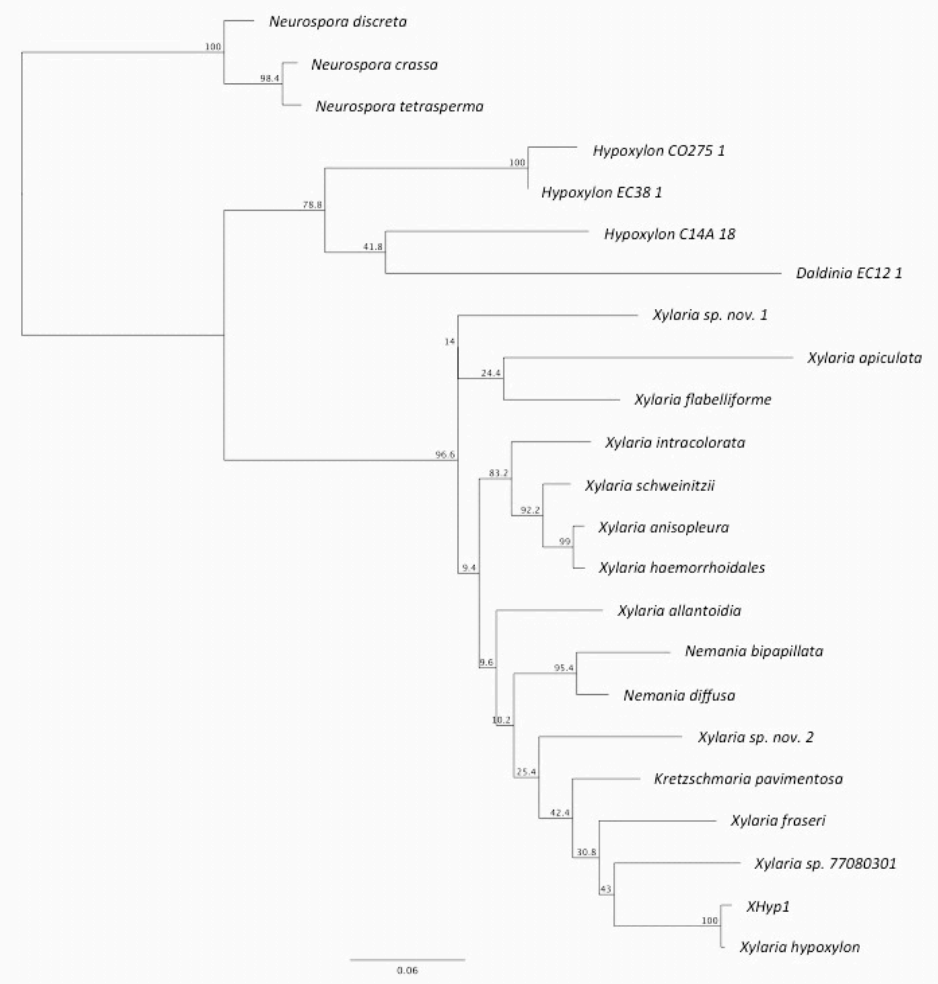

Figure 9. 40S Ripro S3Ae F47/R595 Maximum Likelihood Tree 


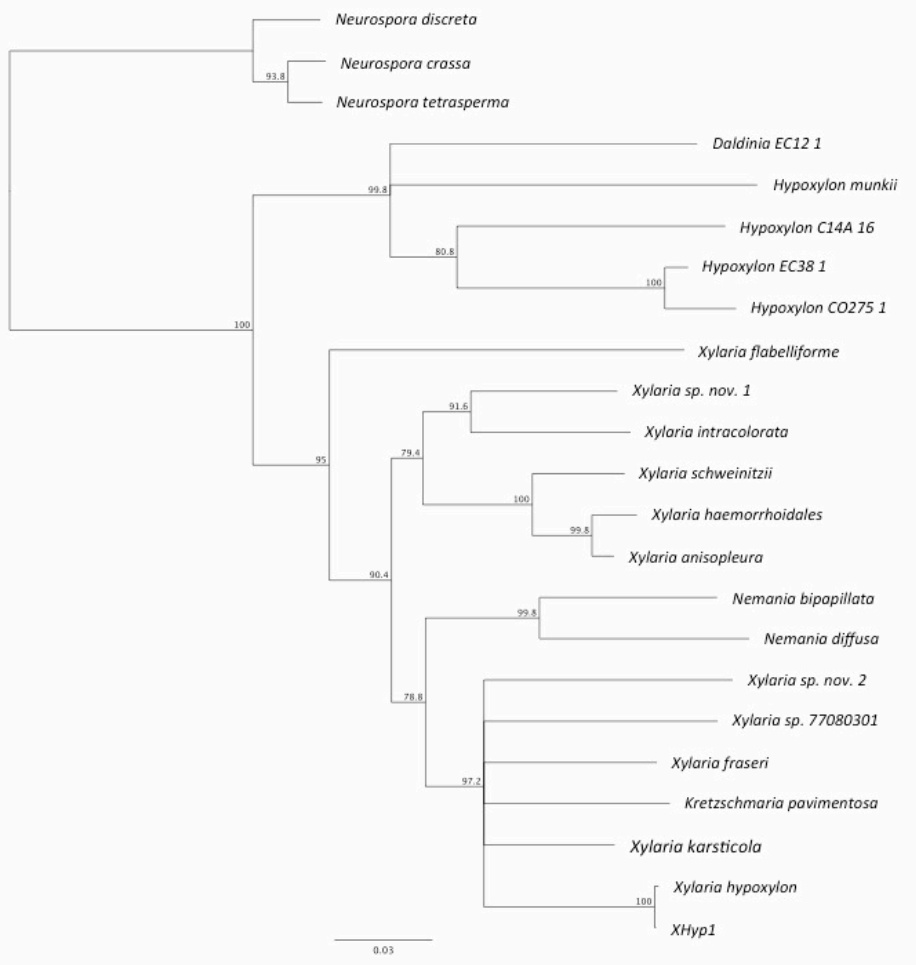

Figure 10. MCM5 F409/R1059 Neighbor-Joining Tree

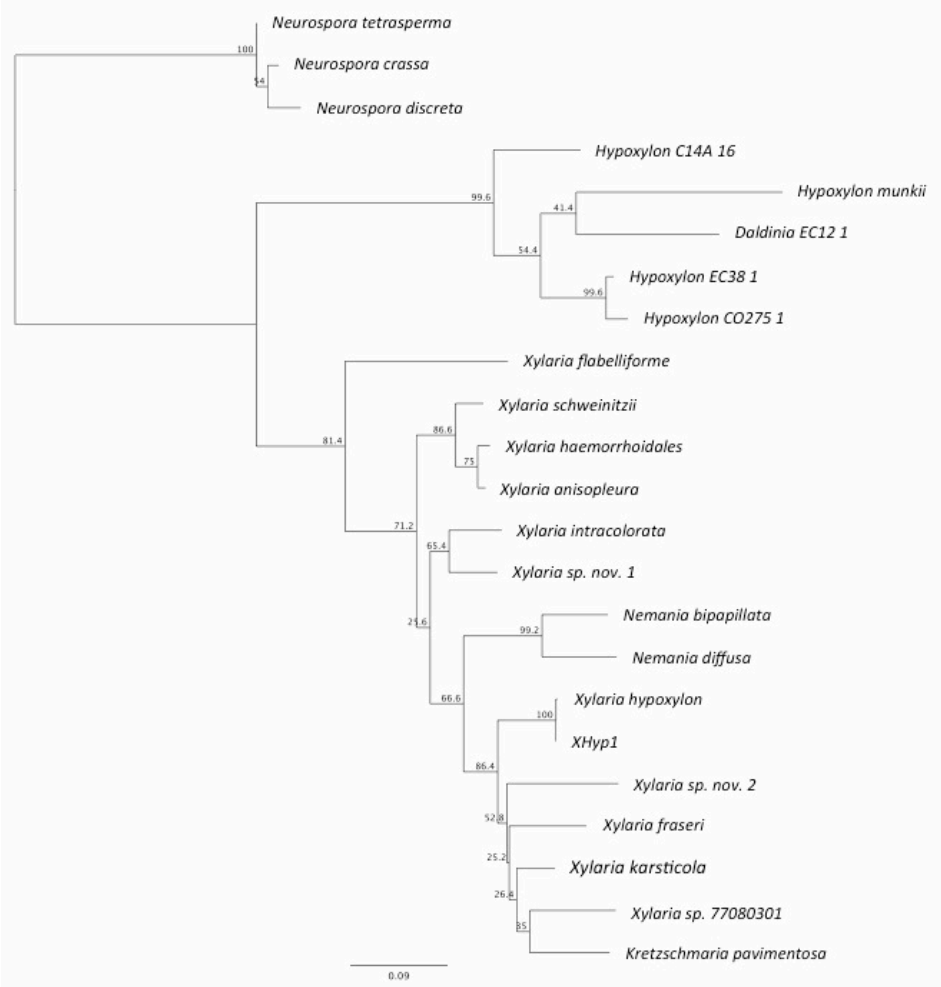

Figure 11. MCM5 F409/R1059 ML 


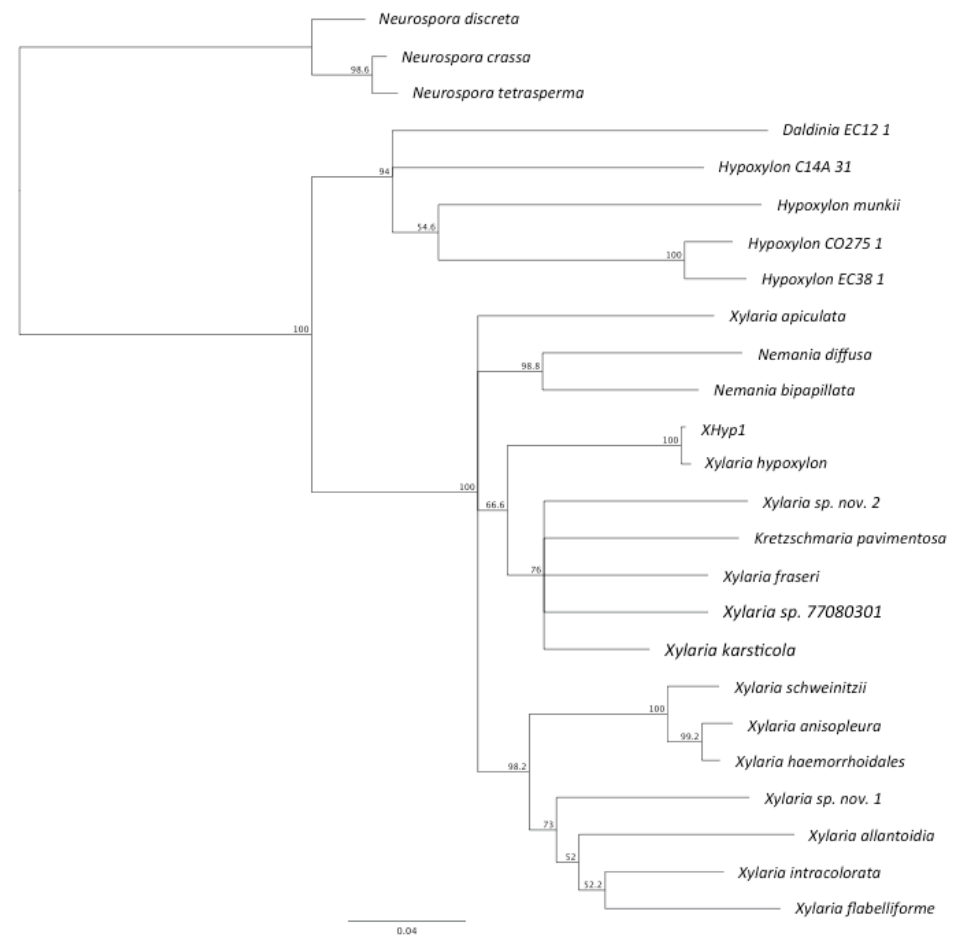

Figure 12. Splicing Factor PRP 43 F1054/R1691 Neighbor-Joining Tree

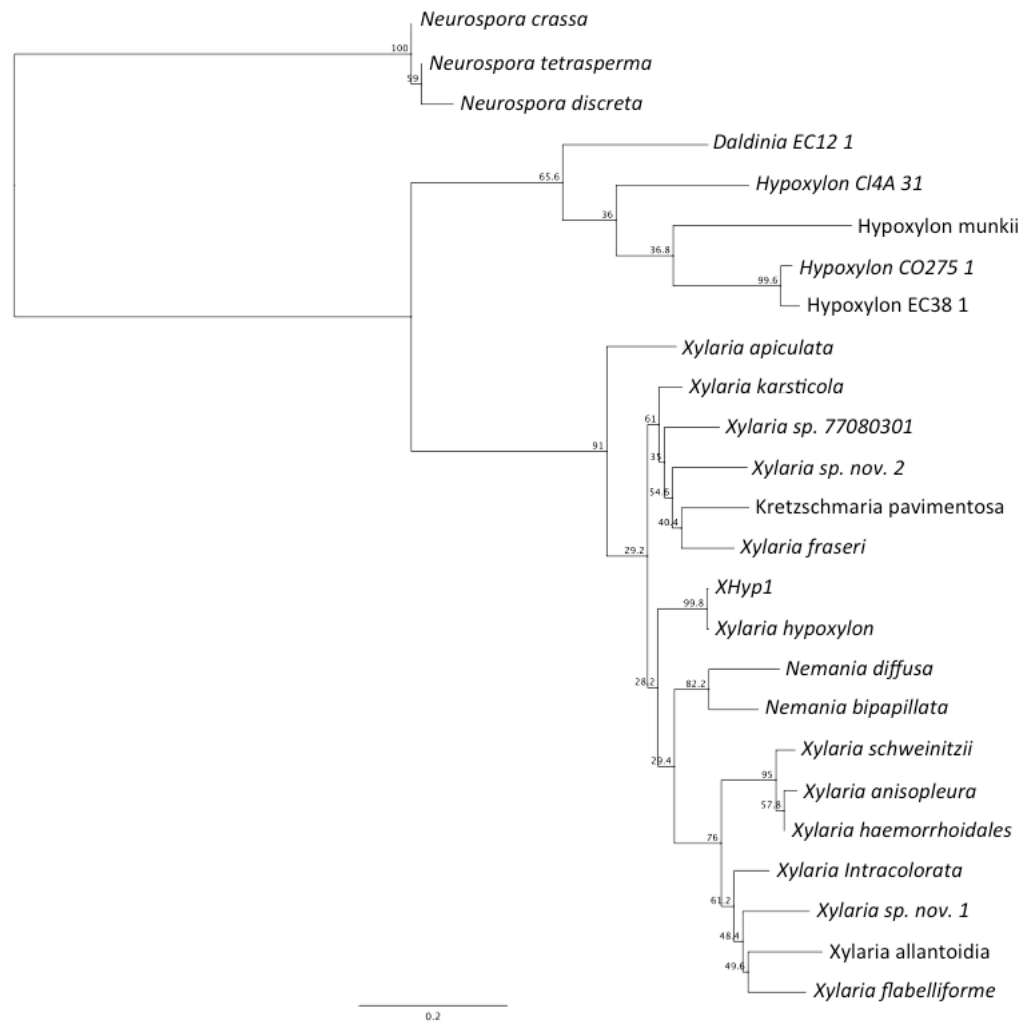

Figure 13. Splicing Factor PRP 43 F1054/R1691 Maximum Likelihood Tree 


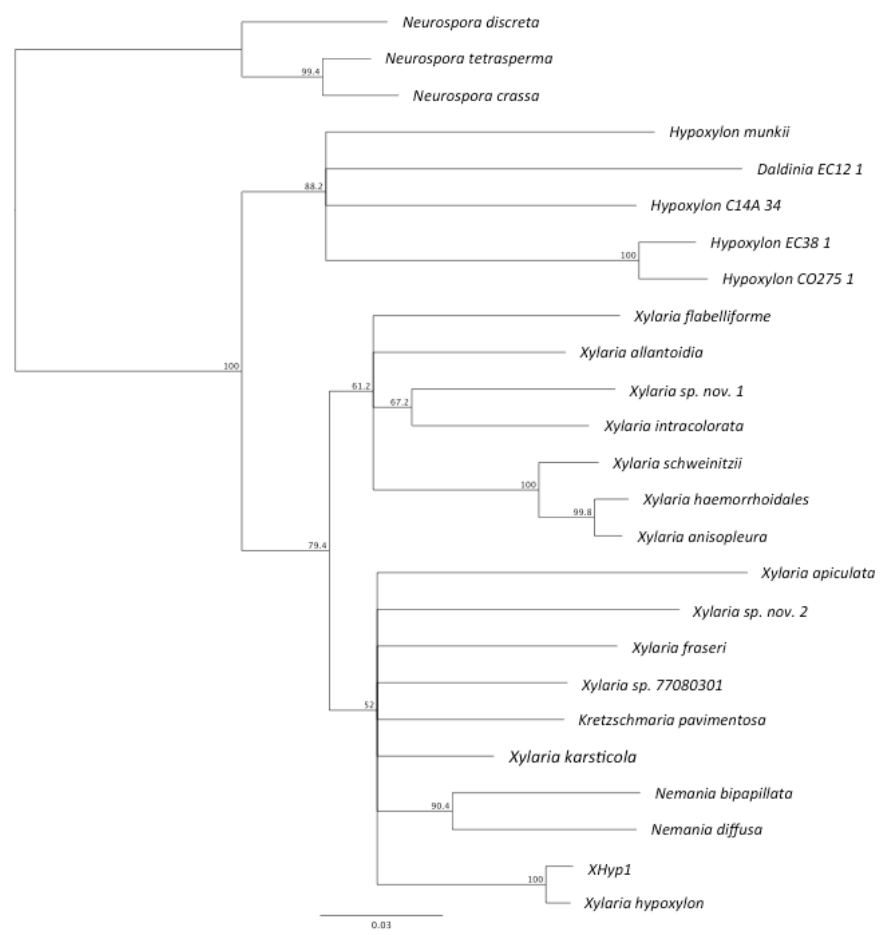

Figure 14. MCM7 F665/R1209 Neighbor-Joining Tree

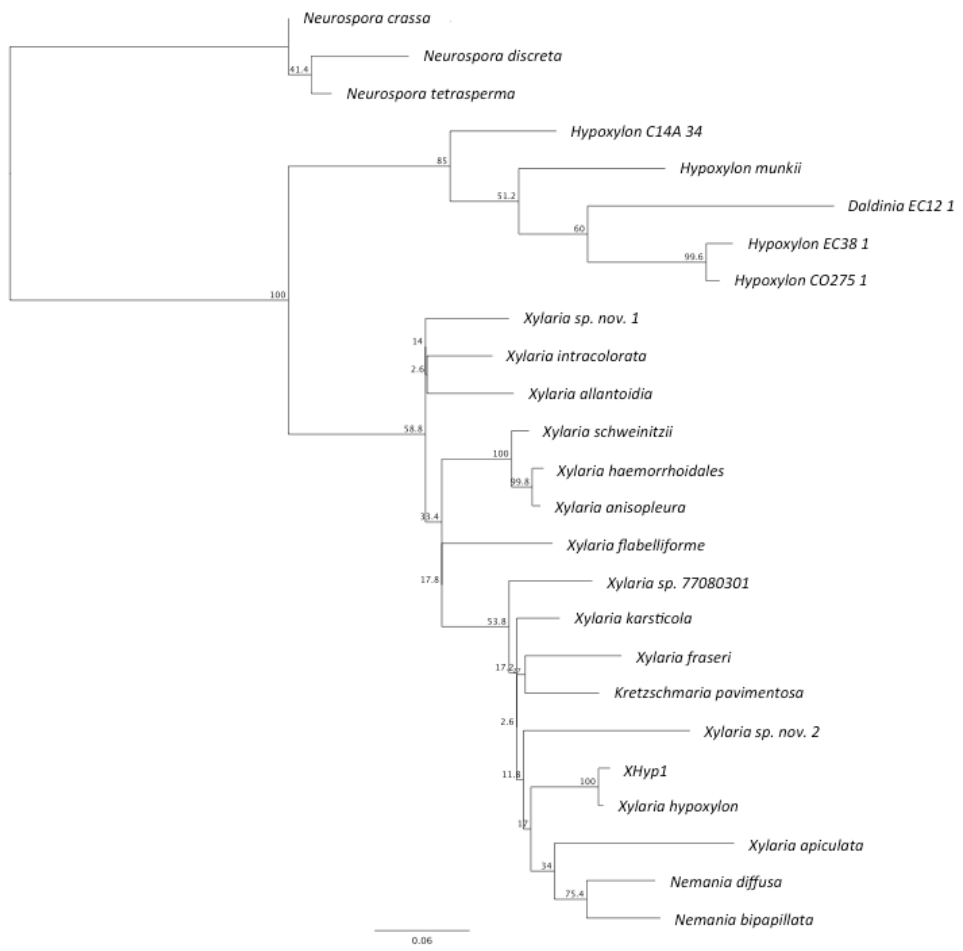

Figure 15. MCM7 F665/R1209 Maximum Likelihood Tree 


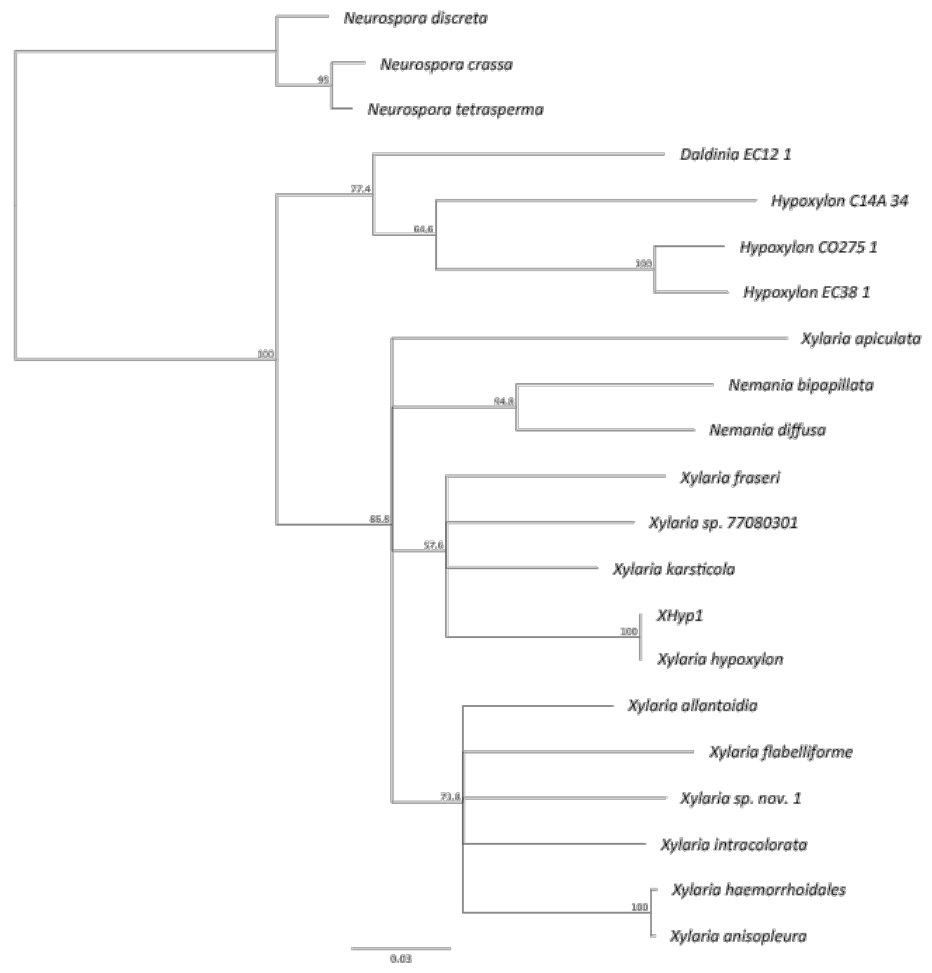

Figure 16. MCM7 F9/R595 Neighbor-Joining Tree

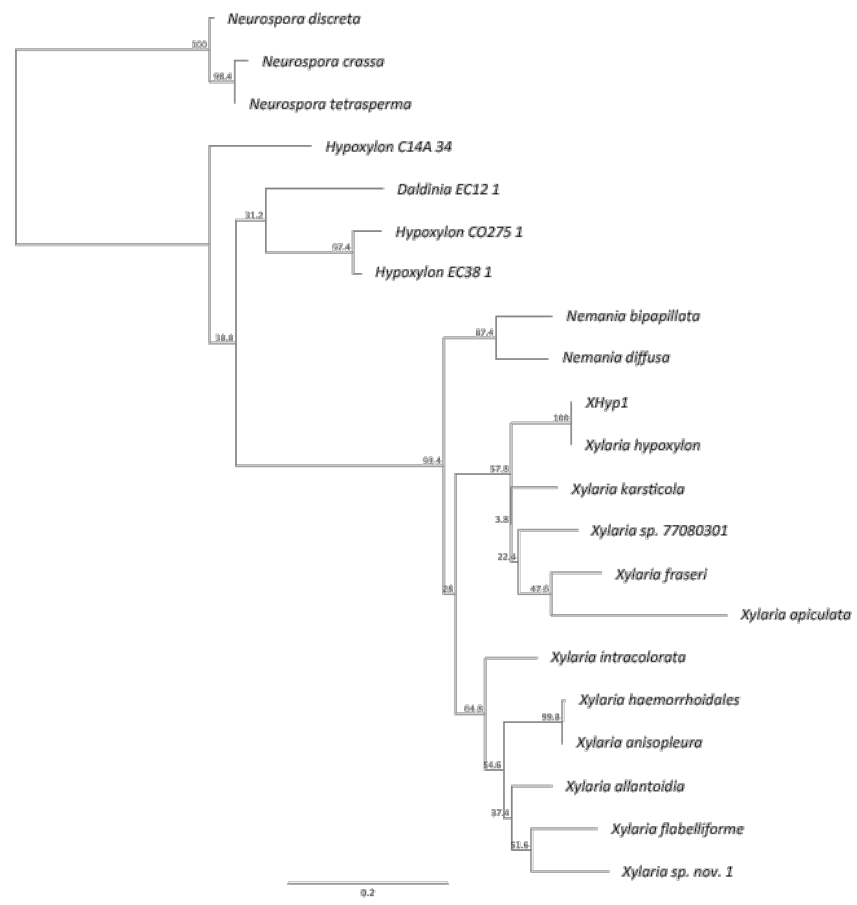

Figure 17. MCM7 F9/R595 Maximum Likelihood Tree 


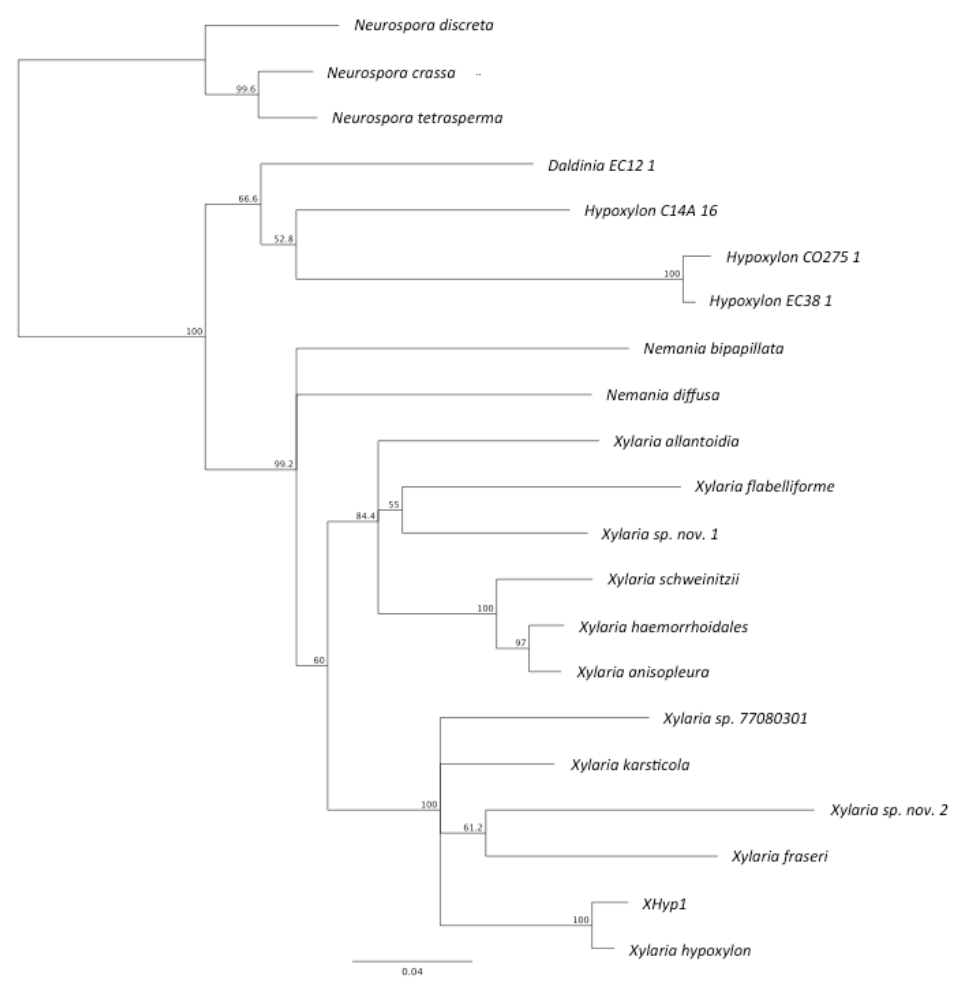

Figure 18. MCM5 F1188/1970 Neighbor-Joining Tree

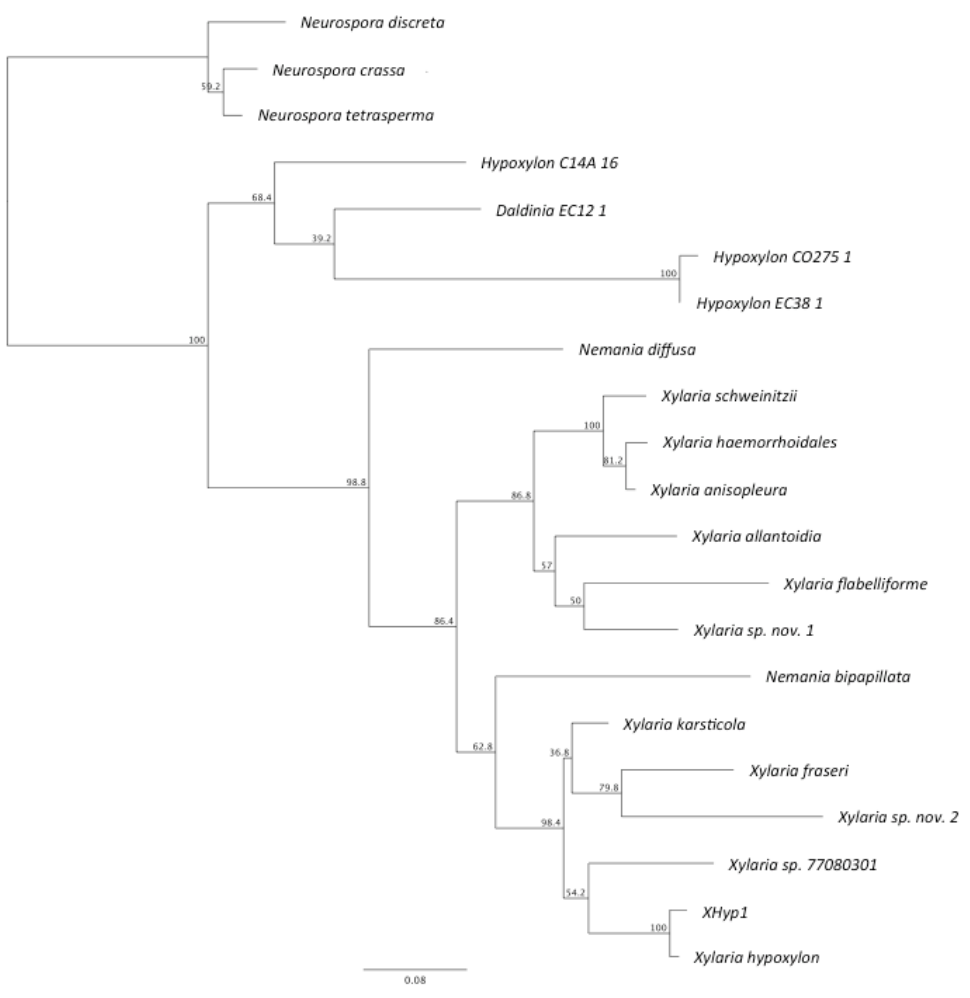

Figure 19. MCM5 F1188/1970 Maximum Likelihood Tree 


\section{ACKNOWLEDGEMENTS}

I wish to express my sincere thanks to Dr. George C. Carroll and Roo Vandegrift for all of their support throughout the year. Your expertise and guidance was vital to this project and my learning experience. You both possess a wonderful dedication to science that has been very inspiring to me. I would like to acknowledge the support of the Roy Lab. Thank you to Dr. Bitty Roy and Dan Thomas for introducing me to the lab and encouraging me throughout the project. I want to recognize Dr. Joseph Spatafora for providing us with the Xylaria hypoxylon genome used in this project. I also wish to express my appreciation for the Hill Fund of the Oregon Community Foundation and the GrEBES for sponsorship of the project. Thank you to Peg Boulay for advising me throughout my college career. Lastly, I would like to take this opportunity to thank my parents, Suzanne Larson and Boun Ly, for supporting me in every way over the years. I cannot thank you enough for always encouraging me to pursue knowledge and my dreams.

\section{REFERENCES}

Álvarez, I., \& Wendel, J.F. 2003. Ribosomal ITS sequences and plant phylogenetic inference. Molecular Phylogenetics and Evolution 29(3):417-434.

Cai L, Jeewon R, Hyde KD. 2006. Phylogenetic investigations of Sordariaceae based on multiple gene sequences and morphology. Mycological Research 110(2):137-150.

Capella-Gutierrez S, Kauff F, Gabaldón T. 2014. A phylogenomics approach for selecting robust sets of phylogenetic markers. Nucleic Acids Research 42(7):54.

Compton T. 1990. Degenerate primers for DNA amplification. In: Innis M, Gelfand D, Sninsky J, White T, editors. PCR protocols: a guide to methods and applications. New York: Academic Press. p. 39-45.

Davis EC, Franklin JB, Shaw AJ, Vilgalys R. 2003. Endophytic Xylaria (Xylariaceae) among liverworts and angiosperms: phylogenetics, distribution, and symbiosis. American Journal of Botany 90(11):1661-1667.

Dennis R. 1956. Some Xylarias of tropical America. Kew Bull 11(3):401-444.

Dentinger B, Margaritescu S, Moncalvo J. 2009. Rapid and reliable high-throughput methods of DNA extraction for use in barcoding and molecular systematics of mushrooms. Molecular Ecology Resources 10(4):628-633.

Felsenstein J. 1985. Confidence limits on phylogenies: An approach using the bootstrap. Evolution 39(4):783-791.

Hsieh HM, Ju YM, Rogers JD. 2005. Molecular phylogeny of Hypoxylon and closely related genera. Mycologia 97(4):844-865. 
Hsieh HM, Lin C, Fang M, Rogers JD, Fournier J, Lechat C, Ju Y. 2010. Phylogenetic status of Xylaria subgenus Pseudoxylaria among taxa of the subfamily Xylarioideae (Xylariaceae) and phylogeny of the taxa involved in the subfamily. Molecular Phylogenetics and Evolution 54(3):957-969.

Huelsenbeck JP. 1995. The robustness of two phylogenetic methods: Four-taxon simulations reveal a slight superiority of maximum likelihood over neighbor joining. Molecular Biology and Evolution 12(5):843-849.

Kiss L. 2012. Limits of nuclear ribosomal DNA internal transcribed spacer (ITS) sequences as species barcodes for fungi. Proceedings of the National Academy of Sciences USA 109:E1811.

Larena I, Salazar O, González V, Julián MC, Rubio V. 1999. Design of a primer for ribosomal DNA internal transcribed spacer with enhanced specificity for Ascomycetes. Journal of Biotechnology 75(2):187-194.

Lee JS, Ko KS, Jung HS. 200o. Phylogenetic analysis of Xylaria based on nuclear ribosomal ITS1-5.8 S-ITS2 sequences. FEMS Microbiology Letters 187(1):89-93.

Lei M. 2005. The MCM complex: Its role in DNA replication and implications for cancer therapy. Current Cancer Drug Targets 5(5):365-80.

Lopez-Giraldez F and Townsend JP. 2011. PhyDesign: An online application for profiling phylogenetic informativeness. BMC Evolutionary Biology 11:152.

Peláez F, González V, Platas G, Sánchez Ballesteros J, Rubio V. 2008. Molecular phylogenetic studies within the Xylariaceae based on ribosomal DNA sequences. Fungal Diversity 31(1): 111-134.

Rogers JD. 1979. The Xylariaceae: systematic, biological and evolutionary aspects. Mycologia 71(1):1-42.

Rogers JD. 2000. Thoughts and musings on tropical Xylariaceae. Mycol Res 104(12):1412-1420.

Sánchez-Ballesteros, J., González, V., Salazar, O., Acero, J., Portal, M.A., Julián, M., ..., Platas, G. 2000. Phylogenetic study of Hypoxylon and related genera based on ribosomal ITS sequences. Mycologia 92(5):964-977.

Sanderson MJ. 1997. A nonparametric approach to estimating divergence times in the absence of rate constancy. Molecular Biology and Evolution 14(12):1218-1231.

Sanderson MJ. 2002. Estimating absolute rates of molecular evolution and divergence times: A penalized likelihood approach. Molecular Biology and Evolution 19(1):101-109.

Schoch CL, Seifert KA, Huhndorf S, Robert V, Spouge JL, Levesque CA, Chen W, Fungal Barcoding Consortium. 2012. Nuclear ribosomal internal transcribed spacer (ITS) region 
as a universal DNA barcode marker for fungi. Proceedings of the National Academy of Sciences U S A 109(16):6241-6246.

Stadler M, Fournier J, Læssøe T, Decock C, Peršoh D, Rambold G. 2010. Ruwenzoria, a new genus of the Xylariaceae from Central Africa. Mycological Progress 9(2):169-179.

Stadler M, Kuhnert E, Peršoh D, Fournier J. 2013. The Xylariaceae as model example for a unified nomenclature following the "One Fungus-One Name" $(1 \mathrm{~F} 1 \mathrm{~N})$ concept. Mycology 4(1):5-21.

Tang A, Jeewon R, Hyde K. 2009. A re-evaluation of the evolutionary relationships within the Xylariaceae based on ribosomal and protein-coding gene sequences. Fungal Diversity 34:127-155.

Triebel D, Peršoh D, Wollweber H, Stadler M. 2005. Phylogenetic relationships among Daldinia, Entonaema, and Hypoxylon as inferred from ITS nrDNA analyses of Xylariales. Nova Hedwigia 80(1-2):25-43.

Folmer O, Black M, Hoeh W, Lutz R, Vrijenhoek R. 1994. DNA primers for amplification of mitochondrial cytochrome c oxidase subunit I from diverse metazoan invertebrates. Molecular Marine Biology and Biotechnology 3(5):294-299.

Walker DM, Castlebury LA, Rossman AY, Sogonov MV, White JF. 2010. Systematics of genus Gnomoniopsis (Gnomoniaceae, Diaporthales) based on a three gene phylogeny, host associations and morphology. Mycologia 102(6):1479-1496.

Walker DM, Castlebury LA, Rossman AY, White Jr. JF. 2012. New molecular markers for fungal phylogenetics: two genes for species-level systematics in the Sordariomycetes (Ascomycota). Molecular Phylogenetics and Evolution 64(3):500-512.

Whalley A. 1996. The Xylariaceous way of life. Mycological Research 100(8):897-922. 


\title{
The Question of Divine Omnibenevolence: What does the Hebrew Bible Reveal about Yahweh's
} Nature?

\author{
Jonathan Faris, Religious Studies*
}

\begin{abstract}
The portrayal of God in the Hebrew Bible as a whole is overwhelmingly positive. However, this perception of the Hebrew Bible God, also known as Israel's patron deity, Yahweh, changes upon further examination of certain biblical passages that appear to portray a malicious, exceedingly violent Yahweh. These passages have caused significant debate among interpreters, with some defending his behavior while others cast Yahweh in a malevolent light. However, these questionable narratives can be better understood by a rather integral thread woven into the fabric of biblical tradition: Yahweh's covenantal relationship with his people. This unique relationship between patron god and people sets Israel apart from other ancient Near Eastern civilizations that had moody, passionate gods, such as Egypt and Babylonia. Yahweh made several covenants with the chosen people, and despite the Israelites' consistent, flagrant violations of the relationship as well as his being devoid of obligation to the group he voluntarily delivered from slavery in Egypt, he maintained his side of the covenant. This faithfulness exemplifies his emotional investment in his people, which manifests itself in divine pathos. Likewise, Yahweh shows care and protection for the Israelites, often in the form of Yahweh voluntarily coming down to earth to act (sometimes violently) on behalf of Israel. When morally ambiguous passages are viewed in light of these biblical contexts, we can attain a more comprehensive view of Yahweh that affirms his omnibenevolence.
\end{abstract}

\section{INTRODUCTION}

Should Yahweh in the Hebrew Bible be interpreted as a positive or negative deity? Through much of the Hebrew Bible, Yahweh is portrayed in a positive light, from his devotion to protecting the Israelites (his chosen people) to his blessings of the leaders of the Israelites; the numerous incidences of a "good god" attest to divine goodness. However, there are several notable narratives, namely the striking down of Uzzah in 2 Samuel 6 and the "martyrdom" of Nadab and Abihu in Leviticus 10, which some argue indicate a moody, even malevolent Yahweh. Scholars have wrestled with these morally ambiguous passages in the Hebrew Bible.

Interpreters like Abraham Heschel and Terence Fretheim have optimistic views of Yahweh, whereas scholars like David Penchansky and Eric Seibert reject divine goodness. The negative

\footnotetext{
* Jonathan Faris is a sophomore from Forest Grove, Oregon who is double majoring in Biology and Religious Studies. Currently, he is involved with the Cresko Lab at the University of Oregon, and is a Mathematics Tutor at the UO Teaching and Learning Center. He plans on pursuing a career in medicine or dentistry. Please direct correspondence to jfaris@uoregon.edu.
} 
depictions ascribed to Yahweh should not be construed as such because these rare instances where Yahweh's goodness appears compromised are a reflection of Yahweh's investment in the covenantal relationship between himself and Israel as well as Yahweh's care for his chosen people.

\section{NATURE OF THE COVENANT}

Throughout the Hebrew Bible, Yahweh enters into several covenantal relationships with biblical characters and groups, a majority of them involving the Israelites, his chosen people whom he delivered from the hands of the Egyptians. These include the Abrahamic covenant promising Abraham that his descendants would be blessed in return for faithfulness (Gen. 12), the Mosaic covenant established after Yahweh brought Israel out of Egypt that included the Ten Commandments as well as Mosaic Law (Exod. 19-24), and the Davidic covenant that promised David and his descendants claim of the royal throne (2 Sam. 7). These covenants are not contracts; a contract implies a legal agreement between two parties, whereas a covenant is a set of promises from both parties that reflects a personal, intimate relationship. Heschel illustrates the distinction between contract and covenant in light of his broader discussion of divine pathos by contrasting the coldness of a contract with the fellowship and loving involvement of Yahweh's covenant (Heschel, 10). This approachable Yahweh is atypical of many ancient gods and as a result, is more willing to sacrifice himself to keep the covenant intact.

Let us focus on the Mosaic covenant, since the exodus account is one of the most significant events in biblical tradition. Joseph had risen up the ranks of the Egyptian hierarchy to be Pharaoh's right-hand man, and as a result, influenced Pharaoh's decision to welcome the Israelites and give them fertile land to inhabit. However, when Pharaoh died and a new Pharaoh arose, the new Pharaoh had no memory of Joseph's relationship with Egyptian leadership and as a result, viewed the Israelites as a threat. He enslaved the Israelites and subjected them to forced labor. Exodus 2:24 marks the beginning of the Exodus account, when Yahweh "heard their groaning" and "remembered His covenants with Abraham, with Isaac, and with Jacob." After a series of ten plagues serving as a warning to Pharaoh against further persecution of the Israelites, Yahweh told Moses and Aaron that he would kill the firstborn of every household, and instructed each Israelite family to procure a year-old lamb on the tenth of the month, slaughter it at twilight on the fourteenth of the month, and put some of its blood on the doorposts and lintel of their houses (Exod. 12:3-13). Each house with the blood mark would be passed over and would escape death (Exod. 12:29). This event, along with the festival of unleavened bread, form the basis of the Jewish Passover holiday that commemorates Yahweh's deliverance of the Israelites from the oppressive grip of the Egyptians. Yahweh performed a violent act in the name of protection of both his people and their covenantal relationship. After the firstborns of the Egyptian households died, Pharaoh told the Israelites to leave his land, but this did not prevent him from pursuing them in their escape and ultimately being swallowed up by Red Sea (Exod. 14:26-29).

Yahweh then led them to their promised land (Canaan) while protecting them from its inhabitants (Canaanites, Philistines, and Amorites, to name a few). On the way to Canaan, when 
they were passing through the wilderness near Sinai, Yahweh descended to Moses at the mountain and delivered to him the Decalogue (Ten Commandments) as well as stipulations of the newly established Mosaic covenant (Exod. 19-24). In return, Yahweh would make Israel his "treasured possession" and a "priestly kingdom and a holy nation" (Exod. 19:5-6). This bond is often represented by marital imagery (Isa. 54:1-6) that personifies Israel as the Bride of Yahweh (Reddish, 782). Much like marriage, the covenantal relationship between Yahweh and Israel required investment from both parties. However, Yahweh was not obligated to initiate the covenant with the Israelites. He owed nothing to the Israelites and they owed everything back since without him, they would still be enslaved by Pharaoh. Instead, he drew himself into the "profane world" and took a risk by being personal and sharing in the fate of the world (Dozeman, 277). By nature of this unbalanced distribution of obligations, this divine covenant "implies that persons under covenant are capable of recognizing the fact that individually and corporately they have received benefits in their past that they have in no way earned" (Mendenhall, 1191). Yahweh delivered the Israelites from the Egyptians, promised them the land of Canaan, and vowed to provide protection from their enemies, all in return for loyalty and adherence to a basic set of rules. Therefore, the violent side of Yahweh is better understood in light of his committed, protective nature.

\section{BREAKDOWN IN COVENANTAL RELATIONSHIP}

Yahweh was clearly invested in his people, and despite the uneven obligations, faithfully fulfilled his end of the covenant. The Israelites inhabited Canaan and the previous occupants were driven out; the book of Joshua recounts the conquest of the land, highlighting events like the capture of Jericho, defeat of the Canaanite coalition of armies, and the allotment of land to the tribes of Israel (Josh. 5:13-19:51). However, Israel regularly turned their back on Yahweh and violated the covenant. This is especially apparent in the book of Judges, which chronicles the events in Canaan directly after the death of Joshua. The newly established tribes started interacting with each other, and were in constant contact with Yahweh through judges, who acted as Yahweh's emissaries but ultimately failed, leading the Israelites to act in a cyclical pattern signifying their inability to live up to the standards set forth in Deuteronomy that outlined how the Israelites should live in Canaan. The tribes repeatedly "did what was evil in the sight of the Lord" and were subsequently punished by Yahweh (Judg. 2:11-15). This offense came in the form of disobeying the law, worshipping other deities (like Baal), and refusing to listen to the prophets. Some scholars even suggest the prophet Isaiah did not expect to be heard, since he had his words recorded in a time when writing was not very widespread among Near Eastern societies due to limited education and social inequalities (Hays, 386).

The prophets were regarded as residing in the highest echelon of society due to their status as "kingmaker" and heightened standing as the intermediary between Yahweh and the people, yet their divinely-inspired calls to return to Yahweh were repeatedly swatted down. For example, in 1 Samuel 8, the Israelites clamored for a king, and despite Samuel's insistence that abuses and problems accompany kingship, the people were not persuaded (Hancock, 290-291). As "kingmaker", he gave the people what they wanted but warned them of the repercussions (Hancock, 296). While monarchy is typically portrayed in a negative light by the authors of the 
Hebrew Bible, some scholars argue the idea of a monarchy was desirable but the motivation behind wanting a king in the first place was contrary to conventional Israelite thought. In 1 Samuel, the people called for a king who could "[make Israel] like other nations, and that our king may govern us and go out before us and fight our battles" (1 Sam. 8:20). Yahweh, Israel's protector and king, would be “'deposed as king' because his role as military protector was to be transferred to Israel's human king” (Howard, 112). Due to Yahweh's longstanding role as Israel's king figure and the almost heretical attitude of the people, this reasoning for a king was erroneous on the Israelites' part, but the Israel monarchy did produce several good kings; King David, despite his faults, fit the mold of an ideal king through his leadership and devotion to Yahweh (Howard, 113). With the guidance of the prophet, the king could be a catalyst for adherence to the covenant; this illustrates the importance of prophetic leadership in Israel's history, especially its monarchal period.

There are considerable parallels between Moses and Samuel, including their miraculous births, distance from initial communities, divine calling, and actions as an intercessor on the Israelites' behalf (Hancock, 295). Additionally, just like Samuel, Moses acted as an advisor to fellow enforcers of the covenant. Moses, due to his subpar speaking ability (Exod. 4:10), relayed divine messages to his brother Aaron, who became his spokesperson to Pharaoh. Later on, however, Moses assumed responsibility of the primary prophetic duties while Aaron became the high priest; this shows his status as temporary advisor to Aaron and eventual advisor to the Israelite people. To illustrate, the Deuteronomistic Historian, the anonymous scholar during the Babylonian exile who compiled the books of the Deuteronomistic History (Joshua, Judges, 1 and 2 Samuel, 1 and 2 Kings), highlighted "the role of prophets in upholding the provisions of the Sinai covenant, concerns that are central for the DH [Deuteronomistic History]" (Hancock, 293). As Israel's history unfolded, the prophets were the enforcers of the covenant who advocated for maintaining the mutual relationship between the two parties (Yahweh and chosen people) and avoiding any strain put on the relationship by the actions of the Israelites. Even with the breakdown of the covenantal relationship despite the efforts of the prophets, Yahweh did not waver and continued to protect the Israelites, thus demonstrating his intrinsic benevolence.

Heschel offers a positive view of Yahweh from the perspective of the prophets, who had the most intimate relationship with Yahweh in ancient Israel and suffered like Yahweh. He asserts that the prophets understood God through his "intimate relation to the world" and most importantly, divine pathos (Heschel, 3). Yahweh was not the "God of the philosophers," who created the world and backed off, oblivious to the state of his creation (Heschel, 4). Instead, Yahweh displays reactive emotion to the actions of his people and cares about the welfare of his people, despite the periods of disobedience and unfaithfulness from the Israelites.

\section{POTENTIAL COMPROMISES OF YAHWEH'S OMNIBENEVOLENCE}

With a clear understanding of Yahweh's unique interest in the covenant as a backdrop, let us now consider the matter at hand: challenges to Yahweh's omnibenevolence. Some argue that there are notable episodes where Yahweh's all-goodness is compromised. David Penchansky, in 
his book What Rough Beast? Images of God in the Hebrew Bible, explores six narratives in the Hebrew Bible that he asserts depict Yahweh as a negative deity, contrary to the traditional, optimistic perspective on Yahweh. He suggests his audience analyze each of these narratives independently (focusing solely on the text itself and no other resources) as well as pretending Yahweh is a character in the story. The primary shortcoming of this approach is when he studies each passage, he disregards the rest of the Hebrew Bible and how this text, as a whole, portrays Yahweh. In his analysis of these passages, he suggests Yahweh is not omnibenevolent and appears insecure, irrational, vindictive, dangerous, malevolent, and abusive. Penchansky's petulant, aloof Yahweh is refuted by closer examination of the Hebrew Bible.

While Penchansky suggests Yahweh is driven by passion, he is instead driven by pathos. Yahweh's covenantal relationship with the Israelites implies this divine pathos. Due to his desire to maintain a good relationship with his people, there is intention behind his emotion; his emotion does not signal "drunkenness of the mind" as Heschel indicates (Heschel, 4). The authors of the Hebrew Bible contrast Yahweh with other ancient Near Eastern gods, who often exhibit passion in their own narratives. For example, in the Mesopotamian Myth of Atrahasis, Enlil (the storm god) decimates humanity with a flood and has a passionate tirade when Atrahasis survives (Herion, 991). These unreasoned actions characterize not only this Mesopotamian god, but Egyptian gods as well. They are often portrayed as unleashing anger in "petty tirades" when they are not pleased by their subjects (Herion, 994). They do not show restraint, in contrast to Yahweh who restrains his power to benefit humanity. After the flood in Genesis 6, Yahweh promises Noah that he would never flood the earth again (Gen. 9:11), showing his desire to restrain his power in order to benefit humanity's future.

In contrast to his self-imposed restriction of power in the flood narrative, Yahweh does not appear to restrain his power when he strikes down Uzzah in 2 Samuel 6. David, Yahweh's anointed king of Judah, has just become king of all Israel and conquered Jerusalem, which he subsequently makes his capital. He desires to make Jerusalem the religious as well as the political center of the kingdom, so he travels to Kiriath-jearim (where the ark was left in 1 Sam. 7) in order to get the ark of the covenant and bring it to Jerusalem. David brings along thirty thousand people, including two sons of a priest Abinadab, named Uzzah and Ahio. They load the ark onto an ox-cart and en-route to Jerusalem, the oxen shake the ark, causing Uzzah to reach out his hand to steady the ark. As a result, the "anger of the Lord was kindled against Uzzah" (2 Sam. 6:7). At first glance, this lashing-out seems excessive considering the good intent behind Uzzah's action in the absence of any clear explanation of his wrongdoing. As a priest, Uzzah likely knew all the Jewish law and history at the time, and if asked a question pertaining to his craft, he would answer in all of the acceptable ways (Long, 18). This leads us to view Uzzah as a pious man, a soul so devoted to following the commands set forth by Yahweh it seemed to be second nature. Thomas Long suggests the solution to this confusing narrative is in Uzzah's spontaneous reaction (Long, 18). The action did not seem in any way a product of Uzzah's quick reasoning due to the speed at which this event occurred, which indicates that Uzzah must have contemplated something negative similar to this happening, implying Uzzah's action was premeditated. If Uzzah believed Yahweh was omnipotent and who he said he was, Uzzah would not have reached out to steady the ark. An omnipotent Yahweh would not need the assistance of a 
newly-appointed priest to "dotter across the street", as Long puts it (Long, 18). Uzzah was so doubtful in Yahweh's power and control that he steadied the ark to cover all his bases, just in case Yahweh was not the omnipotent deity he himself had been professing. Therefore, Uzzah's weak faith was the reason for his death, not the malevolence of Yahweh.

Penchansky gives the example of the strange fire offered by two brothers (Nadab and Abihu) in Leviticus 10 as a case when Yahweh appears dangerous. These two recently ordained priests mixed incense with "strange fire" and offered it to the Lord (Lev. 10:1). As a result, they were consumed by the fire and died. While this may seem like a minor infraction that did not warrant capital punishment, the brothers did indeed violate the law. In Exodus 30:9, Yahweh instructs the priests to "not offer unholy incense." Penchansky himself references biblical critic Gnana Robinson, who suggests that, in context, "the phrases 'strange fire' and 'strange incense' are synonymous" and "both refer to the same thing, namely, the worship of "strange gods" (Penchansky, 57). The issue, then, is the impurity of the ritual. Purity and proper presentation was something Yahweh placed great importance on in Leviticus (Stackert, 576). Aaron's inexperienced sons either produced the fire for the wrong god or used unauthorized incense, both of which are covenantal infractions. Therefore, Yahweh's wrath was justified through his desire for the Israelites to respect the divine covenant, and was not a senseless violent act.

Penchansky's point about Yahweh being wrathful is true, but he overlooks the fact that his anger is a reaction, not an attribute. He and Seibert both make this fundamental error. They believe the instances when Yahweh's wrath seems unjustified reflect his character. Instead, human misconduct compels Yahweh to anger, and his divine anger takes several forms in the Hebrew Bible. The Hebrew word for divine anger in the Bible is 'ap, and two words used in conjunction with 'ap are hrrh and hậhôn (Herion, 990). The verb ḥrh (meaning "to burn") appears with 'ap as the subject in passages like Exodus 22:24 (“...my wrath will burn”) (Herion, 990). Additionally, the word hââon is a term for divine "rage" and literally means "burning"; it is used about three dozen times in association with 'ap (Herion, 990). This abundance of divine anger is justified due to the inspiration of his wrath. Israel's disobedience, evident from their "transgression of the covenant" (Josh. 7:1) and "pursuit of other gods" (Deut. 6:14-15), is almost always the subject of Yahweh's anger; therefore, ḥrh and hāân likely have "a specialized use designating the legitimate rage of a suzerain against a disobedient vassal" (Herion, 990). Divine anger is justified by the Israelites' constant violation of the covenant.

Seibert discusses narratives where Yahweh appears to behave disturbingly. In his first example, Seibert reasons the 613 Mosaic laws of Exodus, Leviticus, Numbers, and Deuteronomy portray Yahweh as a "Deadly Lawgiver" (Seibert, 17). He argues that the laws, especially the ones prescribing capital punishment, are "extreme" and "severe," concluding that God is too harsh on his people whom he is purported to be forgiving and kind towards (Seibert, 18). While these punishments do seem absurd at first glance, looking at them in the broader historical and cultural context reveals a different conclusion. There are many similarities between the Mosaic laws and Hammurabi's Code, an early law code in the ancient Near East. The idea of "an eye for an eye" (lex talionis) originates from this Babylonian code. Harsh punishments were common at the time and this was a culturally acceptable way of dealing with crime. The reason why we 
cringe at capital punishment in contemporary times is that our Western society is less severe than ancient Near East societies. As readers and scholars, our views reflect our cultural perceptions of crime and punishment. However, in order to understand the text fully, we need to be aware of the cultural chasm between our society and ancient Israelite society and view the laws in light of the time and cultural context in which it was written; this anachronism is where Seibert is incorrect.

\section{CARING AND PROTECTIVE YAHWEH}

By expressing his anger at the Israelites when they transgressed the covenant, Yahweh shows his care for them. For example, Yahweh exhibits anger and jealousy when his people worship other gods (1 Sam. 8:7-8). Just as a man feels jealous when another man flirts with his wife at a social gathering, Yahweh feels jealous when his bride (Israel) turns from him in favor of other gods. This type of jealousy is healthy, because indifference in this situation shows no tangible, emotional connection between the two subjects. There is somewhat of a rivalry between Yahweh and Canaanite deities like Baal, and they compete for the loyalty of Israel (van der Toorn, 916). Yahweh shows concern for the Israelites' well-being and showers blessings on those who follow his commandments (Deut. 28:1-14). In the second half of the book of Isaiah, Yahweh calls for the renewal of the covenant and how he will fulfill his side of the relationship, namely, the restoration of Israel after it was punished by the Assyrians for its sin. Yahweh asks the Israelites to "incline [their] ear and come to [him]" as part of his actions on behalf of Israel and delights in her return (Isa. 55:5, 62:4). He is genuinely concerned for the state of humanity and only exhibits anger when the sacred relationship between him and his beloved is broken.

One way Yahweh cares for the Israelite people is through his protection. This often comes in the form of military protection from other ancient Near Eastern cultures, like the Philistines and the Assyrians that were especially hostile to Israel during their infantile stages in the Deuteronomistic History as well as their exilic and post-exilic years. In the Divine Warrior narratives, the personal name for Israel's patron deity is Yahweh Zebaoth (or Sabaoth), which occurs 284 times in the Hebrew Bible and describes Yahweh's power and his command of heavenly hosts (Mettinger, 920). This term is mentioned mostly around discussion of Jerusalem temple theology during the time of the prophets and exists in close connection to the cherubim throne (composed of divine beings that attend to Yahweh) mentioned in 1 Samuel 4:4, 2 Samuel 6:2, and Isaiah 37:16 (Mettinger, 921-922). Through the temple connection, Yahweh is present on earth and on his throne in heaven simultaneously (Mettinger, 923). The significance of the Lord of Hosts is his willingness to descend to earth to protect his chosen people. Isaiah 19:16-17 says, "On that day the Egyptians will be like women, and tremble with fear before the hand that the Lord of Hosts raises against them. And the land of Judah will become a terror to the Egyptians; everyone to whom it is mentioned will fear because of the plan that the Lord of Hosts is planning against them." In Isaiah 37, Yahweh promises Hezekiah that he will preserve the remnant of Judah, and sends an angel to destroy the Assyrian king Sennacherib's army that is laying siege on Jerusalem. Yahweh is so concerned for the Israelites' welfare that he descends from heaven accompanied by his heavenly armies and honors the Davidic covenant that ensured 
David his descendants would inherit the kingship of Judah. This unique, caring relationship is uncharacteristic of ancient Near Eastern deities.

\section{YAHWEH'S SELF-SACRIFICE}

Like Heschel, Fretheim focuses on the prophets, but he looks at how the prophets, as representatives of Israel, bear the sins of the people and how their lives mirror the life of Yahweh (Fretheim, 139). He evaluates divine suffering and reinforces the idea that Yahweh suffers because of the breakdown in the covenantal relationship (Fretheim, 109). Yahweh calls for the Israelites' repentance because he does not enjoy exacting judgment on them. Also, when Yahweh bears those sins, he becomes weary from the burden; many verses illustrate this divine weariness, including Isaiah 7:13 ("you weary my God") and Jeremiah 15:6 ("You have rejected me', says the Lord... 'I am weary of relenting'”) (Fretheim, 140). Extending this idea, Fretheim asserts Yahweh's life is literally eroded as a result of bearing the people's sins. To support this, he analyzes Leviticus 17:11, which states that Yahweh has given the sacrificial blood to mankind for the atonement of their sins (Fretheim, 138). Yahweh, as the life-giver to the animals that are used for sacrifice, gives up part of himself so his people have the ability to repent and gain forgiveness. There comes a time when his long-suffering patience is at its end, and this is when judgment comes. In other words, "it is only because of God's willingness to continue to suffer as long as he has that the people continue to live" (Fretheim, 143). At the beginning of Isaiah (Isa. 1:2-9), Israel is criticized for its defection, and the "survival of even a remnant is already a mark of God's grace" (Williamson, 364). Yahweh, who has the power capable of judgment at any time, is so merciful that he chooses to delay judgment to give his people (whom he is emotionally bound to) a chance to repent using his own lifeblood.

\section{CONCLUSION AND THIS STUDY'S RELEVANCE TO FUTURE HEBREW BIBLE STUDY}

Yahweh's omnibenevolence is best demonstrated through his unique relationship with the Israelite people. Unlike other ancient Near Eastern deities, he does not exist to be appeased and does not lash out in unrestrained rage when his people flagrantly violate the covenant. Instead, he consistently honors the covenant even when the other party does not, which shows his investment in the Israelites. He is emotionally affected by the covenantal violations, but exhibits pathos in expressing his anger. This reasoned wrath in Yahweh's judgment is the result of his long-suffering patience and voluntary depletion of himself in order for the Israelites to have a chance at repentance and forgiveness. Lastly, Yahweh's care for his people is illustrated through his willingness to descend to earth to act on their behalf. Though in some situations Yahweh may appear malicious, the narrative in question cannot be taken independently from the rest of the Hebrew Bible because it is inherently woven into a larger framework that portrays Yahweh as long-suffering, yet forgiving, willing to overlook transgressions in order to allow his chosen people to return to him. This image of an omnibenevolent Yahweh is the one that should guide further exploration of the Hebrew Bible in a larger historical and religious context. 


\section{ACKNOWLEDGEMENTS}

I would like to thank Professor Andrew J. Riley of the University of Oregon's Religious Studies Department and Judaic Studies Program for his guidance and mentorship throughout the composition and revision process.

\section{REFERENCES}

Dozeman, Thomas B. "Exodus." Oxford Encyclopedia of Books of the Bible. Ed. Michael D. Coogan. 2011. Volume 1, 261-282. Print.

Fretheim, Terence. The Suffering of God: An Old Testament Perspective. Philadelphia: Fortress Press, 1984. Print.

Hancock, Rebecca S. "1 and 2 Samuel.” Oxford Encyclopedia of Books of the Bible. Ed. Michael D. Coogan. 2011. Volume 2, 287-305. Print.

Hays, Christopher B. "Isaiah.” Oxford Encyclopedia of Books of the Bible. Ed. Michael D. Coogan. 2011. Volume 1, 384-409. Print.

Herion, Gary A. "Wrath of God (OT).” Anchor Bible Dictionary. Ed. David Noel Freedman. 1992. Volume 6, 989-996. Print.

Heschel, Abraham J. The Prophets: Part II. New York: Harper Colophon, 1975. Print.

Howard, D. "The case for kingship in Deuteronomy and the Former Prophets." Westminster Theological Journal 52.1 (1990): 101-115.

Long, Thomas G. "The Fall of the House of Uzzah...and Other Difficult Preaching Texts.” Journal for Preachers 7.1 (1983): 13-19. Print.

Mendenhall, George E. and Gary A. Herion. “Covenant.” Anchor Bible Dictionary. Ed. David Noel Freedman. 1992. Volume 1, 1179-1202. Print.

Mettinger, T.N.D. "Yahweh Zebaoth.” Dictionary of Deities and Demons in the Bible. Eds. Karl van der Toorn, Bob Becking, Pieter W. van der Horst. 1999. 920-924. Print.

Penchansky, David. What Rough Beast? Images of God in the Hebrew Bible. Louisville: Westminster John Knox Press, 1999. Print.

Reddish, Mitchell G. "Bride of Christ.” Anchor Bible Dictionary. Ed. David Noel Freedman. 1992. Volume 1, 782. Print.

Seibert, Eric. Disturbing Divine Behavior: Troubling Old Testament Images of God. Minneapolis: Fortress Press, 2009. Print.

Stackert, Jeffrey. "Leviticus.” Oxford Encyclopedia of Books of the Bible. Ed. Michael D. Coogan. 2011. Volume 1, 573-581. Print.

Van der Toorn, Karl. "Yahweh." Dictionary of Deities and Demons in the Bible. Eds. Karl van der Toorn, Bob Becking, Pieter W. van der Horst. 1999. 910-919. Print.

Williamson, H.G.M. “Isaiah, Book of.” Dictionary of the Old Testament: Prophets. Eds. Mark J. Boda and J. Gordon McConville. 2012. 364-378. Print. 


\title{
Searching for the Nearest Extragalactic Binary Black Hole: A Spectroscopic Study of NGC 4736
}

\author{
Annika Gustafsson, Physics and Math*
}

\begin{abstract}
Maoz et al. $(1995,1996)$ concluded that the nearby galaxy NGC 4736 is in the late stages of a merger event. After further investigation, Maoz et al. (2005) observed variability in the nuclear region of NGC 4736, revealing a second unknown source of radiation in the nucleus. Since merging systems are an ideal location to search for binary black holes $(\mathrm{BBH})$, we hypothesized that the second source could be a second black hole, making this a potential BBH system. Observational evidence for the existence of BBH remains sparse, even though $\mathrm{BBH}$ are predicted by many theories. To date, only NGC 6240 (Komossa et al., 2003) and Arp 299 (Ballo et al., 2004) have been discovered as merging galaxies with two active galactic nuclei (AGN). In 2008, NGC 4736 was observed with the Gemini-North telescope. We can classify the nature of the unknown source by looking at the optical line ratios following Ho et al. (1997). High signal-tonoise spectra of the unknown source displayed strong emission of [SII] and [NII], but extremely weak [OIII] emission. The unknown source has a calculated $[\mathrm{NII}] /[\mathrm{H} \alpha]$ ratio of 1.37 and an upper limit of 0.6 for the $[\mathrm{OIII}] /[\mathrm{H} \beta]$ ratio. Placing the unknown source on the BPT-NII diagram (Baldwin et al., 1981), we tentatively conclude that it is a second black hole potentially making NGC 4736 the nearest BBH system. The result will enable future observations of a low-luminosity system in extremely late stages of merging, which will be a significant step forward in validating models of galaxy mergers and AGN activity that further our understanding of galaxy formation and evolution.
\end{abstract}

\section{INTRODUCTION}

There are two known astronomical binary black hole systems where both black holes in the nucleus of a single galaxy exhibit active galactic nuclei (AGN) behavior. The first binary black hole (BBH) system was discovered in galaxy NGC 6240, approximately 40 million light years away, by Komossa et al. in 2003 when imaging from the Chandra X-ray Observatory revealed two X-ray sources in the nuclear region of the galaxy. The second, and only other candidate for a BBH system Arp 299, approximately 130 million light years away, was discovered in 2004. NGC 4736 was added to the list of candidates when Maoz et al. (2005) made UV wavelength observations and discovered two sources of UV radiation in its nucleus. Anomalies in the spectrum of the galaxy led Maoz et al. (2005) to hypothesize that the galaxy is in the late stages of a merger, and thus, a likely place to look for a $\mathrm{BBH}$ system. If confirmed as a $\mathrm{BBH}$, this system would represent a much more advanced stage of merging than the previously discovered $\mathrm{BBH}$

\footnotetext{
*Annika Gustafsson, a native of Santa Cruz, California, is a senior physics and mathematics major and business minor. She is also a member of the Robert D. Clark Honors College. Annika's academic interests have always lied in astronomy and physics. She plans to receive her doctoral degree in Planetary Science with the intentions of pursuing a career in observational research.
} 
systems. Hence, the discovery would be extremely important in helping validate theoretical predictions by providing the opportunity to study an older, and presumably more evolved system. Additionally, at a distance of only 16 million light years, NGC 4736 is much closer than the other two galaxies, which offers the ability to study such a system in greater detail.

While $\mathrm{BBH}$ are hypothesized to be common due to the frequency of merging galaxies, there is still little observational evidence to support their existence. However, many theories and computer models support the existence of BBH systems because they can help explain many predicted astrophysical phenomena. One obvious place to look for these systems is in merging galaxies. Collisions, or mergers, occur when galaxies become too close and their gravitational forces pull them together, which results in them joining, or merging. In 2005, evidence from the Hubble Space Telescope led astronomers to predict that black holes and galaxy formation go hand in hand. As a result, it is predicted that every galaxy contains a black hole in its nucleus. Some of these black holes are active, while others are completely dormant. An active galactic nucleus (AGN) is a region at the center of a galaxy, most often with a black hole, which produces enormous luminosities and intensities, sometimes as much as an entire galaxy. The high luminosities result in distinctive spectra that make these systems relatively easy to detect as they are quite different from the spectra of most stars and galaxies whose spectral lines are generally weak and predominately in absorption. The mechanism that causes a black hole to turn its activity on and off is still largely unknown; therefore, studying black holes at extremely low luminosities is important in determining the links between a very luminous, or active, black hole and a quiescent black hole.

When two galaxies merge, the resulting merged galaxy will likely have two black holes in its nucleus, one from each host galaxy, until the larger, or more massive black hole, consumes the smaller. Theories that rely on the existence of BBH systems include BBH triggering star formation and initiating the formation of dusty AGN tori. They can also explain observations as diverse as helically distorted radio jets and quasi-periodic variations in the light curves of some BL Lac objects.

\section{PROPOSAL}

We proposed to analyze extant optical spectroscopy data to determine the exact nature of this unknown second source in the nucleus of NGC 4736. I completed this project under the assistance of my research group at University of Oregon, which consisted of two fellow undergraduate physics majors, my advisor Dr. Scott Fisher, and Dr. Rachel Mason.

Dr. Rachel Mason, Assistant Astronomer at Gemini Observatory in Hilo, Hawaii recognized the importance of the discovery of the second unknown source by Maoz et al. (2005), and submitted a proposal for telescope time at Gemini-North to observe both the known black hole and the second source with the intention of collecting data that would shed light on the nature of the unknown source. Dr. Mason invited me to reduce and analyze the data for this project. 


\section{HYPOTHESIS}

NGC 4736 has been observed in the optical (Taniguchi et al., 1996), UV, and X-ray wavelengths of light (Cui et al., 1997, Roberts et al., 1999 \& Eracleous et al, 2002). The observations made in the optical were performed using a 2 " slit on a small telescope (Figure 1). Due to the lack of spatial resolution, it was impossible to differentiate the two separate sources in the nucleus. Therefore, the much more luminous source dominated the spectrum and the signatures of the unknown source were lost. Our observations from the 8-meter Gemini-North Telescope using a 0.75 " slit provides the resolution needed to spatially resolve the entire nucleus at the primary and secondary source.

There is strong evidence to support our hypothesis that the second source is in fact a lowluminosity AGN. NGC 4736 has already been classified as an AGN due to activity of the primary source in the nucleus. Thus, discovering the nature of the second source to be a black hole would be important as the galaxy would then be the third known BBH system.

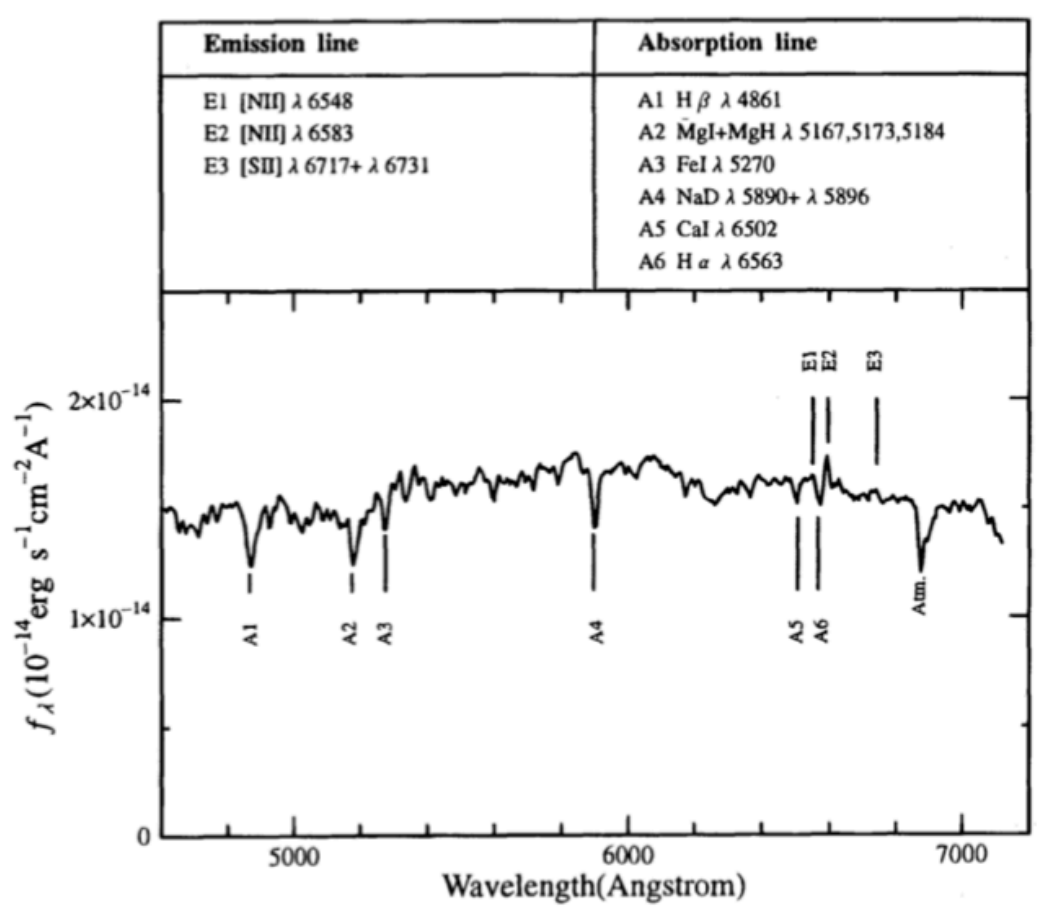

Figure 1: NGC 4736 spectrum from Taniguchi et al. (1996). Notable diagnostic lines are emission in $[\mathrm{NII}]$ and absorption in $[\mathrm{H} \beta]$ and $[\mathrm{H} \alpha]$.

Diagnostic diagrams, like the one created by Baldwin, Phillips \& Terlevich (Baldwin et al., 1981) referred to as the BPT-NII Diagram (Figure 2), help to distinguish the spectral differences between various types of objects including AGN and star forming regions. The Balmer series lines of hydrogen appear in the spectrum of many astronomical objects due to the abundance of hydrogen in space. It is known that $\mathrm{H} \alpha$ and $\mathrm{H} \beta$, two of the Balmer lines, are present throughout the spectrum of all AGN, from quiescent black holes to extremely active black holes. The primary difference in the spectra of AGN and non-AGN sources are the prevalence of high 
excitation emission lines from NII, SII, and OIII. Objects which have a low [NII]/[Ha] and $[\mathrm{OIII}] /[\mathrm{H} \beta]$ ratio are most likely star forming regions, also called HII regions. Objects with a higher $[\mathrm{NII}] /[\mathrm{H \alpha}]$ and $[\mathrm{OIII}] /[\mathrm{H} \beta]$ ratio are classified as AGNs, falling into the Seyfert or LINER categories. The transition line displayed on the BPT plot (Figure 2) separates the AGN objects on the right from the non-AGN objects on the left.

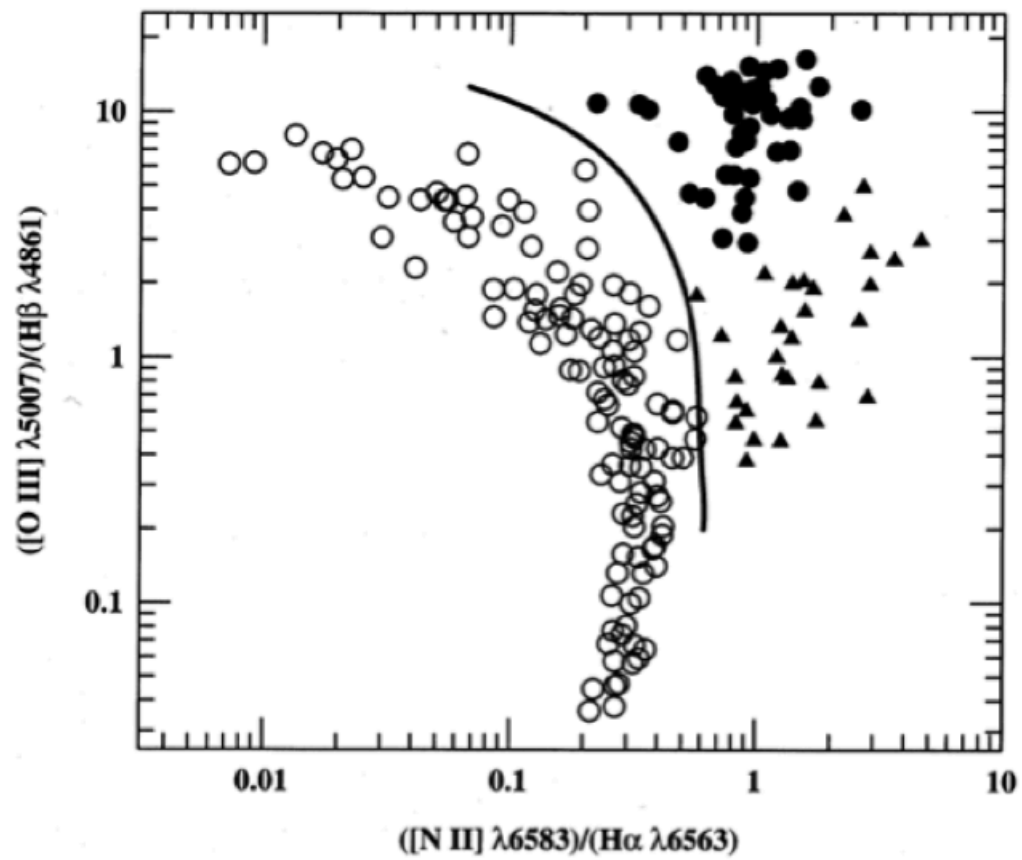

Figure 2: A BPT Diagram helps to distinguish between the different categories of objects that contribute to AGN activity. The open circles represent HII regions, the closed circles represent Seyferts, and the triangles represent LINERs. The axes of the plot, $[\mathrm{OIII}] /[\mathrm{H} \alpha]$ and $[\mathrm{NII}] /[\mathrm{H} \beta]$, contain typical emission line elements of these objects (Baldwin, Phillips, $\&$ Terlevich, 1981).

There are two types of Seyfert galaxies. The classification as a Seyfert 1 or Seyfert 2 depends on the orientation of the galaxy. A Seyfert 1 galaxy is oriented "face on". As such, an observer can view only the black hole jet coming straight out because the galaxy itself blocks the second jet. A Seyfert 2 galaxy is oriented "edge on" allowing the observer to see both the jet above and below the disk of the galaxy. NGC 4736 is a Seyfert 1. This is advantageous because it allows us to see directly down into the nucleus of the galaxy and spatially resolve the two nuclear sources. There are many emission lines we expect to see in a Seyfert 1 galaxy including [Ha], [NII], [SII], [HeI], and many others (Figure 3). 


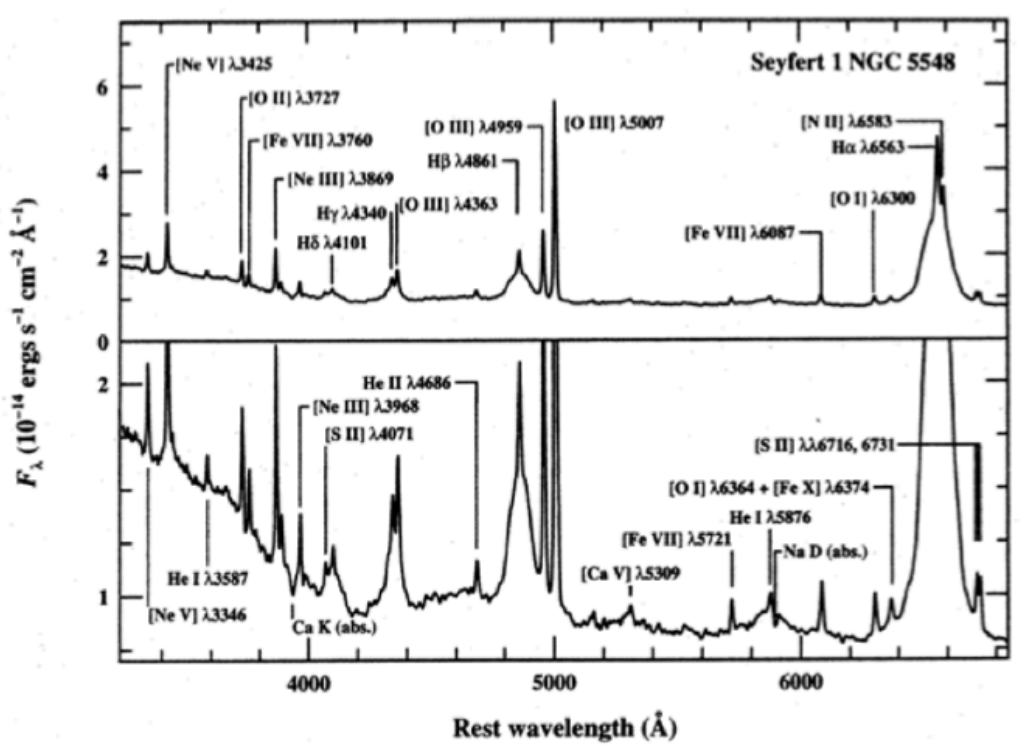

Figure 3: Expected spectra for a Seyfert I galaxy. A Seyfert 1 galaxy, oriented face on, has many characteristic emission lines including $[\mathrm{H} \alpha],[\mathrm{NII}],[\mathrm{SII}]$, and $[\mathrm{OIII}]$ (Peterson, 1997).

A further sub classification of Seyfert galaxies is a special class of object called a Low Ionization Nuclear Emission Region (LINER), a low energy AGN. The spectra of LINERs typically include emission lines from weakly ionized or neutral atoms, such as [O], [OI], [NI], and [SI]. Conversely, the spectral line emission from strongly ionized atoms, such as [OII], [NeII], and [HeI] are relatively weak. The primary source in the nucleus of NGC 4736 has been identified as having LINER behavior (example in Figure 4), but has also been included in catalogs of Transition objects (Constantin \& Seth, 2011).

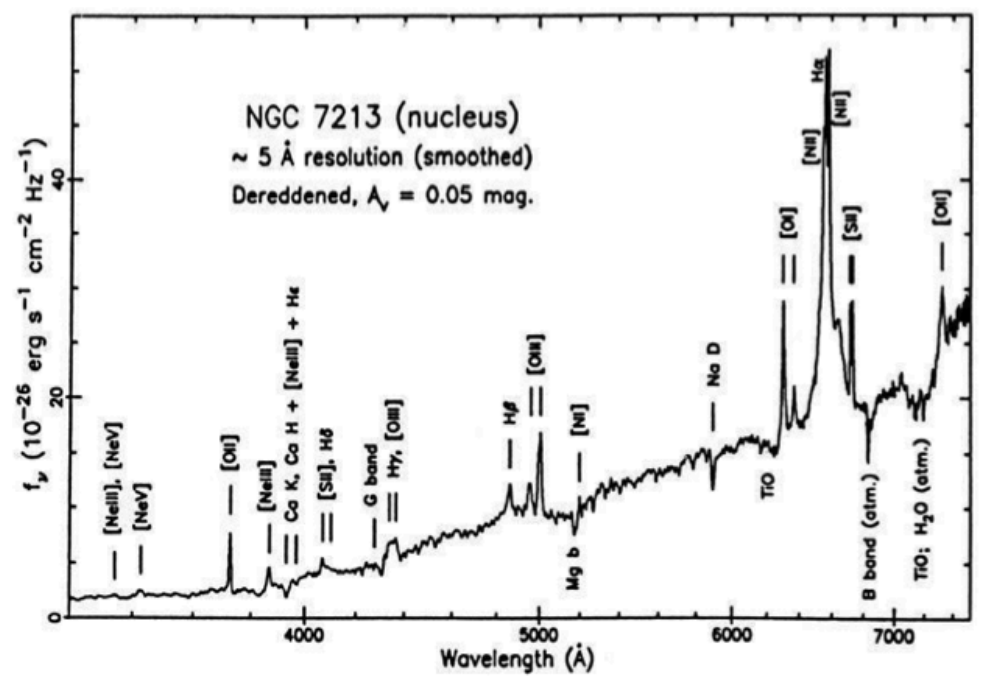

Figure 4: Expected spectra for a LINER galaxy. We expect much weaker emission lines from $[\mathrm{OII}]$, [NeII], and [HeI], and emission of weakly ionized atoms like [O], [OI], [HeI], and [SI] (Filippenko \& Halpern 1986). 
In contrast to the signatures of Seyfert and LINER AGN, young, hot stars mainly power the emission line activity of HII regions. Approximately 50\% of the strong line emitter objects fall into this category. Spectra of HII regions will have prominent strong emission lines for hydrogen and are typically associated with the presence of giant molecular clouds, like the Orion Nebula.

The most valuable research done on NGC 4736 thus far has been X-ray observations. Roberts et al. (1999) and Eracleous et al. (2002) showed evidence of a second source consistent with Seyfert spectra. Observations by Fernandes et al. (2004) ruled out evidence of luminous evolved stars. Together, these observations support AGN activity from a black hole and not an HII region. As a result, we can look at the optical spectra to definitively classify the second source as a black hole.

\section{METHODS}

Dr. Mason defined the technical methods required for obtaining the optical spectroscopic data of NGC 4736 (Appendix A.2). She proposed the use of the Gemini Multi-Object Spectrograph (GMOS) with long slit spectroscopy on the Gemini North telescope, located in Hilo, HI. The data was successfully taken in January of 2008 and the raw data was provided to my research group at University of Oregon in Spring 2013 to be reduced and analyzed (Table 1). Four data files of NGC 4736 were taken along with the necessary calibration files.

\section{Table 1: Summary of Observations}

\begin{tabular}{cccccc}
\hline \hline Type & Filter & Exposure (s) & Grating & Prefix & File \\
\hline NGC 4736 & open & $60.5 \mathrm{~s}$ & B600 & N20080109S & $0220-0222$ \\
NGC 4736 & open & $60.5 \mathrm{~s}$ & B600 & N20080109S & $0224-0225$ \\
NGC 4736 & open & $60.5 \mathrm{~s}$ & B600 & N20080109S & $0226-0227$ \\
\hline Flat & open & $4.0 \mathrm{~s}$ & B600 & N20080109S & 0223 \\
Flat & open & $4.0 \mathrm{~s}$ & B600 & N20080109S & 0228 \\
\hline ARC & open & $25.0 \mathrm{~s}$ & B600 & N20070627S & 0547 \\
ARC & open & $25.0 \mathrm{~s}$ & B600 & N20080109S & 0262 \\
\hline Bias & N/A & $0.0 \mathrm{~s}$ & N/A & N20080103S & 0175 \\
\hline Twilight Flat & N/A & $300.0 \mathrm{~s}$ & N/A & N20070627S & $0468-0469$ \\
Twilight Flat & N/A & $10.0 \mathrm{~s}$ & N/A & N20070627S & $0471-0472$ \\
\hline Std Star Aq. & N/A & $4.0 \mathrm{~s}$ & N/A & N20070627S & $0460-0462$ \\
Std Star Obs. & N/A & $120.0 \mathrm{~s}$ & N/A & N20070627S & 0463 \\
Std Star Flat & open & $4.0 \mathrm{~s}$ & B600 & N20070627S & 0464 \\
\hline
\end{tabular}

Table 1: Observation log for raw calibration and object data files. 


\subsection{DATA FILES}

The GMOS instrument was placed on the telescope in July of 2001. The spectrometer contains three separate charged coupled device (CCD) chips with a gap between each chip, 2.8 $\operatorname{arcsec}(39$ pixels) and an overscan region of 32 pixels (Figure 5). The data is also outputted with short wavelengths on the right and long wavelengths on the left.
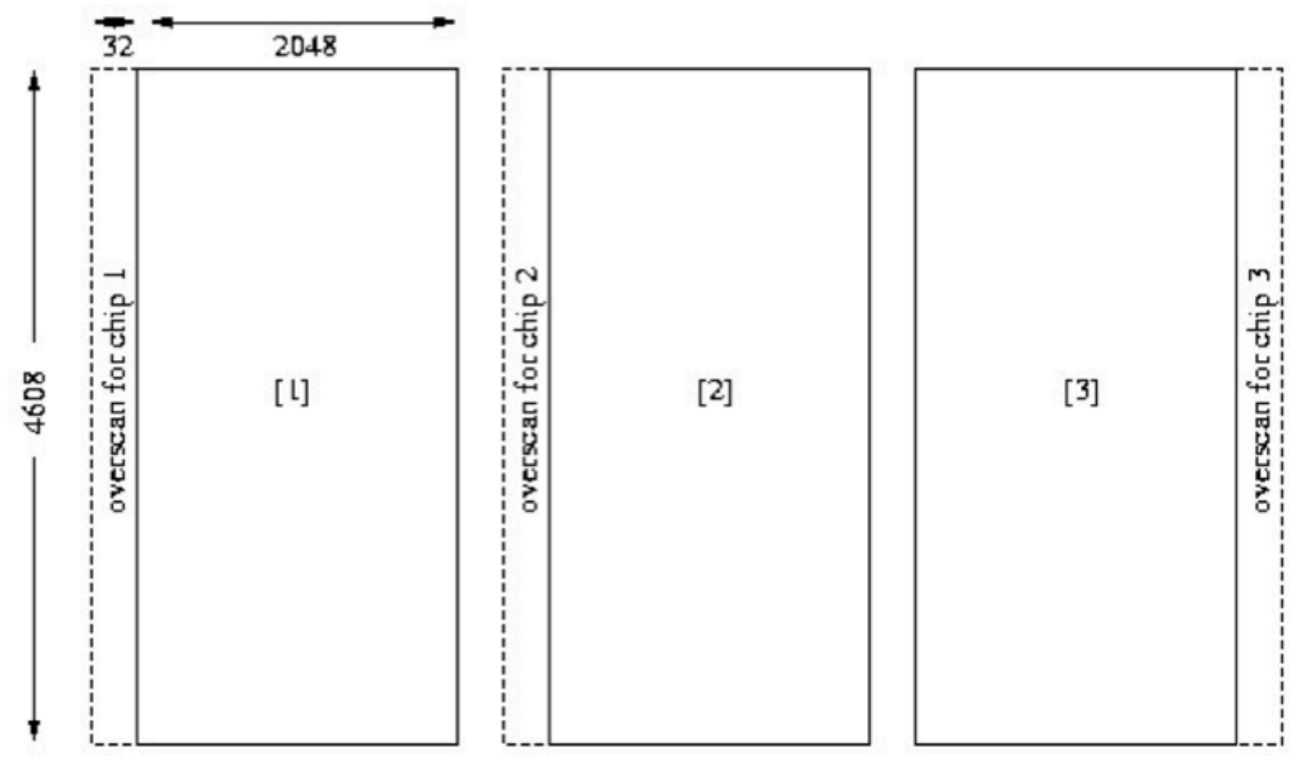

Figure 5: The GMOS instrument contains three separate CCD chips for detection, each of size $2048 \times 4608$ pixels with a 39 pixel gap in between each chip.

There are four main types of observations that are produced when using a CCD for optical spectroscopy: bias images, flat fields, object data, and an arc file. The bias images are used to calculate the zero noise level of the CCD. This is a pixel intensity offset that is inherent to the device, so once calculated, it gets subtracted off all images. A bias offset is used to avoid getting negative intensities in the CCD readout when taking data. There are two ways to evaluate the bias offset--bias images and the overscan region. Bias frames are zero second exposures taken with the shutter closed to have data of unexposed pixels on the readout. The overscan region is a set of rows and columns that are added to each data image. These are not physical rows or columns, but instead pseudo rows and pseudo columns created by scanning additional cycles to the readout. The bias frames are usually more useful than overscan regions because they represent a 2D bias image where you can subtract the bias pixel by pixel off each image, while the overscan is a $1 \mathrm{D}$ vector.

Flat fields are used in a correction process of the detector response. CCDs are not perfect imaging devices. Within the $\mathrm{CCD}$, each pixel responds differently to the light coming in, so it has a different quantum efficiency value when compared to its neighboring pixels. The purpose of a flat field image is to correct for this inconsistency. The goal is to observe a flat field that consists of uniform illumination of every pixel by a light source that has an identical response to that of 
the object data. By dividing by a normalized flat field, the pixel-to-pixel variations are removed. There are two types of flat fields - dome flats and twilight flats. Dome flats are taken using a uniformly illuminated screen on the inside wall of the dome while twilight flats are taken on a blank piece of sky. While flat fields are primarily used to correct for the pixel-to-pixel variations, they are also used to correct for dust donuts that appear on the image frames as a result of dust on the filters or other optical surfaces. Twilight flats were used for the data reduction in this research project.

The arc is the wavelength calibration file that allows for the calibration of the $\mathrm{x}$-axis scale on plots from pixels to wavelength. GMOS-N uses a standard CuAr lamp for wavelength calibration because the spectrum contains a large number of strong emission features between $4000 \AA$ and $7000 \AA$.

The object data for this project consists of four images taken with a 0.75 " long slit over both the primary and second source of the galaxy using the B600 grating which disperses the light at $0.045 \mathrm{~nm} /$ pixel. All of the data files were reduced such that all atmospheric and machine effects were removed. This reduction process produces the final, clean version of the data that we used in our interpretation.

\subsection{DATA REDUCTION}

The programming languages Interactive Data Language (IDL) and Image Reduction and Analysis Facility (IRAF) were used to reduce and analyze the GMOS data of NGC 4736. The method for reducing data in IDL is a much more interactive process, while IRAF has many procedures pre-written for convenience. Both software programs require the same reduction steps. The steps include bias subtraction, trimming, overscan correction, flat field correction, and wavelength calibration. These standard reduction steps were performed on all data files in both languages to verify that the data was correctly reduced. A detailed description of the reduction is outlined in Appendix $\mathrm{C}$.

Gemini Staff Scientist Dr. Kathleen Labrie performed the reduction process in parallel. Every step until the spectra extraction step was consistent between our output files and Dr. Labrie's output files. Our outputted spectra had a flux roughly three times greater than Dr. Labrie's outputted spectra (Figure 6). The mean of the ratio of our extraction to Dr. Labrie's was $2.93(\sigma=0.099)$. Since the absolute calibration of the data is not critical, we chose to proceed forward with Dr. Labrie's outputted data. In the end, this factor of three should not have a significant impact on the data results because we are looking at the relative strengths of the emission and absorption lines ratios and are not interested in the flux value. 


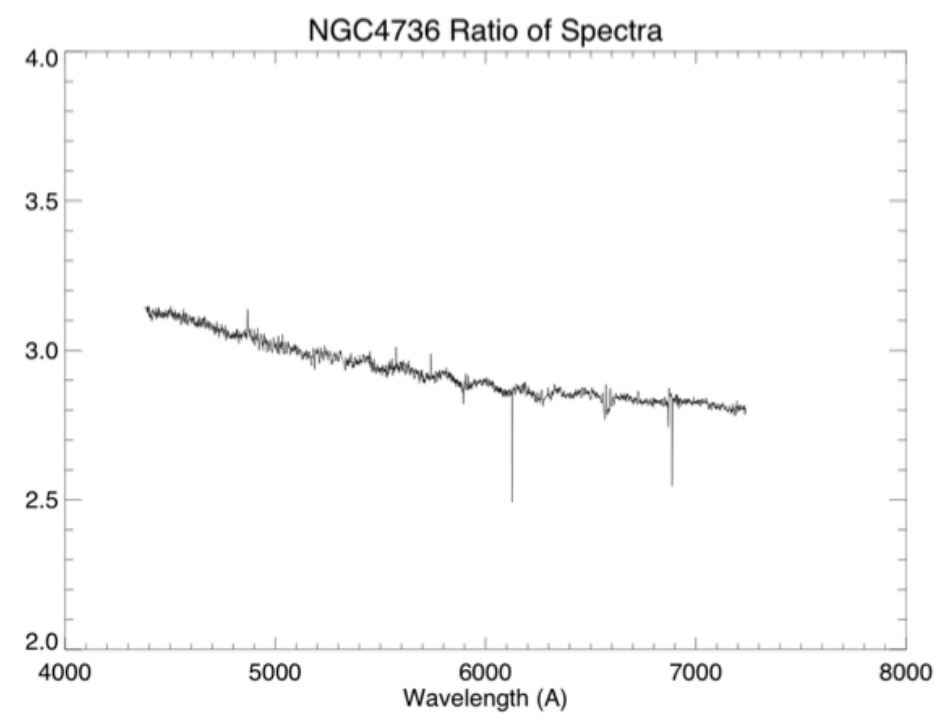

Figure 6: Ratio of Fishergroup extraction to Dr. Labrie's extraction of the nucleus of NGC 4736. ( $\mu=2.93$ and $\sigma=0.0992)$.

\subsection{DATA ANALYSIS}

\subsubsection{SPECTRA EXTRACTION}

The goal was to extract spectra over the known black hole referred to as the primary source, over the unknown source located at 2.5" north of the primary source, and over a baseline, or control, located 2.5" south of the primary source. By placing a range of spectra on the same plot, we plan to compare optical spectral features spatially across the nucleus to determine the nature of the second source. Based on our hypothesis that the second source is a second black hole, the most useful diagnostic emission and absorption lines with given wavelengths are likely to be

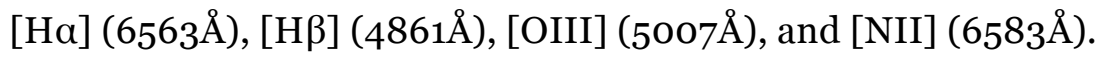

These diagnostic lines will determine the placement of the second source on the BPT diagram and help to definitively prove that NGC 4736 is in fact a BBH system in late stages of merging, allowing astrophysicists to begin validating theoretical predictions about both mergers and AGN.

We performed the spectra extraction in IDL. We extracted spatially across the nucleus of NGC 4736 using an aperture of 1 " from 5 " North of the nucleus to 5 " South of the nucleus about every 1 ". The Gemini data has a spatial resolution in y of 0.1454 "/pixel. We chose to use a 1 " aperture to match the seeing conditions at the time of the data collection. For a 1 " aperture, we used 7 pixels in $y$. Table 2 shows the specific extraction rows for our individual spectra from the image. 
Table 2: NGC 4736 Spectra Extraction

\begin{tabular}{cc}
\hline \hline Location & [Start Pixel:End Pixel] \\
\hline $5^{\prime \prime}$ North & $1380: 1386$ \\
$3.75^{\prime \prime}$ North & $1388: 1394$ \\
$2.5^{\prime \prime}$ North & $1397: 1403$ \\
$1.25^{\prime \prime}$ North & $1405: 1411$ \\
\hline Nucleus & $1414: 1420$ \\
\hline $1.25^{\prime \prime}$ South & $1423: 1429$ \\
$2.5^{\prime \prime}$ South & $1431: 1437$ \\
$3.75^{\prime \prime}$ South & $1440: 1446$ \\
$5^{\prime \prime}$ South & $1448: 1454$ \\
\hline
\end{tabular}

Table 2: 1" (7 pixel) extractions were taken across the nucleus of NGC 4736 in order to compare composition of the unknown source with the stellar population of the galaxy.

\subsubsection{LINE STRENGTHS}

Once we had our nine extractions across the nucleus, we began to classify the second source. To do this, we calculated line strengths for the diagnostic emission and absorption lines to search for changes between the primary and secondary source. We were interested in the diagnostic lines of the BPT-NII diagram- [NII], [Ha], [OIII], \& [Hß]. It is common that a continuum will be fit to the data in order to offset the shape of the spectra. Instead, we made the assumption, following advice from Gemini Staff Scientist Dr. Inger Jorgenson, that each deviation from the mean in the spectra was an emission or absorption line and that there is in fact no continuum for data of this quality. As a result, we did not fit a stellar population model to the entire spectra and instead isolated local continuum regions near the lines of interest to use as our baselines. We fit the baseline, or local value, to the line by averaging the continuum immediately to the right and left of the spectral feature. We subtracted this baseline and integrated under the curve using the Riemann Sum method with bin width of 1 pixel to calculate the strength of the line. If the line of interest was an absorption line, we took the absolute value before integrating so that all line strength values were positive.

\section{RESULTS}

1. The extraction of the nucleus of NGC 4736 (Figure 7) is consistent with what was seen in Taniguchi et al., 1996 (Figure 1). We see emission lines for [NII] and both [SII] lines. We also see emission within a larger absorption for $[\mathrm{H \alpha}]$ and absorption lines for $[\mathrm{H} \beta]$, [HeII], and [OI]. Along with [OIII] and [HeI] which are too weak to see clearly in the plot, these are the key diagnostic lines for identifying AGN. 
2. There is visual evidence to support that the emission and absorption lines are changing spatially across the nucleus of NGC 4736 from 5 " North to 5 " South (Figure 8). We plotted the region around $[\mathrm{Ha}]$ at the unknown source (2.5” North), the primary source, and at the control location (2.5" South) (Figure 9). The plots show clear evidence that $[\mathrm{Ha}]$ is in fact changing across the nucleus, suggesting that something is present in the North at the location of the unknown source that is not in the South.

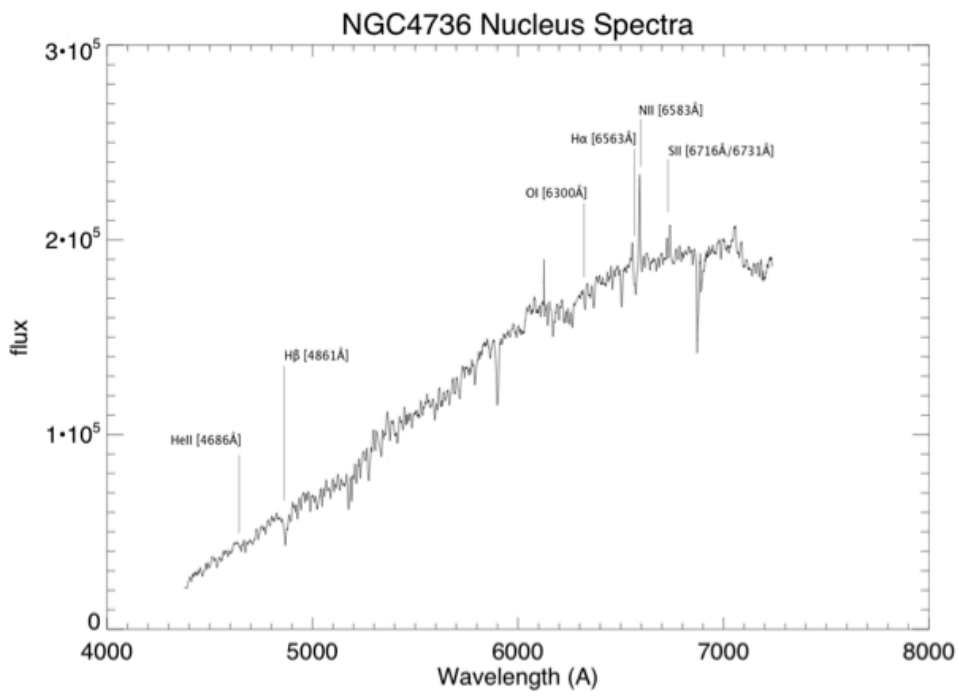

Figure 7: NGC 4736 spectrum of the primary source using a $1^{\prime \prime}$ aperture. The emission and absorption lines are consistent with what was seen in Taniguchi et al., 1996 using a much smaller telescope.

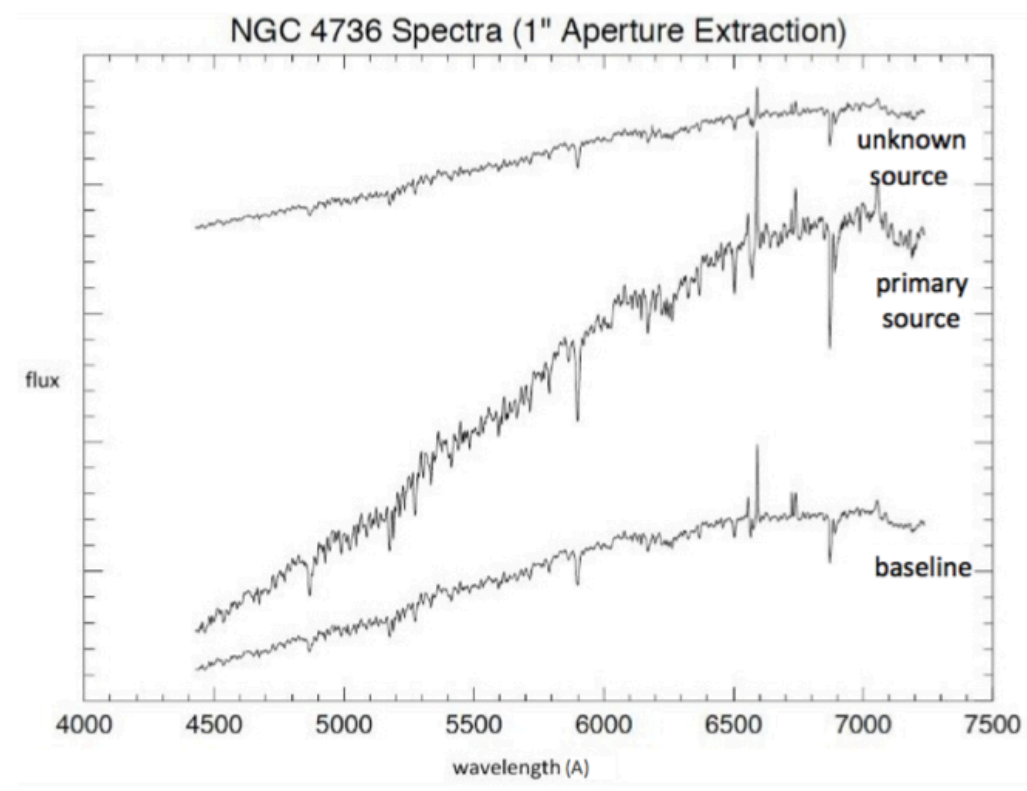

Figure 8: NGC 4736 spectra north $2.5^{\prime \prime}$ and south $2.5^{\prime \prime}$ of the primary source. These are the three key spectra that we will use to determine the nature of the unknown source. 


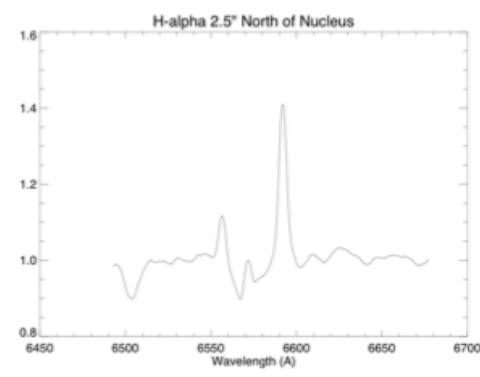

(a)

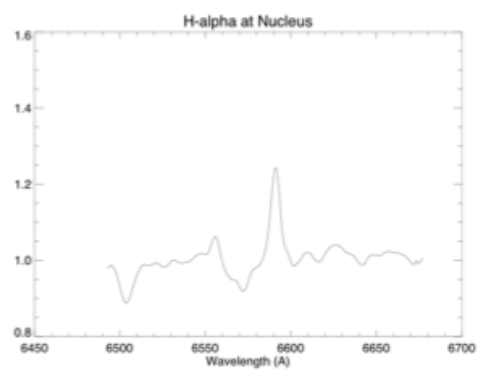

(b)

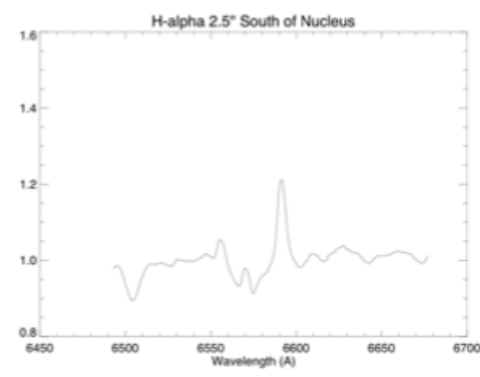

(c)

Figure 9: $[\mathrm{H} \alpha](6563 \AA)$ emission within absorption as it changes across the nucleus of NGC 4736.

3. A different spectral shape is observed at the long wavelength end of the spectrum, which implies that the unknown source is bluer, and therefore presumably hotter, than the background, or local environment (Figure 10).

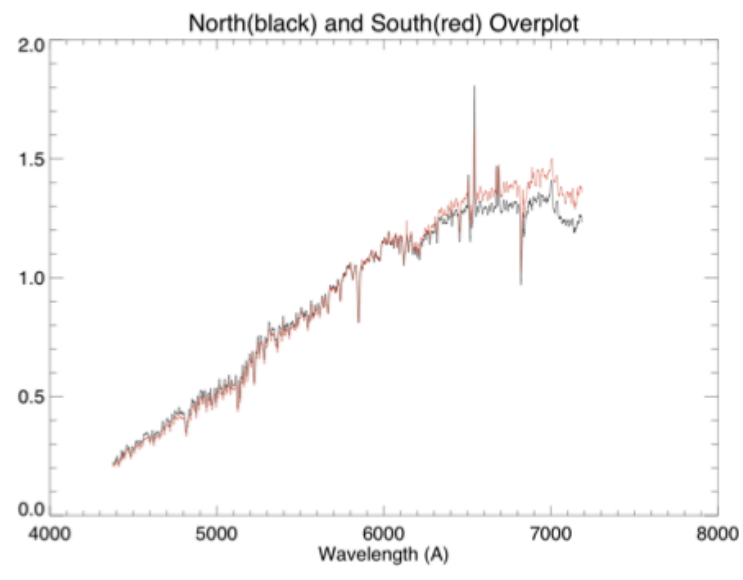

(a)

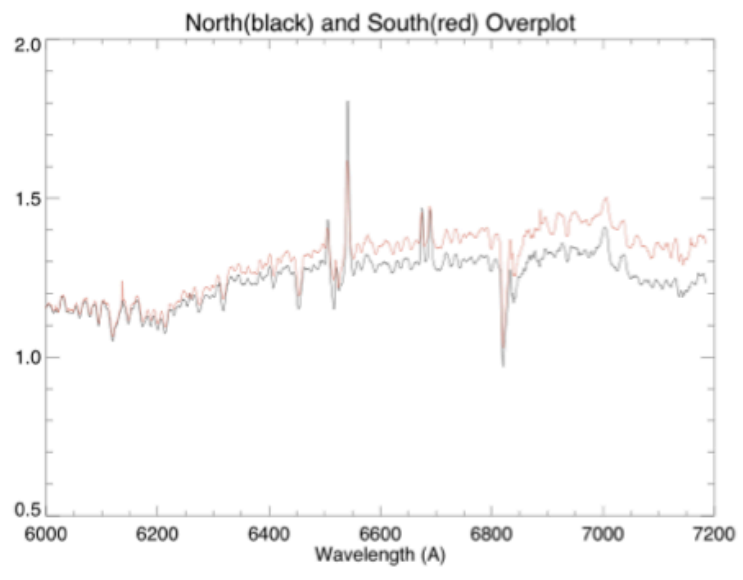

(b)

Figure 10: NGC 4736 overplot of 2.5" South and 2.5" North. The unknown source, plotted in black, is bluer than the local environment, or baseline, plotted in red.

4. If we look at the unknown source, primary, and baseline, we can remove the effects of the local environment by subtracting the baseline. This process removes all gas and dust that is between the observer and the sources. The resulting spectra are representative of characteristics of just the sources (Figure 11).

5. High excitation lines are stronger at the unknown source compared to the baseline at 2.5 " south of the primary source. Figure $11 \mathrm{~b}$ reveals the excess emission in the north in comparison to the baseline, or local environment of the galaxy nucleus. 


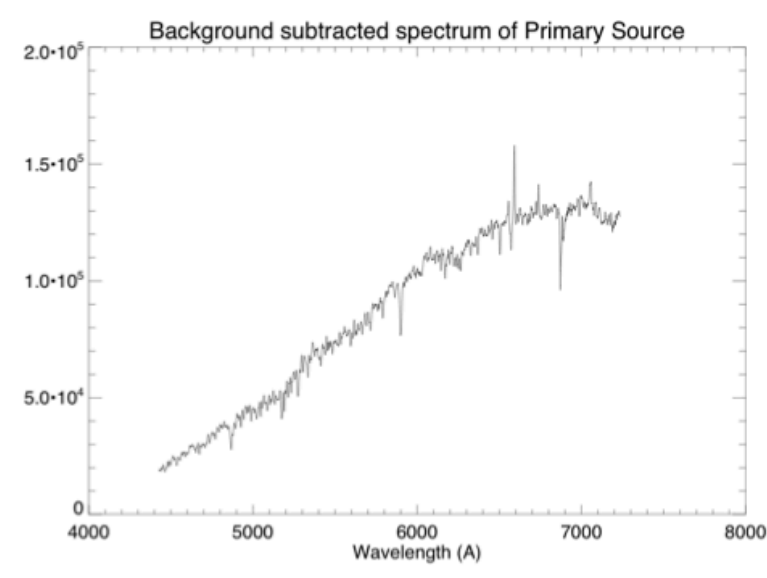

(a)

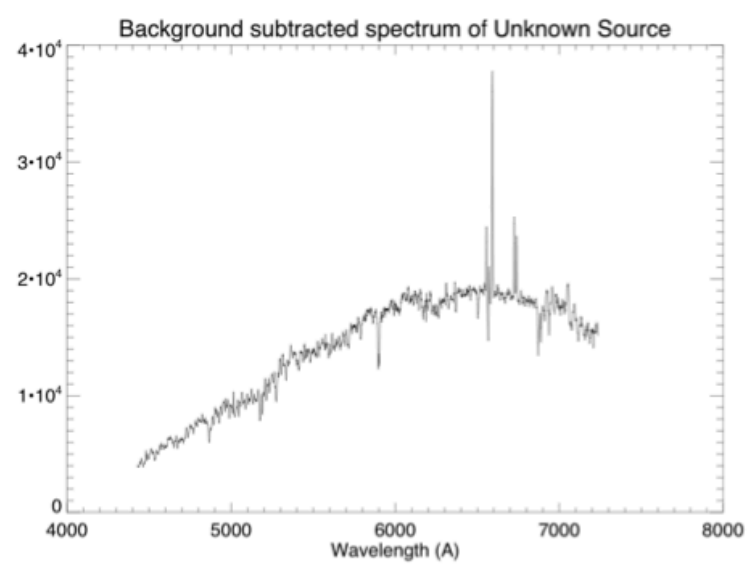

(b)

Figure 11: Spectra of the baseline-subtracted unknown source (left) and primary source (right). With the removed baseline, weaker lines like [OIII] are more prevalent.

6. Line strengths were calculated for the AGN diagnostic lines of the BPT-NII diagram to categorize the unknown source. Table 3 shows the best estimated line ratios of $[\mathrm{NII}] /[\mathrm{H \alpha}]$ and $[\mathrm{OIII}] /[\mathrm{H} \beta]$. We see very weak [OIII] emission in both the primary source and the unknown source (Figure 12).

Table 3: NGC 4736 ratio of $[\mathrm{NII}] /[\mathrm{H} \alpha]$ using the background subtracted spectra.

\begin{tabular}{ccccccc}
\hline \hline Location & {$[\mathrm{NII}]$} & {$[\mathrm{H} \alpha]$} & {$[\mathrm{OIII}]$} & {$[\mathrm{H} \beta]$} & $\log ([\mathrm{NII}] /[\mathrm{H} \alpha])$ & $\log ([\mathrm{OIII}] /[\mathrm{H} \beta])$ \\
\hline Unknown Source & 112000 & 4810 & 6040 & 28400 & 1.37 & -0.6 \\
Primary Source & 256000 & 9140 & 8160 & 155000 & 1.45 & -1.3 \\
\hline
\end{tabular}

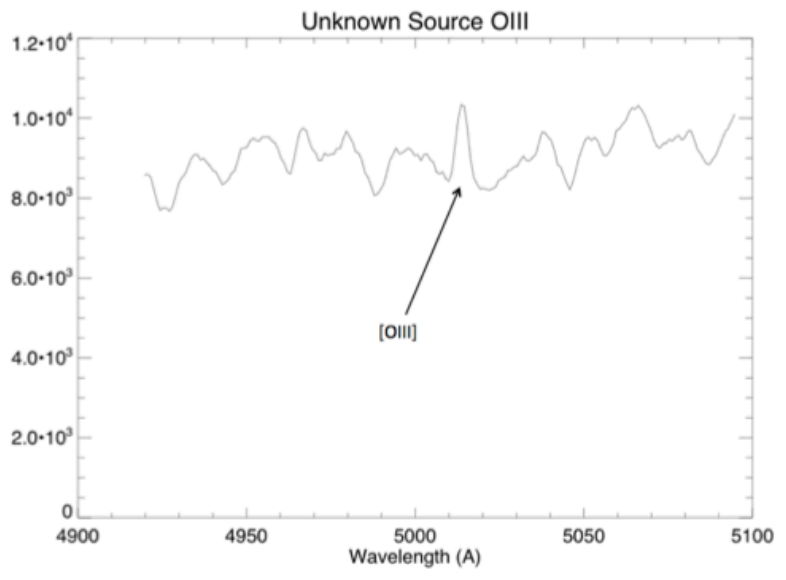

(a)

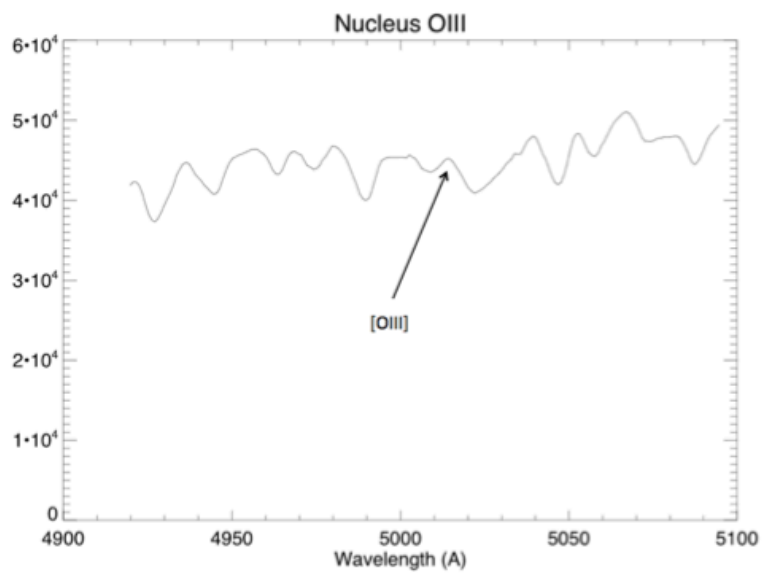

(b)

Figure 12: [OIII] (5007 $\AA$ ) zoomed in for the background-subtracted unknown source (left) and primary source (right). The spectra reveal very week [OIII] emission. 
To provide more evidence that the calculated ratios of $[\mathrm{NII}] /[\mathrm{H \alpha}]$ and $[\mathrm{OIII}] /[\mathrm{H} \beta]$ are in fact correct, we shifted our range for the line integral one pixel (0.1454") in each direction. We saw a vast increase in the value of the $[\mathrm{OIII}] /[\mathrm{H} \beta]$ ratio, and this was our largest source of uncertainty. In this system, [OIII] is such a weak line in comparison to [H $\beta$, our calculated line strength was very dependent on the line width and placement of the baseline. With a one-pixel shift, we calculated an upper limit of 0.6 for the ratio of $[\mathrm{OIII}] /[\mathrm{H} \beta]$. As a result, we placed the primary and secondary sources on the BPT-NII diagram (Figure 13).

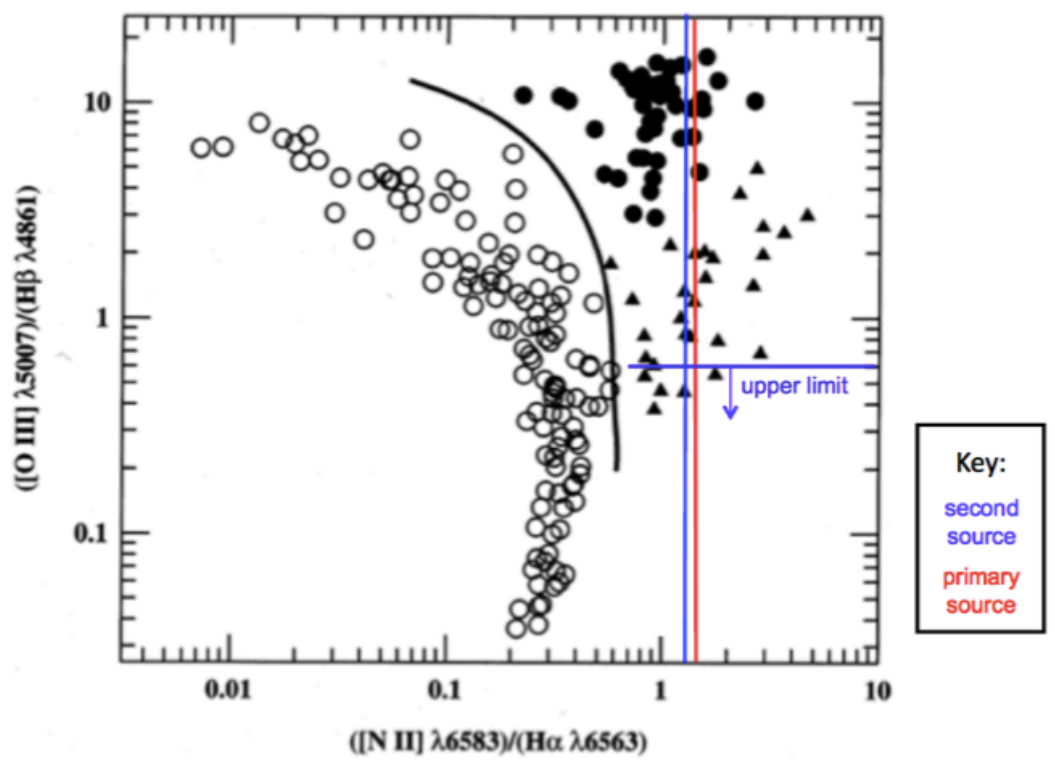

Figure 13: BPT-NII diagram with both nuclear sources plotted using diagnostic line ratios where the local environment has been removed. Only an upper bound can be placed on the $[\mathrm{OIII}] /[\mathrm{H} \alpha]$ due to the weak emission of $[\mathrm{OIII}]$.

\section{CONCLUSIONS}

The second unknown source in the nucleus of NGC 4736 has been observed in multiple wavelengths, and yet, no conclusions have been drawn on its nature. The unknown source is luminous as it emits in the x-ray and visible light, exciting the material around it. This leads us to question whether the second source is luminous enough to be a low luminosity black hole.

Given that the primary source is in fact a LINER, we are led to conclude that the unknown second source must be also be a LINER as it falls very near the primary source on the BPT diagram. We are confident in our calculation of the $[\mathrm{NII}] /[\mathrm{H \alpha}]$ ratio, or the vertical placement, but can only place a vertical upper limit on our calculation of [OIII]/[H $\beta]$ due to the uncertainty in the line strength value of [OIII]. The upper limit falls in the realm of the LINERs, supporting our conclusion.

In the future we plan to reduce and analyze existing infrared data to back up our initial conclusion. If the infrared data confirms our conclusion, we will be able to confidently say that our second source is in fact the third, and closest, dual AGN system to Earth. With the system in 
late stages of merging, astronomers will be able to study the system in great detail to refine merging models and test theories that rely on the existence of these systems.

\section{APPENDIX}

\section{A. RACHEL MASON, OFFICIAL PROPOSAL}

\section{Science Justification:}

Binary black holes (BBH) are expected on theoretical grounds to be common in galaxy nuclei, and are invoked to explain a range of phenomena. If two merging galaxies harbour supermassive black holes, then the black holes will themselves form a binary system during the course of the merger and eventually coalesce, although the timescales for and mechanisms in operation during this process are the subject of some debate. The resulting BBH have been suggested to be triggers of star formation (Taniguchi \& Wada 1996), to initiate the formation of dusty AGN tori (Zier \& Biermann 2001,2002), and may explain observations as diverse as helically-distorted radio jets (e.g. Tateyama et al. 1998) and quasi-periodic variations in the light curves of some BL Lac objects (e.g. Pursimo et al. 2000). Despite the theoretical predictions and their potential importance to astrophysics, though, evidence for the existence of BBH remains fairly sparse.

Several examples exist of images of quasars with another quasar nearby and at the same redshift. Although most of these are the result of gravitational lensing, a handful - based on spectral differences between the two components - seem to be genuinely physically associated quasar pairs, with the smallest separation being $2.5 \mathrm{kpc}$. At closer separations, nearby galaxies in the late stages of a merger are the obvious systems in which to search for BBH, and many of these do in fact have double optical or IR nuclei. However, it is only in rare cases that both nuclei exhibit AGN activity, that is, definitely harbour supermassive black holes. The first to be discovered was NGC 6240, in which Chandra imaging revealed two flat-spectrum, heavily absorbed X-ray sources at a projected separation of 1.5” (1.4 kpc; Komossa et al., 2003). The second, and so far final, candidate is Arp 299 (Ballo et al. 2004).

The recent discovery by Maoz et al. (2005) of variability in a pair of UV sources in the nucleus of the nearby LINER, NGC 4736, may have changed this. Morphological peculiarities in this galaxy led Maoz et al. $(1995,1996)$ to speculate that it is in the final stages of a merger, and the significant variability of the nuclear sources, which are of comparable brightness, is likely to indicate a significant nonstellar contribution to the UV fluxes of both. At a separation of only 60 pc (2.5" at $5 \mathrm{Mpc}$ ), this system would, if confirmed as a $\mathrm{BBH}$, represent a much more advanced stage of merging than the previous examples and be a significant step in validating models of galaxy mergers as well as providing a prime opportunity to study a nearby system in detail. The process(es) giving rise to the off-nuclear UV emission ("NGC 4736b"), however, are not at all well constrained.

To clarify the nature of the nuclear UV sources in NGC 4736, we propose GMOS-N long-slit spectroscopy of this enigmatic LINER. The variability of the sources rules out a stellar cluster as 
the sole source of their UV emission, but it is possible that a single W-R or LBV star could dominate their light output. The "nuclear" UV source (spatially coincident with the radio, optical and IR core) contains a variable hard X-ray point source with a spectral slope typical of those observed in Seyfert nuclei (Roberts et al. 1999, Eracleous et al. 2002), and does not show the spectral features characteristic of luminous, evolved stars (Cid Fernandes et al. 2004), strongly suggesting an AGN origin for the bulk of its flux. Whether an evolved high-mass star could account for NGC 4736b is easily testable from an optical spectrum, for example by searching for strong HeII 4686 line emission.

As the nuclear point source has properties consistent with its hosting an AGN, jet activity, (synchrotron radiation or gas heated by beamed radiation from the nucleus) could account for the UV emission from NGC 4736b, whose spectral properties are completely unknown. The nondetection of radio emission from NGC 4736b (Kording et al. 2005) suggests that the synchrotron explanation is unlikely, but we can test whether it is simply shocked gas by examining the continuum along the slit: enhanced line emission (possibly including high-excitation species) would be expected from shocked gas.

Finally, NGC 4736b could itself be a low-luminosity AGN. Following Ho et al. (1997), optical line ratios will be used to classify that source as a Seyfert, LINER, HII region, or transition object. This classification scheme does not necessarily unambiguously identify AGN but if the alternative explanations can be discounted, detection of a LINER-like spectrum combined with UV variability would itself be very suggestive that this galaxy does indeed harbour the closest known interacting supermassive black holes. NGC 4736 is a bright, nearby object and useful data can be obtained in a short amount of time under poor weather conditions; this programme represents a very modest investment of telescope time for a potentially very exciting result.

\section{Technical Information:}

Optical spectra of NGC 4736 have been taken by Ho et al. 1995 using a 2" slit orientated such that NGC 4736b was not in the slit. Extracted across 4", the flux density in their spectrum was around $25-30 \times 10^{-15} \mathrm{erg} / \mathrm{sec} / \mathrm{cm}^{2 / A}$ from $4200 \AA-6800 \AA$. Under the probably conservative assumption of spatially uniform brightness, this gives a surface brightness of about $3 \times 10^{-15}$ $\mathrm{erg} / \mathrm{sec} / \mathrm{cm}^{2 / \mathrm{A}}$.

The flux of NGC 4736b is not known at optical wavelengths, but it has been up to $30 \%$ brighter and $70 \%$ fainter than the nucleus at UV (2500 $\AA$ and $3300 \AA)$ wavelengths and has a bluer colour (Maoz et al. 1995; 2005). We adopt a V-band surface brightness of $1{\mathrm{X} 10^{-15}}^{-15}$ $\mathrm{erg} / \mathrm{sec} / \mathrm{cm}^{2 / \mathrm{A}}$ per sq. arcsec on which to base our integration time estimates. As the contribution of the point source over the diffuse stellar emission and the strength of any lines from that source are unknown, our strategy will be to maximise the $\mathrm{S} / \mathrm{N}$ on the continuum for the best chance of detecting weak emission lines. To minimise dilution of the point source spectrum by stellar emission, we will use the 0.75 " slit combined with 70\%-ile image quality.

The most useful diagnostic emission lines are likely to be $\mathrm{H} \alpha(6563 \mathrm{~A}), \mathrm{H} \beta$ (4861 A), [O III] (5007 A), [O I] (6300 A), [N II] (6583 A), [S II] (6716 A), (6731 A), [HeII] (4686 A) and [He I] $(5876 \mathrm{~A})$. We therefore use the B600 grating (no filter) with central wavelength $\sim 580 \mathrm{~nm}$ for $\mathrm{R} \sim 800$, and 2x2 CCD binning. We use conditions of 70\%-ile IQ, 90\%-ile CC, SB=any, WV=any, 2 airmasses. This setup gives a S/N of approximately 50-90 in 0.75 " along the slit over the 
wavelength range of interest in $8 \times 30$ min exposures. This should be enough to give us a sporting chance of detecting emission lines from NGC $4736 \mathrm{~b}$.

The baseline calibrations will be sufficient, so allowing for acquisition, we request 5 hours for this project. Please note that the time calculation is for bright time; in grey or dark time we could complete the project in about 1.5 hours.

\section{B. SPECTROSCOPY}

In order to analyze what exactly is happening in these systems, we want to resolve and interpret the optical spectra of the nucleus of the galaxy. A spectrum is a collection of light from a single star, a whole galaxy, or any other astronomical object, which helps in determining physical properties. In practice, an instrument called a spectrometer is used to collect the light and digitize it onto a computer.

For my research, collecting a spectrum from NGC 4736 involves the use of an astronomical spectrometer, also known as a spectrograph. The basic function of a spectrometer (Figure 14) is to take in light and disperse it into its spectral components, digitize the signal as a function of pixels, and read it out through a computer. The first step in this process is to direct light through the telescope into the spectrometer through a narrow aperture known as an entrance slit. The divergent light is then collimated by a concave mirror and directed onto a grating. The grating disperses the spectral components of the light, which are then focused by a second concave mirror and directed onto the detector. Once the light is imaged onto the detector the data is digitized and read out to a computer. The pixel scale is later calibrated to wavelength, so the resulting output data is in the form of wavelength versus intensity. 


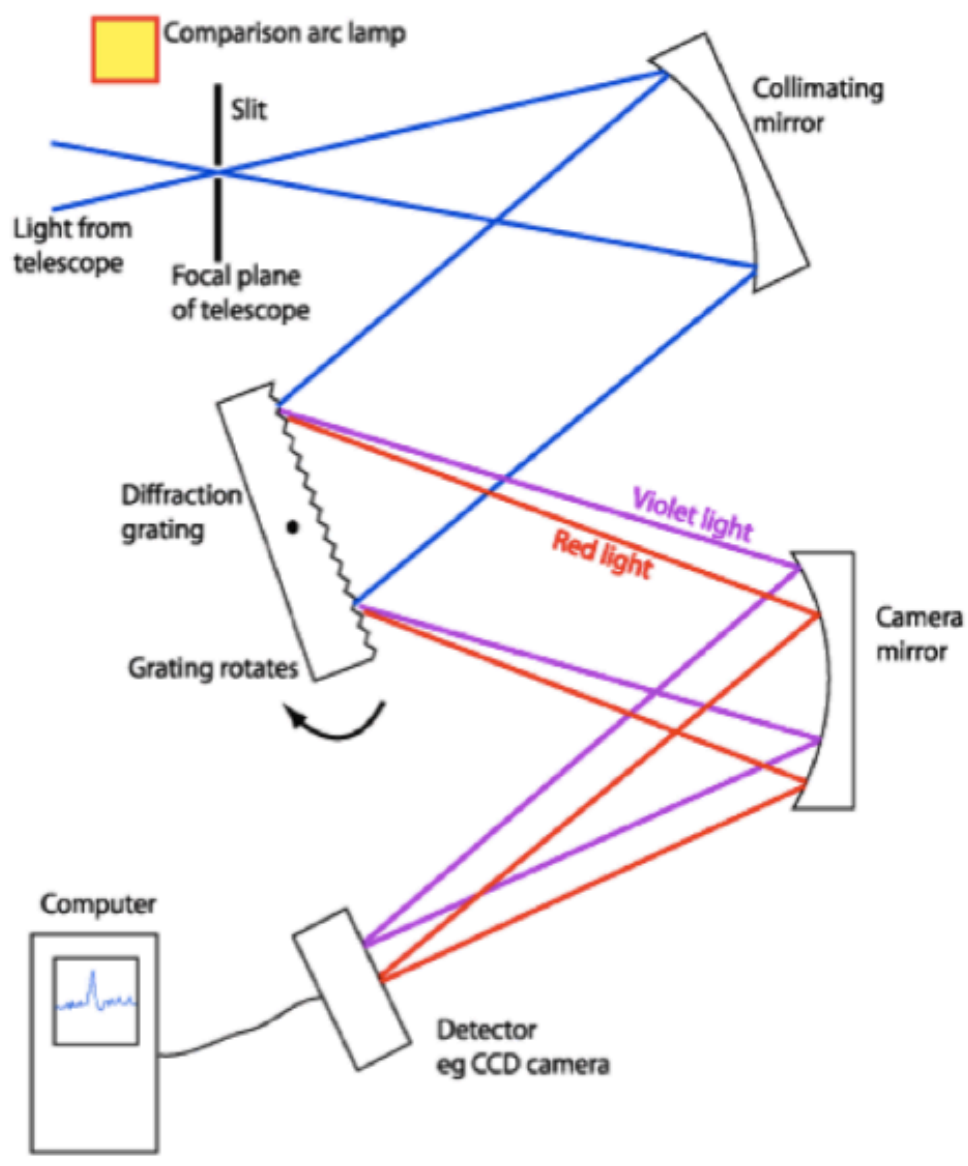

A Schematic Diagram of a Slit Spectrograph

Figure 14: The slit spectrograph diagrams the path the light takes through the telescope and onto the CCD detector where it is then read by the computer.

Because we analyze data from the spectrometer in the form of wavelength, it is important that we understand some properties of light to be able to read the accompanying spectra. In 1864 Scottish theoretical physicist James Maxwell described the precise relationship between electric fields and magnetic fields, thus showing that light was made of electromagnetic waves. For example, if a pebble is dropped over a body of water, then it creates waves, which move radially outward from where the pebble was dropped. These water waves contain both peaks and troughs with a given distance between each (Figure 15). For a steady wave, this quantity is consistent and we call it the wavelength of the wave, denoted by the Greek letter lambda $(\lambda)$. 


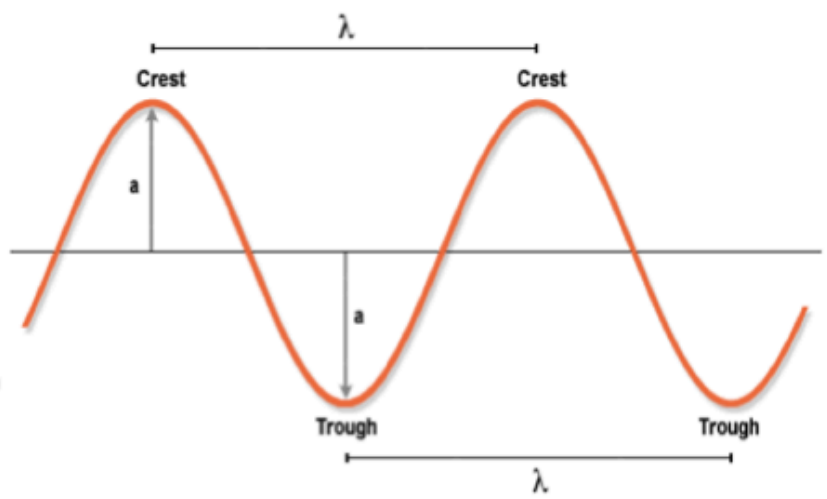

Figure 15: The wave properties of light give a distance between toughs or crests, defined as lambda $(\lambda)$, which defines where the light is on the electromagnetic spectrum.

All light has a wavelength, and that wavelength characterizes where it lies on the electromagnetic spectrum. Typically, when we think of light, we think of what we see, visible light. However, this is only a small portion of all of light, or what scientists call the electromagnetic spectrum (Figure 16). The electromagnetic spectrum ranges from gamma rays, which have the shortest wavelength all the way up to radio waves, which have the longest wavelength. Visible light, also known as optical light, falls on the spectrum between ultraviolet (UV) and infrared (IR). Looking at astronomical objects with different types of electromagnetic radiation is extremely important because it enhances or decreases what can be seen. For example, there is a lot of dust in space, which creates a barrier, limiting the distance to which objects can be viewed in the optical. However, IR radiation can more easily travel through dusty regions of space and therefore we can observe objects in highly obscured region. As a result, different types of electromagnetic radiation give us different windows to view the universe.

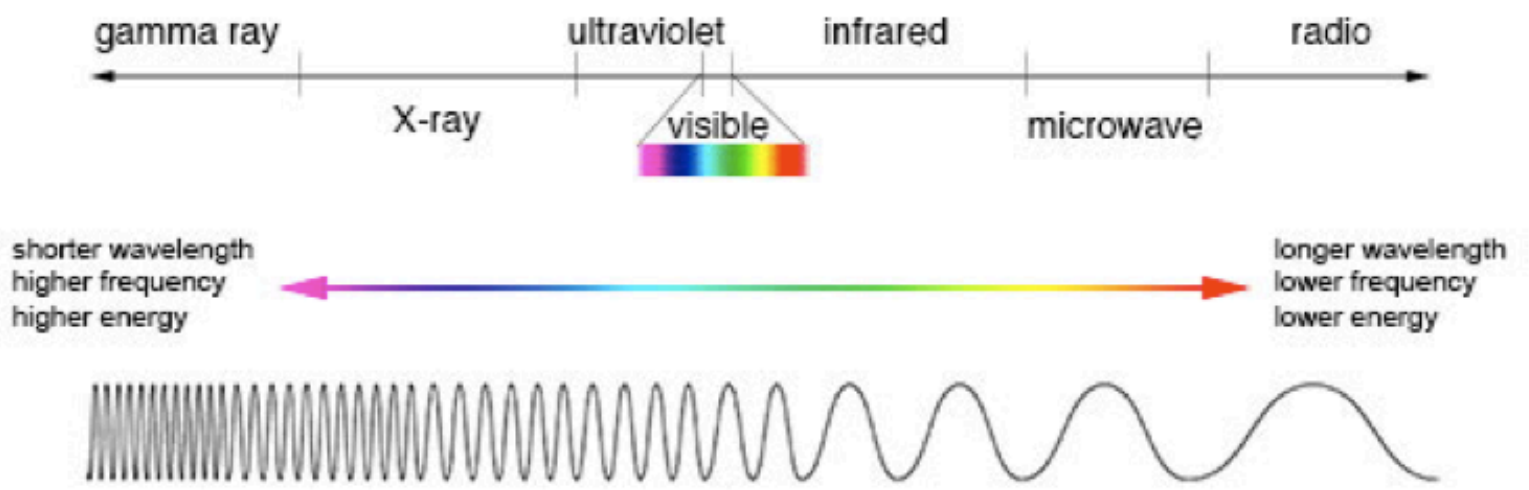

Figure 16: The Electromagnetic Spectrum displays the range of all light in the universe from high energy, short waves to lower energy, longer waves. The visible light is only a small portion of the entire Electromagnetic Spectrum. 
For my project, NGC 4736 was observed in the X-Ray when the two sources were first discovered. While the second source was not seen in UV, we were still able to learn about its properties. My goal now is to analyze the second source in the optical wavelengths to continue narrowing down its properties, some of which will hopefully be easily detectable in the optical.

I expect to see two types of spectra in my data-absorption and emission spectra. I do not expect to see any continuum in the spectra data because the resolution of the spectrometer is high enough that every line in the data is absorption or emission. An emission spectrum involves bright lines associated with increased intensity while an absorption spectrum involves lack of intensity, or very negative peaks in the spectra. The emission lines correspond to photons of discrete energies that are emitted when excited atomic states in the gas make transitions back to lower-lying levels while absorption lines are caused by atoms in the gas that are absorbed at characteristic frequencies. These spectral lines are critical in analyzing the properties of the astronomical object because they allow us to determine the characteristics of the object we are interested in. The wavelengths at which we observe emission and absorption lines correlate with a specific element or compound that is being radiated by a luminous object. An example of a spectrum plot is shown below in Figure 17. The peaks of the plot are the emission lines, while the dips are the absorption lines.

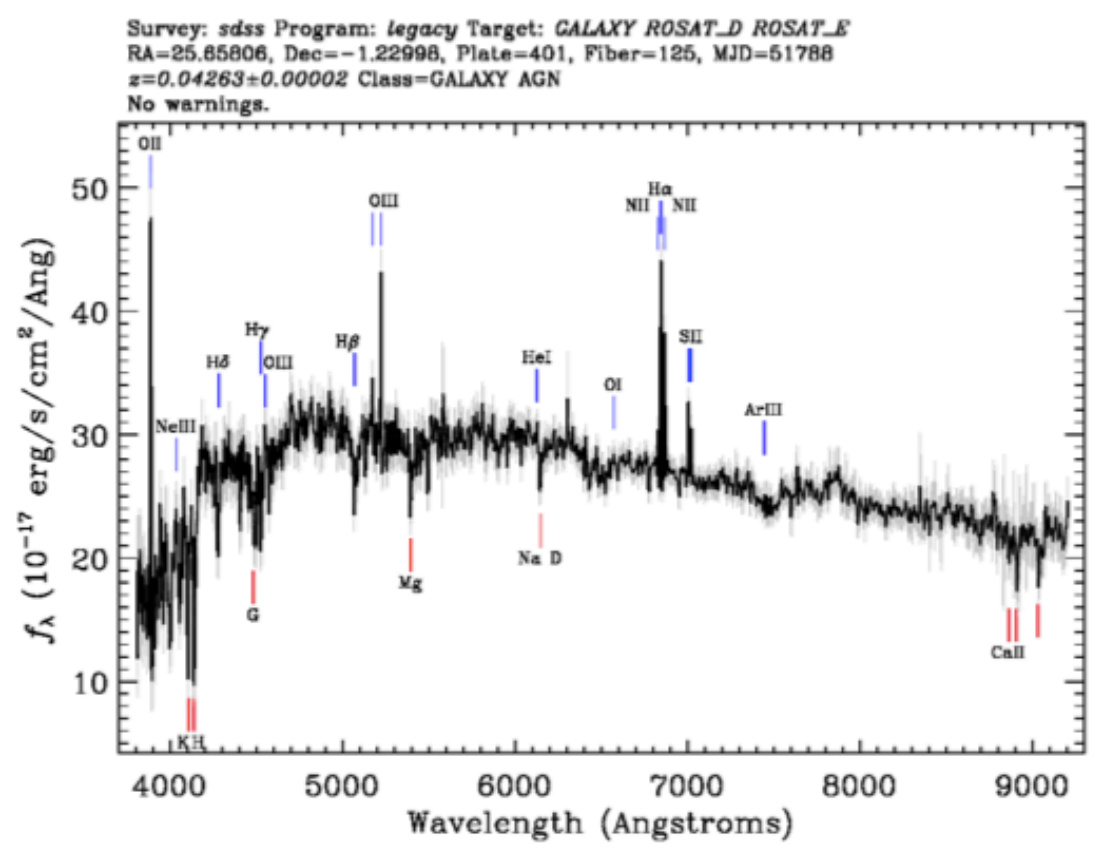

Figure 17: Example spectra containing absorption lines (red) and emission lines (blue).

\section{DATA REDUCTION}

The first step to the data reduction process was to inspect all images to pull out the saturated or irregular files. The data files were also placed into groups based on their file type so that all operations could be performed simultaneously on the data type. 


\section{1 CREATE MASTER BIAS}

As part of the data package, we received an already compiled master bias file. The preprocessed master bias file was created from many biases that are not overscan corrected but are trimmed, and finally averaged together.

GBIAS created a combined GMOS bias image from raw bias images. The raw bias images from GMOS had exposure time 1 sec. These images are taken with the GMOS shutter closed. The input images can be raw or prepared with GPREPARE. If they are raw, GBIAS will call GPREPARE first. The images were trimmed and the overscan level was not subtracted off the input images. The bias images were then combined with the task GEMCOMBINE. Lastly, they were averaged using the median combined option.

\section{C.2 NORMALIZE THE FLAT FIELD}

A similar process was done to create the normalized flat field. The flats were not overscan corrected, but were trimmed. They were also bias subtracted. The response of the flat source was fit detector by detector instead of slit by slit. Each row was then divided by its corresponding fit. The main function of GSFLAT is to remove the GCAL+GMOS spectral response and the GCAL uneven illumination from the flat-field image and leave only the pixel-to-pixel variations and the fringing.

GSFLAT is used to generate a normalized GCAL spectroscopic flat field. GSFLAT accepts as input either a single flat field image or a list of images, which are combined using IMCOMBINE before the response function is determined. The input flats were raw, in which case GPREPARE and GSREDUCE were called. GSREDUCE multiplies each extension by the gain using GGAIN. GMOSAIC was called to mosaic the science extensions into a single frame. The slits are identified using GSCUT.

After processing with GSREDUCE, and GSCUT, GSFLAT fits the response function with a single continuum fit made to the average of the rows within each detector and all the rows are normalized using that fit, retaining any spatial structure. For long slit data, only $85 \%$ of the central third of the slit length is used in determining the normalization, to preserve the flux at the middle and avoid errors due to the bridges.

\section{C.3 REDUCE THE OBJECT DATA}

GSREDUCE is used for basic reductions of GMOS longslit and MOS spectroscopic images. The reduction steps are defined by the flags $\mathrm{fl}_{\text {over }}, \mathrm{fl}_{\text {trim }}, \mathrm{fl}_{\text {bias }}, \mathrm{fl}_{\mathrm{gscrrej}}, \mathrm{fl}_{\text {dark }}, \mathrm{fl} \mathrm{f}_{\text {flat }}, \mathrm{fl}_{\mathrm{gmosai}}, \mathrm{fl} \mathrm{f}_{\mathrm{fixpix}}$, $\mathrm{fl}_{\text {gsappwave, }} \mathrm{fl}_{\text {cut }}$, and $\mathrm{fl}_{\text {title. }}$. For our data reduction we had the overscan subtraction off, trimming on, flat field correcting on, mosaic on, and wavelength solution on.

\section{C.4 WAVELENGTH CALIBRATE}


The ARC data was again reduced in a similar fashion as above with the object data using GSREDUCE. Then, GSWAVELENGTH was used for establishing the wavelength calibration for the GMOS spectra. We performed our wavelength fitting without using the interact mode, which we had previously already done. We found our results using interact on and off to be consistent. GSTRANSFORM was applied to fit a 2D wavelength solution to the data.

\section{C.5 SKY SUBTRACT}

GSSKYSUB was used to subtract sky from the GMOS spectra. The resulting sky sample is usually of the form "r1:r2,r3:r4", where r1:r2 defines the rows on one side of the object aperture and r3:r4 defines the rows on the other side of the object aperture.

\section{ACKNOWLEDGEMENTS}

I would like to thank Gemini Observatory and Dr. Rachel Mason for supplying the data to our research group and Dr. Scott Fisher for acquiring the data and allowing his undergraduate students the opportunity to experience front line research. I would also like to thank Dr. Elsa Johnson and Dr. Joseph Fracchia for their support serving on my committee and Teiler Kwan and Jeremy Bullis for their assistance and support throughout the entire process. Lastly, I want to thank the Oregon NASA Space Grant Consortium for their support in funding my research. This project would not have been possible without all of the support I received.

\section{REFERENCES}

Abramowicz, M., Gunnlaugur Bjornsson, and J. E. Pringle. Theory of Black Hole Accretion Disks. Cambridge, UK: Cambridge UP, 1998. Print.

Alloin, D. M., Rachel Johnson, and Paulina Lira. Physics of Active Galactic Nuclei at All Scales. Berlin: Springer, 2006. Print.

Ball, David W. The Basics of Spectroscopy. Bellingham, WA: SPIE-The International Society for Optical Engineering, 2001. Print.

Beckmann, Volker, and Chris R. Shrader. Active Galactic Nuclei. Weinheim, Germany: Wiley$\mathrm{VCH}$, 2012. Print.

Begelman, Mitchell C., and Martin J. Rees. Gravity's Fatal Attraction: Black Holes in the Universe. New York: Scientific American Library, 1996. Print.

Constantin, Anca, and Anil C. Seth. "M94 As a Unique Testbed for Black Hole Mass Estimates and AGN Activity at Low Luminosities.” Advances in Astronomy 11th ser. 5.2 (2011) Print.

Cui, W., D. Feldkhun, and R. Braun. "Detection of Compact Nuclear X-Ray Emission in NGC 4736." The Astrophysical Journal 477 (1997): 693-99. Print. 
Eracleous, Michael, Joseph C. Shields, George Chartas, and Edward C. Moran. "Three LINERs Under the Chandra X-Ray Microscope.” The Astrophysical Journal 565 (2002): 108-24. IOP Science. Web. 2 Feb. 2014.

Frammert, Hartmut, and Kristine Kronberg. "Messier 94.” Messier Object 94. SEDS, 2 Sept. 2007. Web. 06 Feb. 2014.

Frolov, V. P., and Andrei Zelnikov. Introduction to Black Hole Physics. Oxford: Oxford UP, USA, 2011. Print.

“How Does a Spectrometer Work?” BW Tek. N.p., 2014. Web. 06 Feb. 2014.

Giacconi, Riccardo, Lex Kaper, HeUVel, Edward Peter Jacobus Van Den, and P. A. Woudt. Black Holes in Binaries and Galactic Nuclei: Diagnostics, Demography, and Formation: Proceedings of the ESO Workshop Held at Garching, Germany, 6-8 September 1999, in Honour of Riccardo Giacconi. Berlin: Springer, 2001. Print.

Howell, S.B. “CCD Imaging.” Handbook of CCD Astronomy. Cambridge, U.K.: Cambridge UP, 2000. 47-74. Print.

Jalocha, Joanna, Lukasz Bratek, and Marek Kutschera. "Is Dark Matter Present in NGC 4736? An Iterative Spectral Method for Finding Mass Distribution in Spiral Galaxies.” The Astrophysical Journal 679 (2008): 373-78. IOP Science. Web. 3 Feb. 2014.

Kaper, L., E.P.J. Van Den HeUVel, and P.A. Woudt. Black Holes in Binaries and Galactic Nuclei: Diagnostics, Demography, and Formation. New York: Springer, 2001. Print.

Kitchin, C. R. Galaxies in Turmoil: The Active and Starburst Galaxies and the Black Holes That Drive Them. London: Springer, 2007. Print.

Koekemoer, Anton, and Mario Livio, eds. Black Holes: Proceedings of the Space Telescope Science Institute Symposium, Held in Baltimore, Maryland, April 23-26, 2007. Cambridge, UK: Cambridge UP, 2011. Print.

Krolik, Julian Henry. Active Galactic Nuclei: From the Central Black Hole to the Galactic Environment. Princeton, NJ: Princeton UP, 1999. Print.

Lin, Dacheng, Jimmy A. irwin, Didier Barret, and Ronald A. Remillard. "Discovery of Highly Variable Dipping Ultraluminous X-Ray Source in M94.” Astrophysical Journal 11th ser. 5.2 (2013) Print.

Maoz, Dan, Neil M. Nagar, Heino Falcke, and Andrew S. Wilson. "The Murmur of the Sleeping Black Hole: Detection of Nuclear Ultraviolet Variability in LINER Galaxies." The Astrophysical Journal 625.2 (2005): 699-715. Print.

Mason, Rachel. "Proposal for NGC3736 GMOS-N Optical Spectroscopy.” Thesis. Gemini Observatory, 2007. HubbleSite. NSF. 
Massey, P. “A User's Guide to CCD Reductions with IRAF.” IRAF NOAO., 15 Feb. 1997.

Miller, Joseph S. Astrophysics of Active Galaxies and Quasi-Stellar Objects. Mill Valley, CA: University Science, 1985. Print.

Osterbrock, Donald E. Astrophysics of Gaseous Nebulae and Active Galactic Nuclei. Mill Valley, CA: University Science, 1989. Print.

Peterson, Bradley M. An Introduction to Active Galactic Nuclei. Cambridge: Cambridge UP, 1997. Print.

Roberts, Mallory S. E., and Robert W. Romani. "The ASCA Catalog of Potential X-Ray Counterparts of GeV Sources.” The Astrophysical Journal Supplement Series 122 (2001): 451-65. IOP Science. Web. 2 Feb. 2014.

Robinson, Keith. Spectroscopy: The Key to the Stars. New York: Springer, 2007. Print.

Steiner, J. E., R. B. Menezes, T. V. Ricci, and A. S. Oliveira. "PCA Tomography: How to Extract Information from Data Cubes.” Monthly Notices of the Royal Astronomical Society 395 (2009): 64-75. Print.

Villard, Ray, and John Kormendy. "Black Holes Shed Light on Galaxy Formation.” HubbleSite. HubbleSite, 5 June 2000. Web. 06 Feb. 2014. 


\title{
Adamov's Alienation Effect: Showing the Absurdist Slant of the Epic Theatre Aesthetic
}

\author{
Nicholas Maurer, Clark Honors College*
}

\begin{abstract}
Epic Theatre and Absurdism could not be further apart. Epic Theatre was constructed in order to teach audiences morality, while Absurdism asserts that the world is deprived of morality and meaning. The contrast between styles can be seen by comparing the work of Bertolt Brecht to Samuel Beckett, figureheads of these two movements. Although these styles seem to originate from two separate schools of thought, they actually exist under the umbrella of modernism, and their connection is exemplified by the works of Arthur Adamov, who used Brechtian theory for his absurdist plays. Most notably, Adamov borrowed Brecht's alienation effect. In his plays Professor Taranne, Paolo Paoli, and Ping Pong, Adamov adapted Brecht's alienation effect in order to allow the audience to remove themselves from the exaggerated, absurd plot of the play. Instead of showing morality, this effect allows the plays to be more humorous than if an audience was to become invested in the onstage plight.
\end{abstract}

\section{INTRODUCTION}

In the world of the arts, as with many other parts of life, we are constantly borrowing and building off those who came before us. The story of Arthur Adamov's alienation effect exemplifies this. The end of the 19th century brought about a transformation of the theatrical aesthetic, which went from star-driven, melodramatic styles to the Naturalism and Realism aesthetics that mark the beginning of the modernism period. The playwrights and theatre artists of the Naturalism and Realism movements wanted to express truth onstage, by drawing the audience into the reality of life presented onstage. This period is the origin of the concept of the Fourth Wall, which refers to the audience looking onto the stage as if they were looking through a window pane. In response to his predecessors of the Realism and Naturalism movements, Bertolt Brecht created the aesthetic of Epic Theatre. At the crux of Brecht's theories is his Verfremdungseffekt, which is less than aptly translated by some scholars to "alienation effect". This quintessential component of Brecht's theories boils down to separating the audience from the play in order to invoke an objective response from the audience. Brecht often used this tool in his plays in order to teach the audience a moral lesson through the mistake of the characters onstage. When we think of Brecht and his work, critics and academics often return to the moral

* Nicholas J. Maurer is a Mathematics, Theatre Arts double major in the Robert D. Clark Honors College at the University of Oregon, focusing on playwrighting and theatrical design. He has recently been awarded the Very Little Theatre Memorial Scholarship as well as the Theatre Art Alumni Scholarship for his work academically and artistically in the theatre department. He has also recently presented at the 3 rd annual Climate Change and Indigenous Peoples Conference hosted at the University of Oregon. After college, he hopes to become a playwright or screenwriter. Please direct correspondence to nicholas.j.maurer@gmail.com. 
questions and lessons that Brecht centered his plays around. These strongly didactic motives blind us from acknowledging the humor present in Brecht's works or in other plays that use the alienation concept.

Absurdism is an theatrical aesthetic that rose in the aftermath of World War II. The philosophy of absurdism centers around the concept that life is meaningless and the search for meaning is also inherently meaningless. For the theatrical aesthetic, this lead to numerous comedic plays, which heighten simplistic plotlines to extraordinary proportions. One of the most famous examples is Samuel Beckett's Waiting for Godot, a full length play where two friends try to pass the time waiting on a person named Godot, who never comes. Beckett labels this play a Tragicomedy, referring to the humor we can take in the depressing boredom the main characters must fend off. Although Absurdism and Epic Theatre have little in common, the Russian playwright Arthur Adamov borrowed tools from both aesthetics in his fusion of the genres that make up his own work.

When examining his plays, it becomes clear the Adamov's main tool for humor is Brecht's alienation effect. Brecht used the effect for his didactic objectives. However, it is a common misunderstanding that this distancing removes the emotional weight of the action onstage (Oliver 230). Instead, when used adeptly, the alienation effect heightens the emotional response of the audience. This can be exemplified through the work of Arthur Adamov, a lesserknown contemporary playwright of Brecht, who bridged the Epic Theatre and Absurdist styles by adapting this alienation effect to highlight the absurdism within the plots, the characters, and the tones of the plays. This paper focuses on how Adamov uses his adapted alienation effect in three plays, namely Professor Taranne, Paolo Paoli, and Ping Pong. These three plays represent the breadth of situations and devices that Adamov created in order to alienate the audience. Through his three plays, Professor Taranne, Paolo Paoli, and Ping Pong, Arthur Adamov adapts Brecht's concept of the Verfremdungseffekt (alienation effect) in order to prevent the audience's natural empathetic tendencies and bar them from being drawn into a frivolous plot. In these three plays, Adamov adapted Brecht's theory by historicizing the plot, revealing plot points, and incorporating projections and numerous scenic changes in order to reveal to the audience the ridiculousness of the plight of the characters and the plot Adamov had constructed.

Drawing upon the practices of his predecessor Pisactor, Brecht developed alienation effect as a method of educating the audience (Brecht, "On Experimental Theatre" 15). Brecht described alienation as "the process of [historicizing], of presenting events and persons as historical, therefore as ephemeral” (Brecht, "On Experimental Theatre” 14). Brecht's most common method of historicizing was setting his plays in a distant time and place, physically separating the social boundaries of the world of the play from the boundaries in reality. For example, Brecht sets The Good Person of Szechuan in China and The Threepenny Opera in nineteenth century Victorian England. This removal of place separates the audience from a personal connection to the time and place of the play. His hope was that "by presenting a situation in a striking and unaccustomed light, [it would] draw the audience's critical attention to the social forces which determine human destiny" (Steer 639). By drawing out the audience's attention, Brecht forces them to actively, rather than passively, engage in the play. Active 
attention incites the audience's continuous judgment of the characters' actions as well as the situations in which the characters find themselves. It also allows the audience to compare their own lives to the experiences onstage from a more rational, rather than emotional, perspective. Therefore "to 'alienate' does not mean... to separate the actor from the character or the stage from the audience" (Dort and Ostergren 31). Rather, the alienation effect "removes the stamp of familiarity from phenomena capable of being modified by society" (Dort and Ostergren 30). This is not to say that the emotional connection between the audience and the action is entirely removed. It is simply becomes sympathy instead of empathy, which allows the audience to feel for the action onstage without losing focus on the message being communicated. Alienation distances the audience from time and place, but not from human emotion and moral obligation.

\section{ALIENATION AND ADAMOV}

Brecht utilizes this alienation in order to force the audience into an objective position, through which they can have visceral reactions to characters part of an entirely different world. In order to achieve this state of being, the "stage and auditorium must be purged of everything 'magical' and that no 'hypnotic tensions' should be set up" (Brecht 136). This purging is usually achieved by stripping the stage of anything extraneous. Sets need not be minimal, but they cannot be elaborate and should not hide the structure of the theater. Lighting fixtures can be in sight of the audience. Costumes do not need to represent any particular period; they just have to be larger than life. Epic Theatre abandons the concept of the unity of design, asserting a cacophony of elements, which remind the audience of their presence in the theater (Brecht, "On Experimental Theatre" 15-16). All of these small details remind the audience that they are sitting in a theater watching a play, so that their mind does not become hypnotized by the action. Through the rejection of orthodox theatrical conventions, Brecht's Epic Theatre "intended purely to show the world in such a way that it becomes manageable" (Brecht, Brecht on Theatre 140). With a "manageable" world-view, the audience can break down the plot and characters into their fundamental moral components and learn from their faults onstage. Brecht's rejection of hypnosis should not be convoluted with a rejection of emotional connection. Brecht wrote that "we need a type of theatre which not only releases the feelings, insights, and impulses possible within the particular historical field of human relations in which the action takes place, but employs and encourages those thoughts and feelings which help transform the field itself" (Brecht on Theatre 190). The constant interruption of the viewing experience should not remove the emotional reactions of the audiences, only distance their empathetic connections and their submersion in the world. The end goal of the alienation effect is to emphasize the spectacle, the morality, and the objective perception of the audience in order to have a didactic production.

Adamov adapted this method of alienation for his own work. William Oliver suggests, "alienation in absurdist drama is... an effect incompatible with the play itself" (Oliver 230). At first thought, alienation and absurdism should conflict, since absurdism is dependent on the lack of meaning. Without the possibility of a didactic production, Brecht's alienation effect is rendered useless. Yet Adamov draws upon alienation techniques in order to augment the absurdism of the situation for his audience. For the characters in these plays, butterfly hunting and conquering pinball machines have progressed to life or death situations; therefore, the 
alienation effect is necessary in order to rid the audience of any empathetic feelings for the ridiculous dilemmas of the characters, thus producing humor. "Adamov seems to have tried to avoid the complete alienation of the spectator" (Dietemann 53). Instead of constantly reminding the audience of the theatrical setting, throughout his plays Adamov allows the audience to have reoccurring epiphanies of the theatrical nature of the play. Through his adaptation of Brecht's alienation effect, Adamov crafted a form of separation between the audience and the stage that best highlights the absurdism in his plays.

\section{PROFESSOR TARANNE}

In Professor Taranne, Adamov achieves his tragic farce by isolating the professor, and thereby alienating the audience. Tragically, Professor Taranne is mostly forgotten by nearly every character with whom he comes in contact. At one point a fellow professor, known only as Smart Woman believes she recognizes the professor. At the point we are about to learn Taranne is, we discover that Smart Woman has mistaken him for someone else. By refusing to share Taranne's identity with the audience, Adamov shows us Taranne's "self-imposed image... as a destroyer of true self" (McCann 40). This continual questioning of the truth or deceit behind Tarenne's identity interrupts our understanding of him. In a moment, the audience is simultaneously pushing him onward as well as solving his identity mystery. This multidimensional pull of Taranne is a form of Adamov's alienation effect. By the end of the play, Taranne begins to strip off his clothes, the crime he was charged with and which he denied in the opening scene (Adamov, Two Plays 30). This completes our mistrust of Taranne, as the play ends without revealing the truths and falsities of what Professor Taranne has told the police, and subsequently the audience. Besides being an element of alienation from the character, this moment at the end of the play is absurd and humorous, in what can otherwise be described as Tarenne's nightmare. If the audience was emotionally drawn into the play, these final moments might be misconstrued for the tragic message of Taranne becoming the man society thinks he is, which does not coincide with the absurd philosophy. From an alienating point of view, the audience instead understands the psychotic nature of Taranne, which reveals the humor within the confusion of the world that just passed before them.

In addition to the isolation of Professor Taranne, Adamov relies heavily on the authorities' and audience's active judgment of Professor Taranne as another alienation element stemming from Brechtian practices. Twice in this play, Taranne is accused by police and stripped of his liberty in the process (Adamov, Two Plays). Since these actions happen immediately at the top of each scene, until the final moment the audience is asked to be a jury of peers in this play-judging whether or not Taranne is a criminal based upon circumstantial evidence. By asking the audience to fulfill this role of judgment in the story, the audience must immediately call upon their objectivity, forcing them to distance themselves from Professor Taranne and the plot. This call to action is typical in Brecht's work and is borrowed here by Adamov to achieve an alienation effect. 


\section{PAOLO PAOLI}

In Adamov's play Paolo Paoli, Adamov alienates the audience by historicizing the action. Paolo Paoli is set in the years prior to World War I, starting in 1900 and ending right before the war in August of 1914 (Adamov, Paolo Paoli). Since Adamov wrote this play in the 1950s, he has distanced his French audience in time, but not in place. The audience is aware of the aggressive political actions leading to war, yet the characters are more concerned with the acquiring and trading of butterflies than politics, even when Czar Nicholas II writes to Wilhelm II stating that Wilhelm "may be obliged to mobilize" (Adamov, Paolo Paoli 116). Europe was about enter the bloodiest war it had ever seen, which was similar to the war that Europe had recently lived through at the time Paolo Paoli premiered, but these characters are in conflict over butterflies. By setting this play in this historical context, the major conflict instantly becomes a trifle, thus the plot and the characters are simply absurd in comparison. This absurdism would not be possible without this historicization. Without the context, absurdism within the play would not exist, or at least not be as potent. Adamov establishes this historical context by projecting the year and a few headlines and quotes from different sources in that year. Accentuation of the projections in combination with the play is critical to the establishment of Adamov's alienation effect.

The second prominent method Adamov uses to alienate his audience in Paolo Paoli is the multitude of setting changes that occur through the play. The play swiftly moves from Paolo's residence to Hulot's residence to Robert's residence and everywhere else in between (Adamov, Paolo Paoli). These rapid changes of location reminds the audience that the world onstage is a created world rather than allowing them to submerse themselves inside a single location or a one-piece set. The movement of place allows audiences personal insight into each character, as they visit each residence. After bouncing between the residences of the Abbe, Paolo, and Hulot, we finally come to Robert's domicile in the Act II, which is described as "whitewashed walls. A small iron bedstead, sheets of paper and newspapers are strewn about the floor" (Adamov, Paolo Paoli 96). This contrasts heavily with the lavish locations the audience has been visiting throughout the play, which only augments the disparity between the classes and the abuse of the lower classes by the upper classes in this period of French society. Alienating this location, and thus the characters foreign to this location, creates a plot that critiques the problems among the upper class and comments on the inflated trifles through which the well-off "suffer".

\section{PING PONG}

Adamov uses some similar methods of alienation in his play Ping Pong. First and foremost, Adamov historicizes the play, although he uses a different method than in Paolo Paoli. Rather than setting the play in a certain place and time period, Adamov historicizes the play by extending the time frame of the play to cover most of the entire lives of the two main characters, Arthur and Victor. The play starts with both of these characters as students in university (in their early twenties) and ends with these two as "white-haired septuagenarians" (Adamov, Two Plays 120). This fifty-plus-year span of the plot creates a false sense of history that has passed 
during their lifetimes as well as the play, without citing any particular dates (Adamov, Two Plays). Every time the play leaps forward in time, the audience must disconnect from the world in order to recognize the new age of all the characters and the time that has passed from the last scene. This interruption alienates the audience in order to follow the progression of the pinball addiction through Arthur and Victor's lives.

In addition to historicizing the plot, Adamov also makes use of a number of major scenic shifts in Ping Pong, rarely revisiting the same location twice. Mrs. Duranty, who begins the play owning and operating a small bar, is constantly trading her business for another operation, as she moves to a bathhouse, then to a dance studio, then to a public park, before her final scene outside an arcade (Adamov, Two Plays). Similar to Paolo Paoli, these rapid scenic changes also remind the audience of their presence in a theater, alienating them from a stable sense of the world of the play. This time, Adamov uses these changes to augment the passage of time. The audience would not assume that Mrs. Duranty has a new business everyday, thus we can guess that a larger amount of time in between one business and the next. There could be more design choices that also include this passage of time, notably in the costumes of the play, yet these changes are not documented in the text (Adamov, Two Plays).

In Ping Pong, Adamov centers the conflict on a trivial matter, which Arthur and Victor's debate over what bells and whistles make up the perfect pinball machine. The play is about the pinball industry, referred to simply as the "Organization", and the attempted mastery of the pinball machines, referred to as the "machine" (Adamov, Two Plays 40-1). By heightening a trivial matter while alienating the audience, Adamov succeeds in augmenting the absurdity of the plot and characters within the play. When reading or seeing the play, we can recognize that much of the humor "results from the distance between the grandiose effort, constant concern, flights of poetry and persistent energy of the principal characters and the relative triviality of the object of their dedication" (McCann 79). In dire pursuit of the perfection of the game, Arthur and Victor almost completely sacrifice the things of value within their own lives, such as their education, their career, and even their relationship. This destructively obsessive pursuit of a trivial matter is a didactic and humorous component to Adamov's absurd play. Therefore, Ping Pong highlights the importance of the alienation effect in absurdist drama, contradicting William Oliver's statement that "alienation in absurdist drama is... an effect incompatible with the play itself" (Oliver 230). Instead, the alienation effect can be used to draw out the humor in theatre. The machine is "a concrete object which dominates the protagonists' existence, corrupts their vision, informs their language, and invalidates their energies" (McCann 80). The machines rip apart every character in this play. Even Roger, the only character without an obsession of the machines, is destroyed through his relationships with others who are infected. This play allows characters to destroy their own liberty because of their relationship with these machines. The audience follows the tragic comedy as the characters humorously fall into the trap of a meaningless, childish addiction.

Of the three plays discussed, Ping Pong draws the most upon Brecht's alienation effect. Along with the other examples of alienation in Ping Pong that have already been cited, which can be considered methods duplicated in his other works, Adamov presents several moments in 
this play that serve to completely remove the characters from the world they inhabit. In these moments the curtain is down while Arthur and Victor are walking in front of the curtain, lit solely by follow-spots. It is in these moments that Adamov indicates a major time-shift as well as reveals future plot points, such as the impending rejection of their pinball proposal to $\mathrm{Mr}$. Constantine. Before they present their idea to Mr. Constantine, Victors tell Arthur, "We had no choice. It was a case of now or never. I admit, it is a rather an irrational step to take, but I couldn't resist it" (Adamov, Two Plays 103). Adamov uses the past tense when referring to a presentation that has not happened for the audience, thus informing the audience of what is to follow onstage. The audience is alerted that Mr. Constantine will reject the proposal before the scene begins, thus they can judge the merits of the proposal and the obsession of the characters rather than rooting for the characters' success. Yet, rather than judging the proposal for a moral lesson, the audience judges the proposal for how frivolous and absurd these changes would be since they only add more bells and whistles to the machine.

Adamov's alienation of the audience throughout Ping Pong provokes a more prevalent emotional response than simply humor. By the end of the play Arthur and Victor's obsession over the machine transforms into an obsession over Ping Pong, the title game of the play. While arguing what the Ping Pong rules should be, Victor suddenly dies. This abrupt death ends the decades of debates Victor and Arthur shared in order to perfect something as ridiculous as a pinball machine, thus "we are left with the beautiful unresolved ambiguity of knowing who is the 'victor;" Victor who dies and escapes, or Arthur who lives on, but who is now old and alone, robbed of the one meaningful factor in his life, his friendship with Victor" (McCann 83). It is in this moment that tragedy strikes Arthur. Since the alienated audience has judged the quarrels induced by the machine between the two companions from the beginning, this moment evokes a more empathetic reaction to the end of the play. It is only after the audience has judged Victor and Arthur's trivial pursuit throughout the entire play that this moment evokes the strongest possible feeling of empathy because of the life and time that had been wasted. While Brecht and others have traditionally used the alienation effect as a didactic device, this is an example of the alienation effect being used as an emotionally evocative tool.

\section{CONCLUSION}

In his three plays Professor Taranne, Paolo Paoli, and Ping Pong, Adamov adapts Brecht's alienation effect (used first in his Epic Theatre) in order to apply it to the new wave of absurdism. Adamov adapted Brecht's theory in order to communicate humor that would have otherwise gone unnoticed within his plays. In addition, this adapted alienation effect was used to augment the absurdity as well as the humor of the dramas. It is likely that Adamov's other plays (which could not be located in English translations) use similar devices, which bridge the theatrical ideologies of Epic Theatre and Theatre of the Absurd. In the end, this analysis demonstrates the breadth of reactions that alienation effect can inspire. The common myth is that Epic Theatre and the alienation effect create an emotionless response from the audience, but on the contrary, the alienation effect can be used to evoke a wide range of emotions in a disengaged audience. 


\section{APPENDIX}

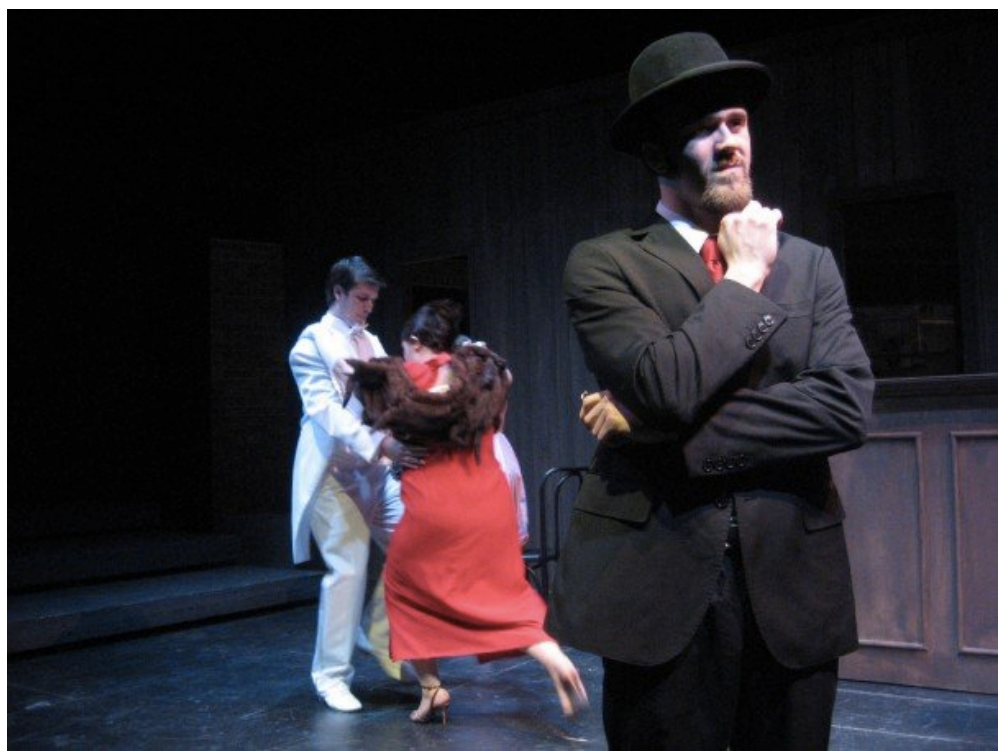

Figure 1. A contemporary production of Adamov's Professor Taranne, with Christian Grunnah playing the title character. Professor Taranne is separated from the other two characters through space, light, and costume. Taranne is pulled to the front of the stage and is left isolated at several instances during the play.

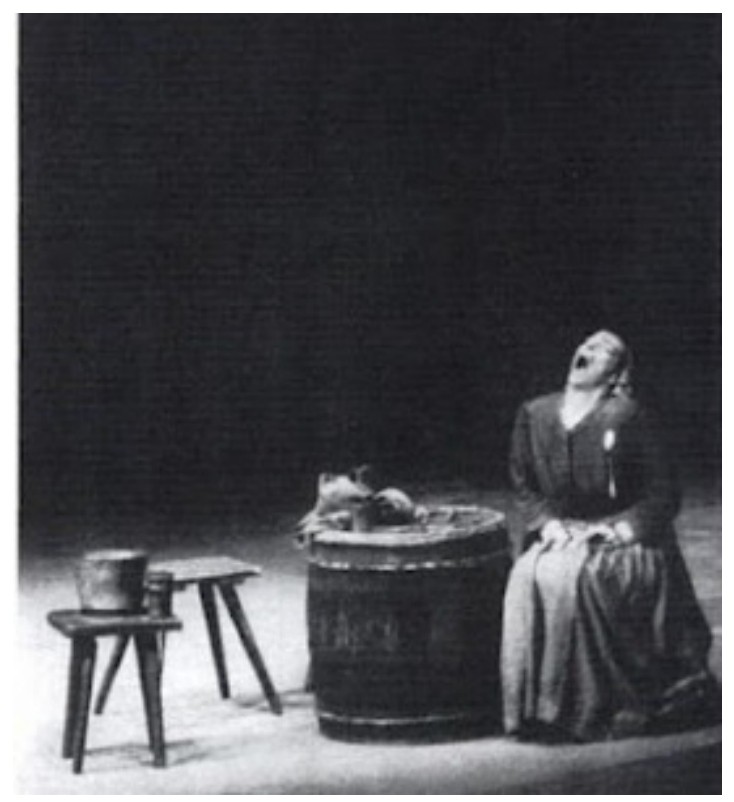

Figure 2. Helene Weigel playing the title character in Brecht's Mother Courage. This photo is used as a defining image of the alienation effect. Weigel mimes the silent scream, lamenting the loss of her sons. The audience cannot hear the scream they expect to hear from the character in this moment. This surprising silence separates the audience from the world of the play. (Alfrun) 


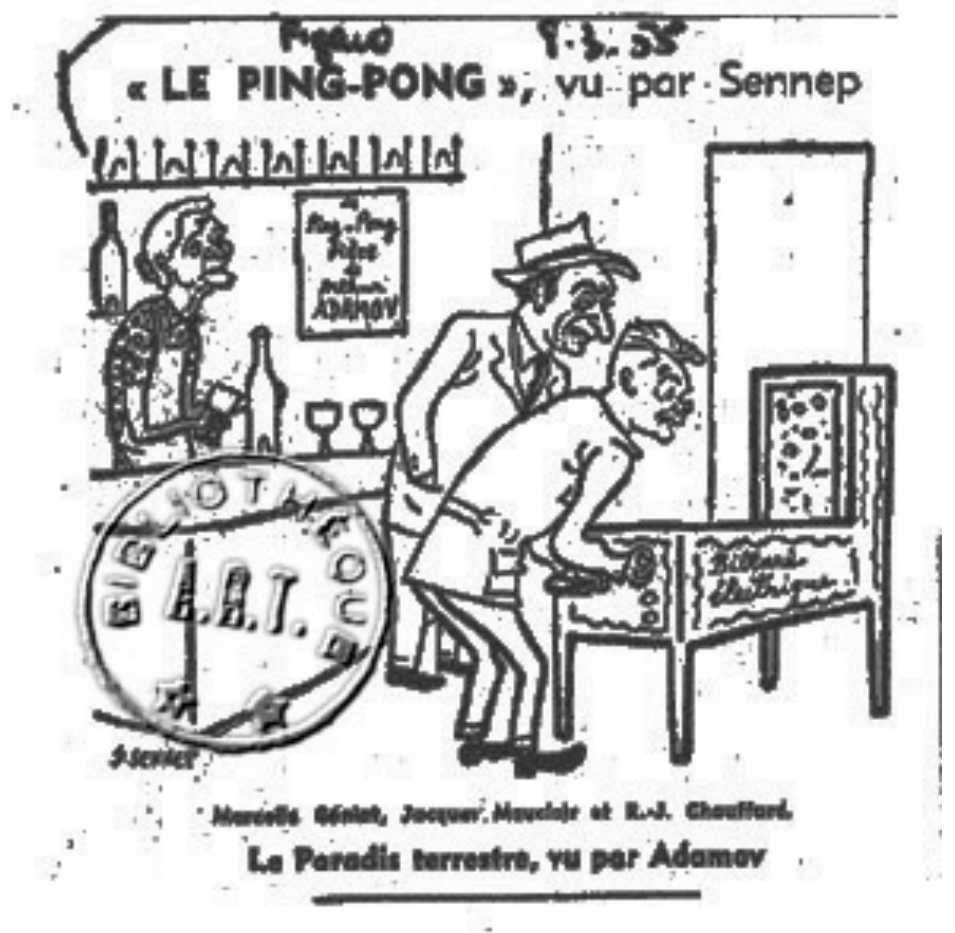

Figure 3. A drawing depicting the opening scene of Ping Pong. Arthur and Victor are captured by the machine, while Mrs. Duranty cleans glasses. All three characters in this image have their eyes focused on the machine. (Sennep)

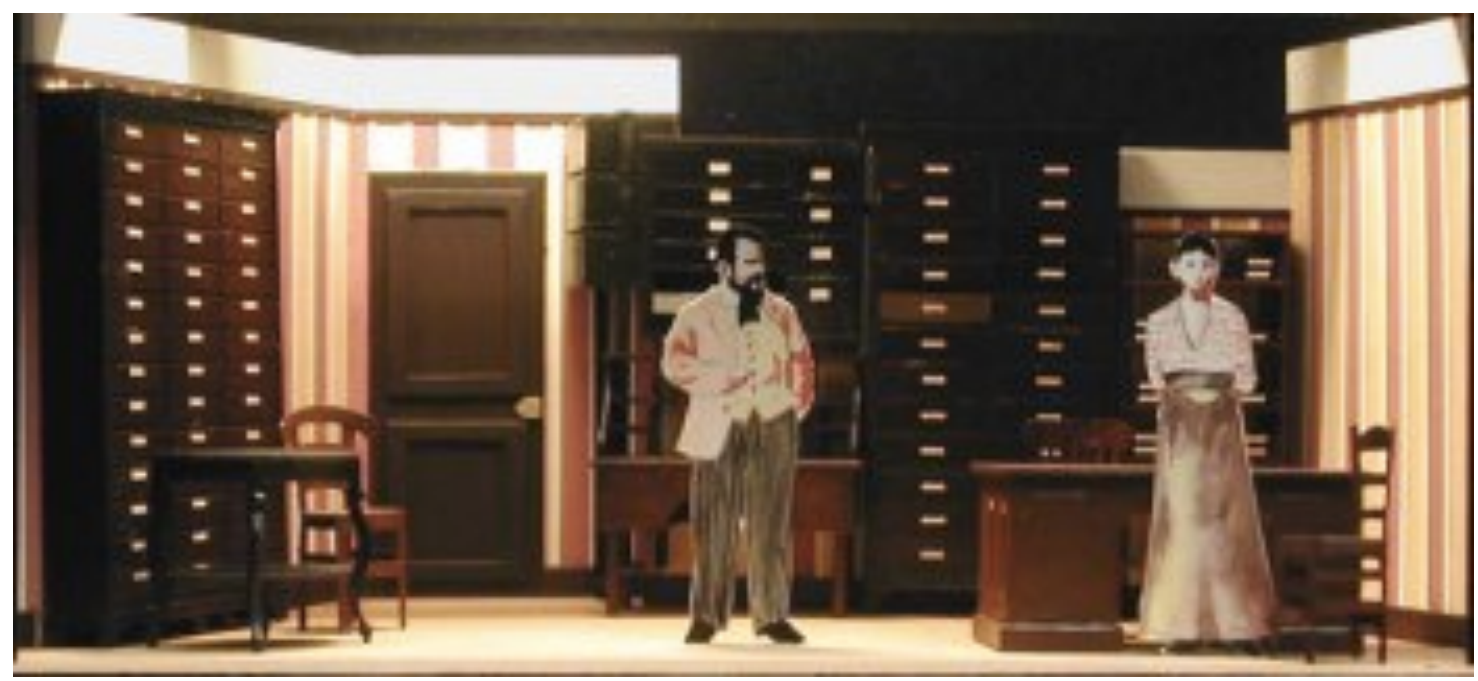

Figure 4. A set design by Rene Allio of Roger Planchon's 1958 production of Paolo Paoli in Paris. Paolo and Rose are shown having a conversation in Paolo's study. Disparity between Paolo, the businessman, and Rose, the servant, is shown through costuming. (Douaire, et al.) 


\section{REFERENCES}

Adamov, Arthur. Paolo Paoli. Trans. Geoffrey Brereton. London: John Calder LTD, 1959. Print.

---. Two Plays: Professor Taranne and Ping Pong. Trans. Peter Meyer and Derek Prouse. London: John Calder LTD, 1962. Print.

Alfrun. The Silent Scream. Masks, Mime, Puppets and Physical Theatre, Wordpress, 25 Jan. 2013. Web. 3 June 2015.

Brecht, Bertolt. Brecht on Theatre: The Development of an Aesthetic. Trans. John Willet. New York: Hill and Wang, 1964. Print.

---. “On the Experimental Theatre.” Trans. Carl Richard Mueller. The Tulane Drama Review 6.1 (1961): 2-17. Electronic.

Dort, Bernard and Ostergren, Christopher. "Epic Form in Brecht's Theatre” Theater 1.2 (1968): 24-34. Electronic.

Douaire, Martin, et al. Scene from Arthur Adamov's Paolo Paoli directed by Roger Planchon, set by René Allio, at Le Théâtre du Vieux-Colombier, Paris, 1958. Photograph. Set Design:1950s, The Red List. Web. 3 June 2015.

McCann, John J. The Theater of Arthur Adamov. Chapel Hill: University of North Carolina at Chapel Hill, 1975. Print.

Oliver, William I. "Between Absurdity and the Playwright." Educational Theatre Journal 15·3 (1963): pp. 224-235. Electronic.

Sennep. The Ping Pong. 1958. Association of A.R.T. Theatre Board, Paris. Web. 3 June 2015.

Steer, W. A. J. “Brecht's Epic Theatre: Theory and Practice” Modern Humanities Research Association 63.3 (1968): pp. 636-649. Electronic. 


\title{
GPU-Imogen: An Astrophysical Hydrodynamic Code Built for Graphics Processing Units
}

\author{
Isaac Brown, Tom Wolken, Physics and Math*
}

\begin{abstract}
We describe Graphics Processing Unit-Imogen (GPU-Imogen), an astrophysical hydrodynamics computer code, developed by Erik Keever and Scott Ernst. GPU-Imogen uses the Harten-Lax-van Leer-Contact (HLLC) fluid scheme to simulate the compressible Euler equations (equations governing a fluid with no viscosity or heat conduction). The fluid scheme is performed on the GPU, with the possibility of parallelization to multiple GPUs per node and/or GPU clusters. We describe the fluid scheme and GPU parallelization to understand the robustness and efficiency of the code. Benchmark tests of one-, two-, and three-dimensional problems are provided to verify robustness. User friendly features of GPU-Imogen are also explored. GPU-Imogen is shown to be a strong choice for an astrophysical hydrodynamics code.
\end{abstract}

\section{INTRODUCTION}

\subsection{BACKGROUND}

GPU-Imogen was written for use in numerical studies of astrophysical fluid flows such as spiraling gas around a star. Numerical methods can involve either serial or parallel computation. Serial computation is when one calculation is carried out at a time. In some problems, like fluid dynamics and graphics processing, it becomes more efficient to break the problem into many smaller parts that can each be solved with the same scheme simultaneously. This is one example of a parallel computation. GPU-Imogen's fluid scheme is parallelizable, so it performs the bulk of its computations in parallel on a single GPU, or on any number of GPUs working in parallel with each other. Parallelization makes GPU-Imogen highly efficient, which is particularly important for computational astrophysics, where high resolution experiments can take days to run.

\footnotetext{
* Tom Wolken is a fourth year physics and math double major from Portland, OR. He is a math tutor and an undergraduate researcher in in Dr. Imamura's astrophysics lab. He hopes to further his education by pursuing a Ph.D. in astrophysics. Always having a passion for outer space, he is currently interested in the computational aspect of astrophysics. Please direct correspondence to thomas.wolken@gmail.com.
}

Isaac Brown is a fourth year physics and math double major from Springfield, OR. He has worked as lab manager in the physics teaching labs for two years, spent several terms as a physics undergraduate teaching assistant, and currently works in the math drop-in center at the Math Library. He enjoys watching bad movies and staying inside on sunny days. Before becoming a physics major, Isaac studied vocal performance at the UO school of music, and enjoys playing the piano and singing. Please direct correspondence to brwnisaac@yahoo.com. 
Two subfields of computational astrophysics are computational fluid dynamics (CFD) and magnetohydrodynamics (MHD). GPU-Imogen is currently a CFD code. In these fields, computer schemes can be developed to approximate the dynamics of fluids under conditions that are difficult to achieve in a laboratory. For example, the plasma in the core of the sun can reach pressures of 100 billion atmospheres, and temperatures of 15 million degrees Kelvin. Both CFD and MHD codes are currently analyzing important unsolved questions in astrophysics., ${ }^{1,2,3,4}$ MHD codes are inherently more complicated than CFD codes since they must incorporate the additional physics of magnetism. Even though MHD codes account for more physics, there is still a need for specialized CFD codes in astrophysical research. Implementing a robust CFD code is arguably simpler than implementing a robust MHD code, so if magnetic effects can be ignored then CFD codes are advantageous. Examples of astrophysical CFD codes are Art, Enzo, and Heracles, 5,6,7 while examples of astrophysical MHD codes are Athena, Nirvana, and ZeusMP. ${ }^{8,9,10}$ The name "Imogen" in GPU-Imogen follows the trend of using Greek mythological names for astrophysical codes.

\subsection{HISTORY OF GPU-IMOGEN}

The code that is now GPU-Imogen is an evolution of a code first developed by Scott Ernst, which was originally named Imogen. Imogen ran only on central processing units (CPUs) and used a different fluid scheme presented by Jin and Xin. ${ }^{11}$ Imogen was an MHD code that Ernst used to investigate magnetic accretion shocks in his thesis. ${ }^{12}$ Beginning in 2009, Erik Keever modified Imogen into a GPU-based parallel code, GPU-Imogen. Up until 2013, GPU-Imogen kept the scheme used in the original Imogen. In 2013, Keever presented this version of GPUImogen at a conference on supercomputing. ${ }^{13}$ In late 2013, Keever replaced the original fluid scheme with a new fluid scheme developed by Toro et al named Harten-Lax-van Leer-Contact (HLLC). ${ }^{14}$ This scheme was chosen for its known robustness and efficiency in CFD. We worked under the direction of Keever to first understand and then use GPU-Imogen. This paper is our description of tests that we ran and information that we compiled on the most recent version of GPU-Imogen. The source code for GPU-Imogen is available to download for free online at https://github.com/imogenproject/GPUImogen.

\subsection{FEATURES OF GPU-IMOGEN}

A key feature of GPU-Imogen is that the fluid scheme is performed on the GPUs (and is hidden from the user), while the initial conditions for the experiments are generated using a user friendly language called MATLAB. The fluid scheme can be thought of as the laws of physics for our program since they are unchanging and do not need to be tampered with by the user. On the other hand the setup of each experiment needs to be accessible to the user so it is written in MATLAB. Once GPU-Imogen runs the initial conditions, it sends them to be evaluated on GPUs automatically. It then prints images and data files at specified intervals, making analysis straightforward. GPU-Imogen also contains pre-built functions, allowing for automatically generated supersonic shocks, static cells (cells that act as a solid wall), and potential fields (such as gravity). This makes it even easier for users to quickly generate a new experiment. 


\section{THEORY}

\subsection{BASIC EQUATIONS FOR CFGD}

GPU-Imogen implements a fluid scheme to solve the compressible Euler equations. In conservative and Cartesian form, the Euler equations are:

$$
\begin{aligned}
& \frac{\partial \rho}{\partial t}=-\frac{\partial}{\partial x_{i}} \rho v_{i} \\
& \frac{\partial\left(\rho v_{i}\right)}{\partial t}=-\frac{\partial}{\partial x_{j}}\left(T_{i j}+\mathbb{I} P\right) \\
& \frac{\partial E}{\partial t}=-\frac{\partial}{\partial x_{i}} v_{i}(E+P)
\end{aligned}
$$

for mass density $\rho$, fluid bulk velocity $v_{i}$, momentum stress tensor $T_{i j}=\rho v_{i} v_{j}$, identity tensor $\mathbb{I}$, scalar thermal pressure $P$, and total energy density $E=\frac{1}{2} \rho v^{2}+\epsilon$. Where $\epsilon$ is specific internal energy. These equations represent the conservation of mass, momentum, and energy respectively. The equation for pressure is $P(\epsilon)=(\gamma-1) \epsilon$. Here, the term $\gamma$ is the adiabatic index. Physical values of $\gamma$ lie within $1<\gamma \leq 5 / 3$.

\subsection{RIEMANN PROBLEMS AND SOLVERS}

A Riemann problem is a fluid dynamics problem where the initial values for the problem are piecewise constant with one discontinuity. One example of a Riemann problem is shown in Figure 1a. Riemann problems occur naturally in CFD, where scientists are often interested in studying shock waves and other phenomenon that are inherently discontinuous. Also, the discreteness of grids used in CFD leads to discontinuities at cell boundaries. Scientists such as Godunov have derived exact solutions to one-dimensional Riemann problems. ${ }^{15}$ The evolution of the exact solution to our Riemann problem pictured in Figure 1a is shown in Figure 1b. In Figure $1 \mathrm{~b}$, region one is the not-yet affected high density region. Region two is known as the rarefaction wave. The discontinuity between region three and four is the contact discontinuity. The discontinuity between region four and five is the shock front, and region five is the not-yet affected low density region.

Unfortunately the exact solutions to one dimensional Riemann problems do not carry over to the two-dimensional case, so approximate Riemann solvers are used. In this way, GPUImogen's fluid scheme uses an approximate Riemann solver. 


\section{High Density}

\section{Low Density}

Figure 1a: Two regions of differing density in contact. This specific Riemann problem is often referred to as Sod's shock tube.

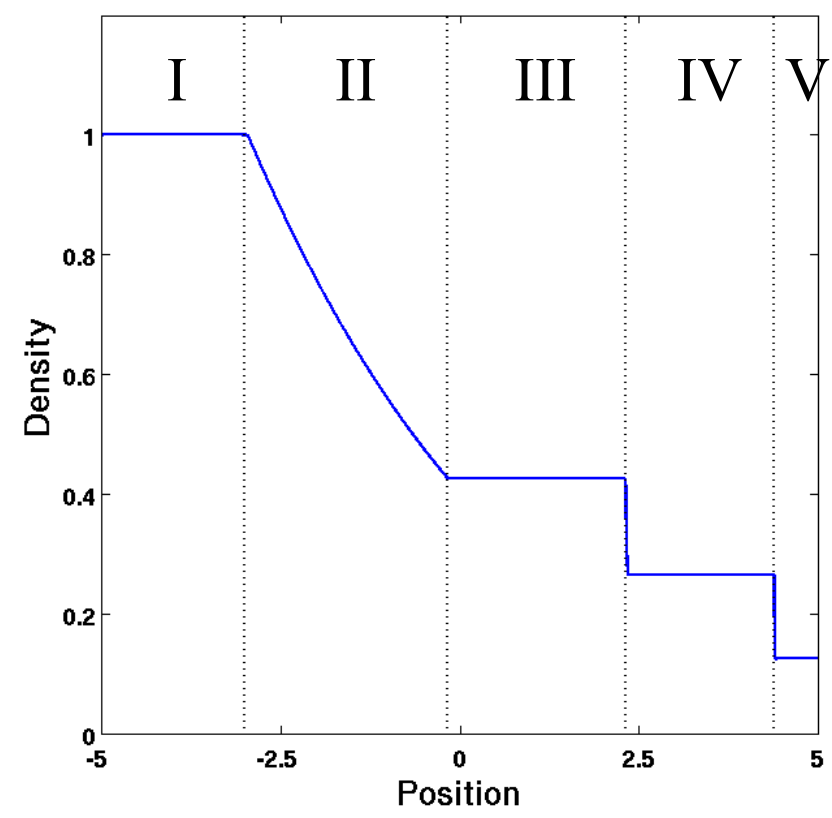

Figure 1b: The exact, time evolved, solution to Sod's shock tube.

\subsection{DISCRETIZATION}

In theory, fluids are continuous and infinitesimally fine. In practice, computer algorithms must approximate the continuous flow of fluid by discretizing the space of the problem. GPUImogen does this by hashing the problem domain into equally sized cells. In one dimension, these cells are line segments. In two-dimensions they are squares, and in three dimensions they are cubes. This type of discretization is known as a finite volume Cartesian grid. The continuous spatial coordinates are $(x, y, z)$ and the cell represented by $(i, j, k)$ is centered at $\left(x_{i}, y_{j}, z_{k}\right)$.

Space is not the only thing to be discretized, as time is also broken into a finite number of steps. We follow the notation that the current time step is denoted in superscript by "n." The length of a given time step is then $\Delta \mathrm{t}^{\mathrm{n}}=\mathrm{t}^{\mathrm{n}+1}-\mathrm{t}^{\mathrm{n}}$. Notice how the length of a given time step depends on $n$ (from here on we drop the $\mathrm{n}$ superscript on $\Delta \mathrm{t}$ ). This is because the time step needs to be small enough to ensure that the fastest wave does not cover more than one discrete cell within the time step. To ensure this, we use the Courant-Friedrichs-Lewy (CFL) condition: $\Delta \mathrm{x}<\Delta \mathrm{t}\left(\left|\mathrm{v}_{\mathrm{i}}\right|+\mathrm{C}_{\mathrm{s}}\right)$ where $\Delta \mathrm{x}, \Delta \mathrm{t}, \mathrm{v}_{\mathrm{i}}$, and $\mathrm{C}_{\mathrm{s}}$ represent the change in space, time step, bulk fluid velocity of the $\mathrm{i}^{\text {th }}$ cell, and the speed of sound in the fluid. 


\subsection{ONE-DIMENSIONAL FLUID SCHEME}

For completeness, the details of GPU-Imogen's fluid scheme in one dimension is introduced. In one dimension the conservation form of the Euler equations (1) - (3) can be represented as

$$
\frac{\partial \boldsymbol{q}}{\partial t}+\frac{\partial \boldsymbol{f}}{\partial x}=0
$$

where the vectors $\boldsymbol{q}$ and $\boldsymbol{f}$ stand for the conserved quantities and their fluxes as

$$
\begin{gathered}
\boldsymbol{q}=\left\langle\rho, \rho \mathrm{v}_{\mathrm{x}}, \rho \mathrm{v}_{\mathrm{y}}, \rho \mathrm{v}_{\mathrm{z}}, \mathrm{E}>\right. \\
\boldsymbol{f}=\left\langle\rho \mathrm{v}_{\mathrm{x}}, \rho \mathrm{v}_{\mathrm{x}}{ }^{2}+\mathrm{P}, \rho \mathrm{v}_{\mathrm{x}} \mathrm{v}_{\mathrm{y}}, \rho \mathrm{v}_{\mathrm{x}} \mathrm{v}_{\mathrm{z}},(\mathrm{E}+\mathrm{P}) \mathrm{v}_{\mathrm{x}}>\right.
\end{gathered}
$$

where $\rho, v_{x}, v_{y}, v_{z}, E$, and $P$ stand for the mass density, Cartesian components of velocity, energy, and thermal pressure respectively. Equation (4) can be recast as an integral over one discrete cell spatially and a time $\operatorname{step}(\Delta \mathrm{t})$ temporally to obtain

$$
\begin{gathered}
\boldsymbol{q}_{i}^{n+1}=\boldsymbol{q}_{i}^{n}-\frac{\Delta t}{\Delta x}\left(\boldsymbol{f}_{i+\frac{1}{2}}^{n+\frac{1}{2}}-\boldsymbol{f}_{i-\frac{1}{2}}^{n+\frac{1}{2}}\right) \\
\text { where } \\
\boldsymbol{q}_{i}^{n}=\frac{1}{\Delta x} \int_{x_{i-1 / 2}}^{x_{i+1 / 2}} \boldsymbol{q}\left(x, t^{n}\right) d x
\end{gathered}
$$

is a vector of volume averaged conserved quantities, and

$$
\boldsymbol{f}_{i-\frac{1}{2}}^{n+\frac{1}{2}}=\frac{1}{\Delta t} \int_{t^{n}}^{t^{n+1}} \boldsymbol{f}\left(x_{i-\frac{1}{2}}, t\right) d t
$$

are time averaged fluxes at the location $\mathrm{x}_{\mathrm{i}-1 / 2}$. Being able to compute (5) means that we can calculate the values for our cell centered conserved quantities at the next time step. Starting from (6) a piecewise linear reconstruction scheme is used to compute $\boldsymbol{q}_{L, i-1 / 2}$, and $\boldsymbol{q}_{R, i-1 / 2}$ which represent the conserved quantities on the left and right side of the interface between cells $\mathrm{i}-1$ and i. Figure 2 provides a visual. The reconstruction scheme is outlined in, ${ }^{8}$ and is shown to be second order accurate and total variation diminishing by Sweby. ${ }^{16}$ Slope limiters are used in the reconstruction scheme to ensure that no new extreme values are created. An approximate Riemann solver is used to compute (7). The approximate Riemann solver for GPU-Imogen is introduced in section 2.5. 


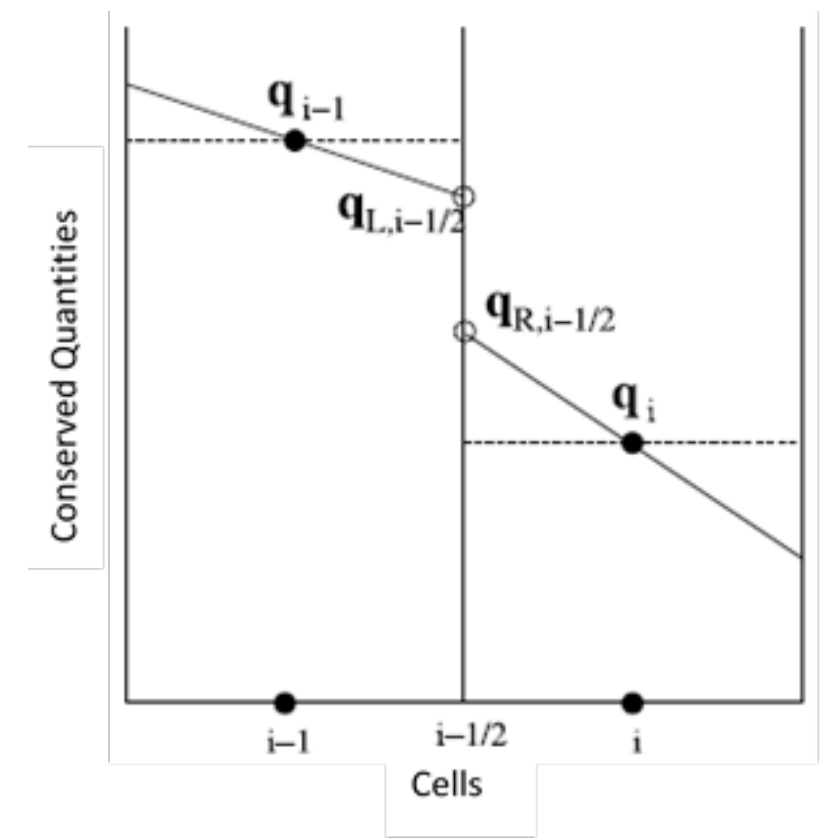

Figure 2: A piecewise linear reconstruction of conserved quantities from the center of each cell $\left(\boldsymbol{q}_{i-1}, \boldsymbol{q}_{i}\right)$ to the left and right sides of the cell interface $\left(\boldsymbol{q}_{L, i-1 / 2}, \boldsymbol{q}_{R, i-1 / 2}\right)$. Notice how the conserved quantities are discontinuous at the cell boundary. This discontinuity defines a Riemann problem. Figure credit Stone. ${ }^{8}$

We will now outline the steps for the one dimensional fluid scheme:

Step 1: From $\boldsymbol{q}_{i}^{n}$, calculate $\boldsymbol{q}_{L, i-1 / 2}$, and $\boldsymbol{q}_{R, i-1 / 2}$ at every cell boundary by using the piecewise linear reconstruction scheme.

Step 2: Compute the fluxes (7) by using an approximate Riemann solver (solver is introduced in section 2.5).

Step 3: Use (5) to update the new cell centered conserved quantities.

Step 4: Advance the time from $\mathrm{t}^{\mathrm{n}}$ to $\mathrm{t}^{\mathrm{n}+1}$ by the relation $\mathrm{t}^{\mathrm{n}+1}=\Delta \mathrm{t}+\mathrm{t}^{\mathrm{n}}$. Use the CFL condition $\Delta \mathrm{x}<$ $\Delta \mathrm{t}\left(\left|\mathrm{v}_{\mathrm{i}}\right|+\mathrm{C}_{\mathrm{s}}\right)$ to calculate an appropriately small time step $\Delta \mathrm{t}$ for the next cycle.

Step 5: Repeat steps 1-4 until the final time is reached.

\subsection{APPROXIMATE RIEMANN SOLVER FOR GPU-IMOGEN}

The current approximate Riemann solver for GPU-Imogen was developed by Toro, Spruce, and Speares. ${ }^{14}$ Toro et al had taken an existing approximate Riemann solver developed by Harten, Lax, and van Leer ${ }^{17}$ (called HLL) and restored the missing contact wave back into the scheme. They called their new scheme HLLC (the $\mathrm{C}$ stands for contact). To evolve the system in time, the solver will have to approximate the solution to the Riemann problems at the boundaries seen in Figure 2. HLLC approximates the solution to the Riemann problem by 
splitting up the problem domain into four separate regions $\left(\mathrm{U}_{\mathrm{L}}, \mathrm{U}_{\mathrm{L}}{ }^{*}, \mathrm{U}_{\mathrm{R}}{ }^{*}\right.$, and $\left.\mathrm{U}_{\mathrm{R}}\right)$ as seen in Figure 3. The horizontal axis of this figure represents position (x) and the vertical axis represents time ( $\mathrm{t}$ ). The middle of Figure 3 is the position where the initial discontinuity between cells occurs. The domains are separated by the lines $S_{L}, S_{M}$, and $S_{R}$. Respectively, these lines track the location of the fastest wave moving to the left, the contact discontinuity, and the fastest wave moving to the right. After approximating the Riemann problem, the fluxes in step two of the fluid scheme can be calculated. For an exact description of how these fluxes are calculated see Batten's paper. ${ }^{18}$

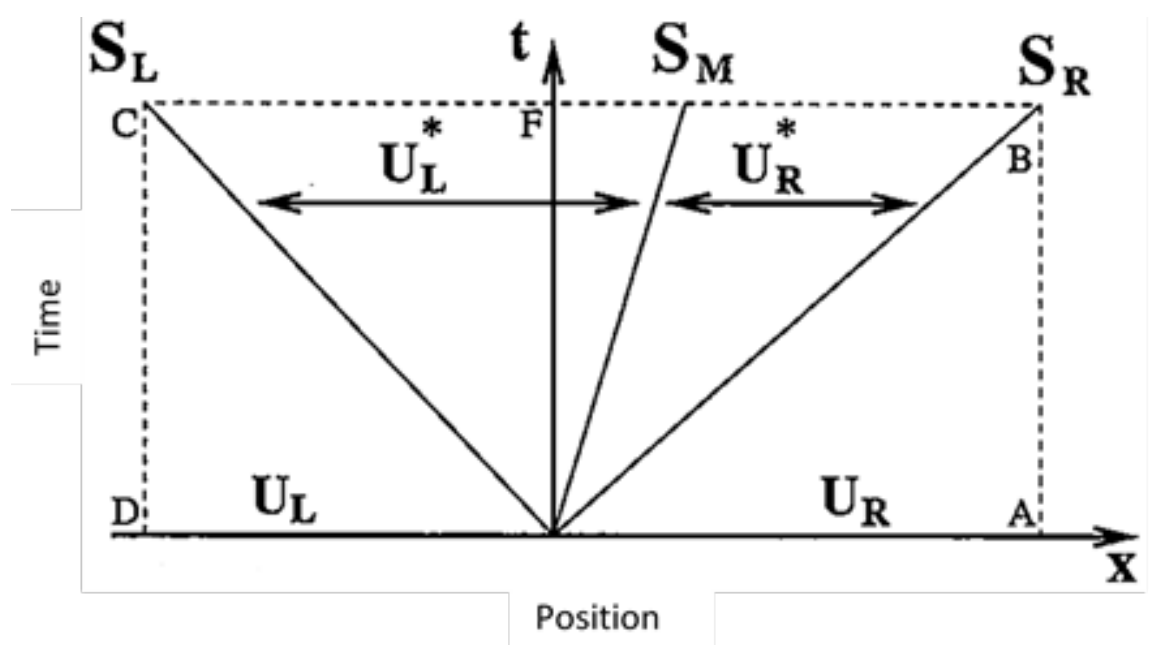

Figure 3: A visualization of how HLLC approximates a solution to the Riemann problem. Figure credit Batten. ${ }^{18}$

HLLC has been proven to be positivity conserving by Batten et $a l,{ }^{18}$ meaning that a problem with initially positive density will remain positive throughout the simulation. This is important because negative pressures are unphysical (they do not occur in nature) and they can cause codes to malfunction. Being positivity conserving is a property that not all approximate Riemann solvers have. For instance the Roe scheme ${ }^{19}$ has been shown to produce negative pressure and fail when given certain initial conditions such as Einfeldt's strong rarefaction test. ${ }^{20}$ Furthermore, Batten et al proves that by tracking the location of the contact discontinuity, HLLC has the ability to perfectly resolve stationary contact discontinuities.

\subsection{DIMENSIONAL SPLITTING}

We have described the fluid scheme in one dimension. In two dimensions, the one dimensional scheme is essentially run again independently in the second spatial dimension. In three dimensions, the process is split into three parts. This process is called directional splitting, or Strang splitting, as it was proposed by Strang in $1968 .{ }^{21}$ Since the flux calculation is split amongst dimensions, there is a possibility that some small systematic error will favor one direction. We explore this effect in section 4.2a.

\section{COMPUTER IMPLEMENTATION}




\subsection{COMPUTER ARCHITECTURE}

User level files for GPU-Imogen are written in MATLAB, a commonly used programming language by scientists and engineers. This means that at user level, GPU-Imogen is easy to understand and modify. The fluid scheme is written in CUDA, a parallel language for GPUs. Figure 4 shows the architecture of GPU-Imogen. If the user wants to run a simulation on only one node (one computer) then the left route in Figure 4 is taken. The user has the option to use one or multiple GPUs contained on that node. If the user wants to use multiple nodes (such as a GPU cluster) then MPI or "message passing interface" is used for communication between nodes.

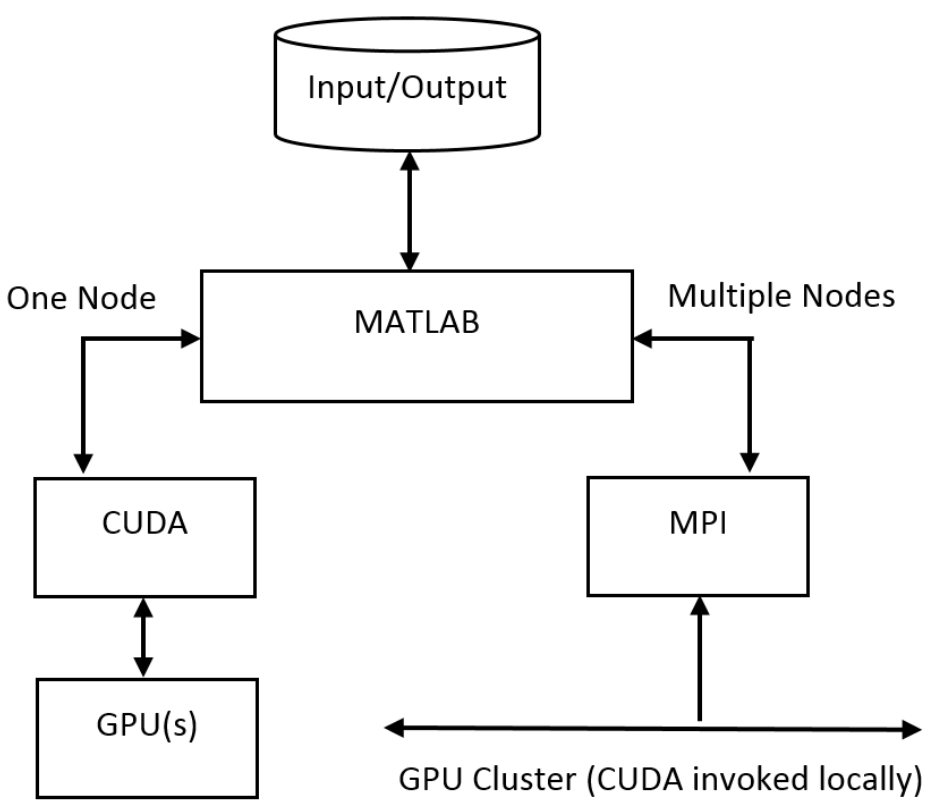

Figure 4: Architecture of GPU-Imogen.

\subsection{PARALLEL SCALING}

In parallel computing, weak scaling is the impact on efficiency when a problem is scaled up in size while the workload for each processor remains constant. For example, start with a problem of size $\mathrm{X}$ with $\mathrm{Y}$ processors, then double the size to $2 \mathrm{X}$ while also doubling the number of processors to $2 \mathrm{Y}$. If the amount of time to solve the new problem if roughly the same as the amount of time to solve the original, then your problem exhibits flat weak scaling and would translate nicely to a massively parallel environment. Keever explored weak scaling for one- and two-dimensional problems on his poster ${ }^{13}$ and found that GPU-Imogen exhibited roughly flat weak scaling for all tests. GPU-Imogen was tested on up to 72 GPUs simultaneously with the University of Oregon's supercomputer ACISS. With this flat weak scaling, GPU-Imogen can handle an arbitrarily large problem if given enough computing power. 


\section{BENCHMARK TESTS}

\subsection{ONE-DIMENSIONAL TESTS}

\section{1a Sod Shocktube}

\section{i. Background}

The Sod shock tube problem was first proposed in 1978 by Gary Sod, ${ }^{22}$ and has been regarded as a prototypical CFD test. This problem was designed to reveal the three different primitive waves in fluid dynamics, and to evaluate a code's ability to resolve each of these waves. These are the rarefaction wave, contact discontinuity, and shock wave.

\section{ii. Initial Conditions}

This test is defined by the following parameters: the left half of the tube has density $\rho=1$ and internal energy $\mathrm{e}=1$, while the right half has $\rho=.125$ and $\mathrm{e}=.1$.

\section{iii. Time-Evolved Behavior}

When released, the high pressure region on the left sends a shockwave to the right, which propagates through the low density region. The slower contact discontinuity also propagates to the right. The rarefaction wave recedes to the left. 

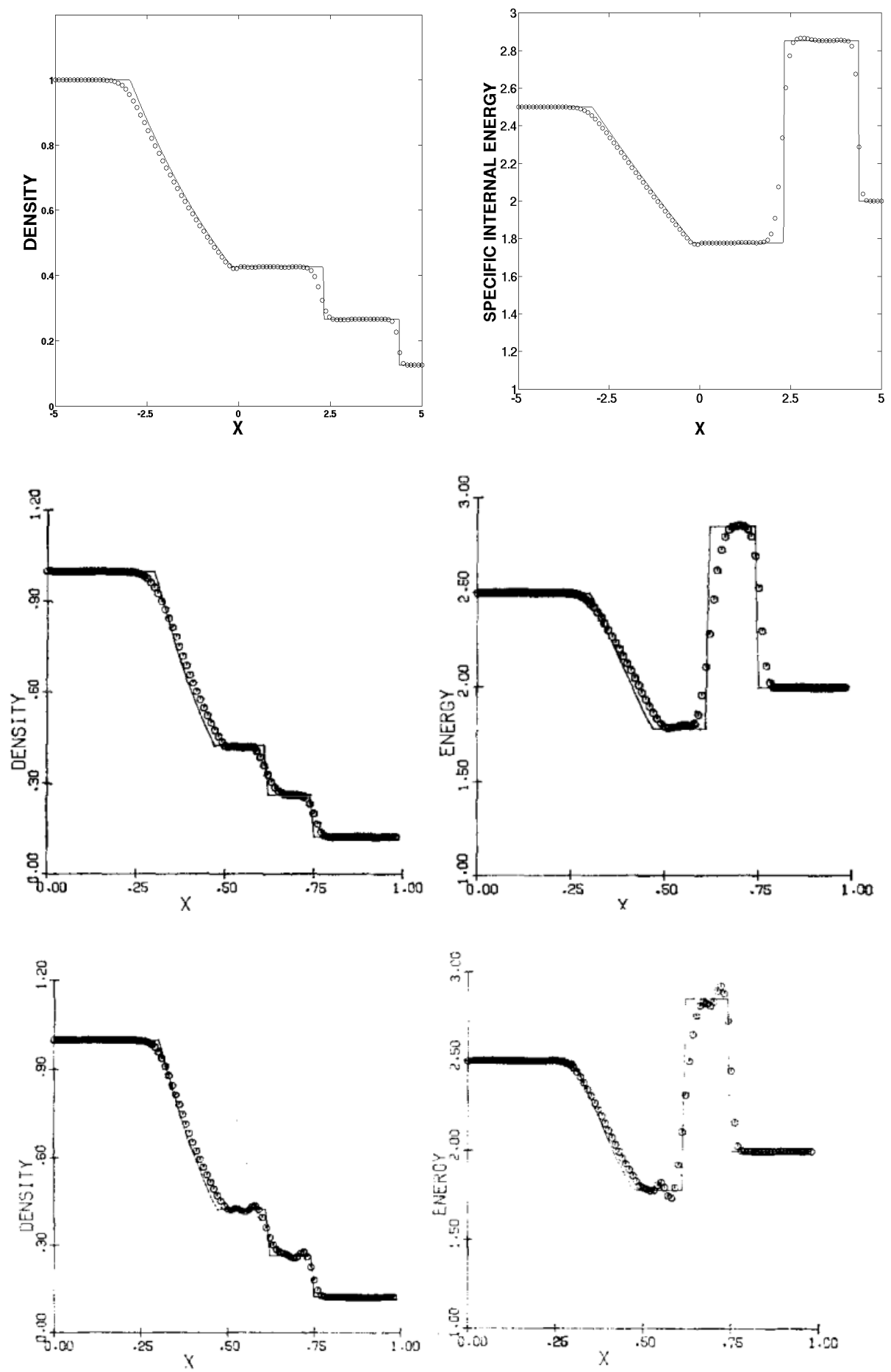

Figure 5: Sod Shock Tube at $t=.25$ for density (left) and specific internal energy (right). Spatial resolution of 100 cells. Analytic (exact) solutions are shown as solid lines, while each of the 100 computed cells are shown as circles. Schemes compared are GPU-Imogen (top), a 1storder Godunov scheme (middle), and a second-order MacCormack scheme (bottom).

MacCormack and Godunov figures credit Sod ${ }^{22}$ 
The contact discontinuity experiences diffusion, which has the effect of smearing out the contact. This is a non-physical artifact, because the velocity on either side of the contact is identical. If all the fluid around the contact is moving at the same speed, there should be no forces to induce mixing, so the contact should remain sharp. Notice how HLLC (the scheme used by GPU-Imogen) does not smear features as much as the first-order Godunov scheme. Also, HLLC does not suffer from the oscillatory overestimations at the contact and shock that MacCormack's second-order scheme introduces.

\section{1b Einfeldt Strong Rarefaction test}

\section{i. Background}

Einfeldt's Strong Rarefaction test evaluates a code's ability to maintain positivity (as defined in section 2.5) under extreme rarefactions. This happens when two slabs of fluid move away from each other, pulling a significant quantity of material out of some region, creating a low density region at the origin.

\section{ii. Initial Conditions}

To set up the test, we separate the grid into two equally sized regions on the right and left end of the grid. We define uniform density $\rho=1$ and internal energy e $=3$ everywhere, but with the fluid on the left moving to the left with momentum of -2, and the fluid on the right moving to the right with momentum of 2 .

\section{iii. Time-Evolved Behavior}

When released, the region in the center of the grid experiences a strong density rarefaction. Many fluid codes will overcompensate in their computation of this rarefaction, as outlined in Batten et al. ${ }^{18}$ In particular, many codes will, at some point, calculate a negative density within the rarefaction, which is a non-physical error, as mass density cannot have a negative value. However, HLL solvers (HLLC included) are guaranteed to maintain positivity under these conditions. ${ }^{18}$ We compared the results from Einfeldt and Roe et al, ${ }^{20}$ who used a similar firstorder HLL solver called HLLE to evaluate this test, to our results using GPU-Imogen. The results are shown in Figure 6. The results confirm that GPU-Imogen handles the rarefaction test well, maintaining positivity as advertised. 

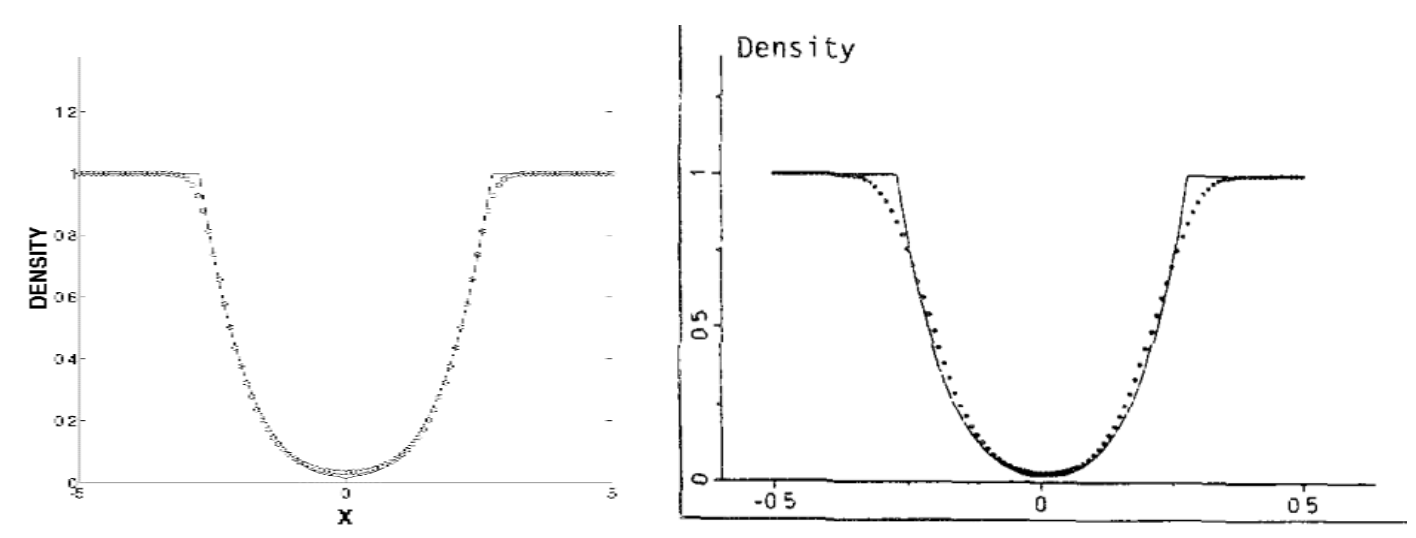

Figure 6: Numerical result of the HLLC-scheme (left) and the HLLE-scheme given in Einfeldt ${ }^{20}$ (right) at time $t=0.1$.

\section{1c. Shu-Osher test}

\section{i. Background}

This test evaluates a code's ability to capture both shocks and fine detail in smooth regions simultaneously. The particular details of the test were laid out by Shu, C and Osher, S. ${ }^{23}$

\section{ii. Initial Conditions}

For this test, we use a domain of $(-5,5)$ for $\mathrm{x}$. The left tenth of our grid (ie $-5<\mathrm{x}<-4)$ is a high pressure region moving to the right (density $\rho=3.857$; horizontal velocity $\mathrm{Vx}=2.629$, pressure $\mathrm{P}$ $=10.333$ ), and the rest of the grid contains a stationary series of low-density sinusoidal waves. These sinusoidal fluctuations are described by

$$
\rho=1+0.2 \sin (5 x) ; V x=0 ; P=1
$$

in the region of $-4<x<5$.

\section{iii. Time-Evolved Behavior}

When released, the shockwave propagates into the density structures. These structures become distorted, attaining both higher frequency and higher amplitude. This frenetic region can prove problematic for certain codes. In particular, some of the extremes in this region can be lost. In Shu and Osher's 1989 paper, ${ }^{23}$ they compared the numerical solutions of this test for several different solvers. Shu and Osher observe that higher order schemes are significantly better at capturing detail in the frenetic region, as seen in Figure 7. In Figure 8, we notice that GPU-Imogen is better at capturing all extrema in the frenetic region than the MUSCL scheme, despite both schemes being second order. We see that the accuracy and robustness of a code depends on more than its order, which prompts a discussion of convergence order, detailed in section 5 . 

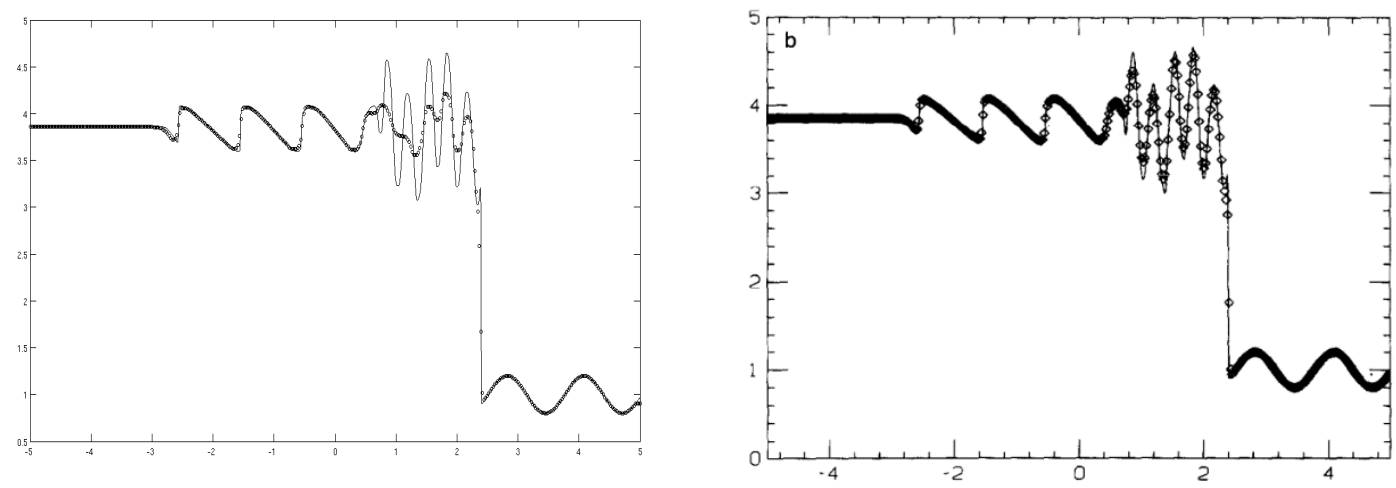

Figure 7: GPU-Imogen using 2nd order HLLC (left) compared with 3nd order ENO (right), both at 400 points. Note that the 3 rd order code provides nearly perfect resolution of the extrema.
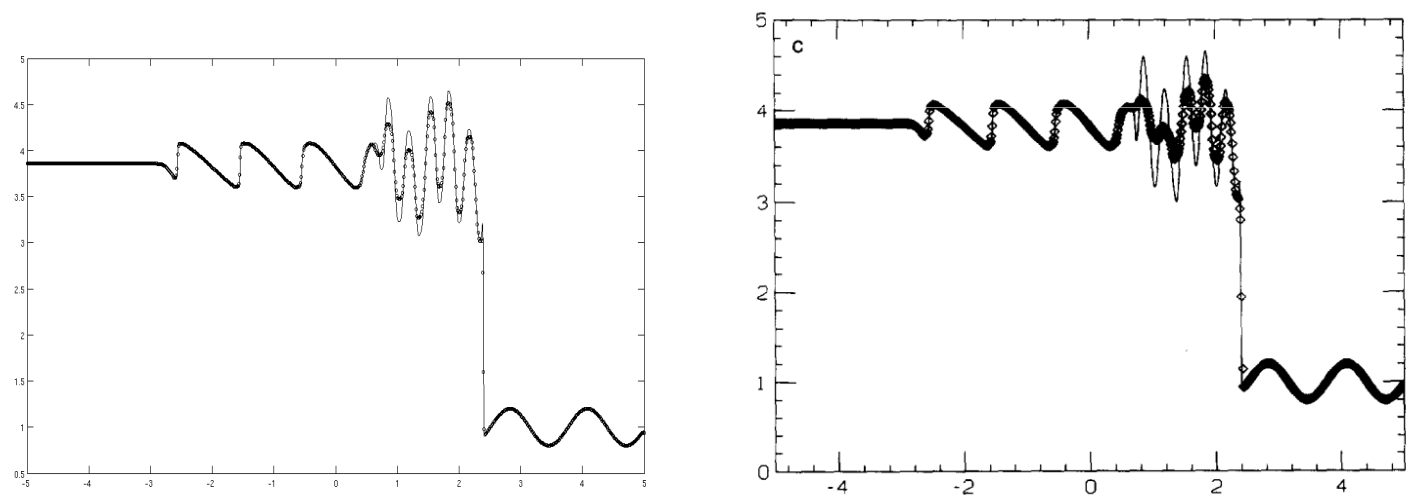

Figure 8: GPU-Imogen using 2nd order HLLC (left) compared with 2nd order MUSCL (right), both at 800 points.

\subsection{TWO-DIMENSIONAL TESTS}

\section{2a Implosion Test}

\section{i. Background}

This is a test often used to demonstrate the preservation of symmetry, or failure to preserve symmetry, along diagonal lines. HLLC uses a dimensional splitting method, as described in section 2.4. When fluid is moving along a diagonal path, its motion may first be updated left-toright, then later updated top-to-bottom. Though this makes the calculations far simpler, it has the effect of disturbing the diagonal symmetry of a flow. To demonstrate this, we run the implosion test, first conceived by $\mathrm{Hui}, \mathrm{Li}$, and $\mathrm{Li}^{24}$ 


\section{ii. Initial Conditions}

In Hui, Li, and Li's test, they placed a square diamond of low density and pressure in the center of an otherwise uniform square grid, creating a quadrilaterally symmetric flow upon release. We instead simulate only the upper right corner of Hui, Li, and Li's model, as previously done by Liska and Wendroff. ${ }^{26}$

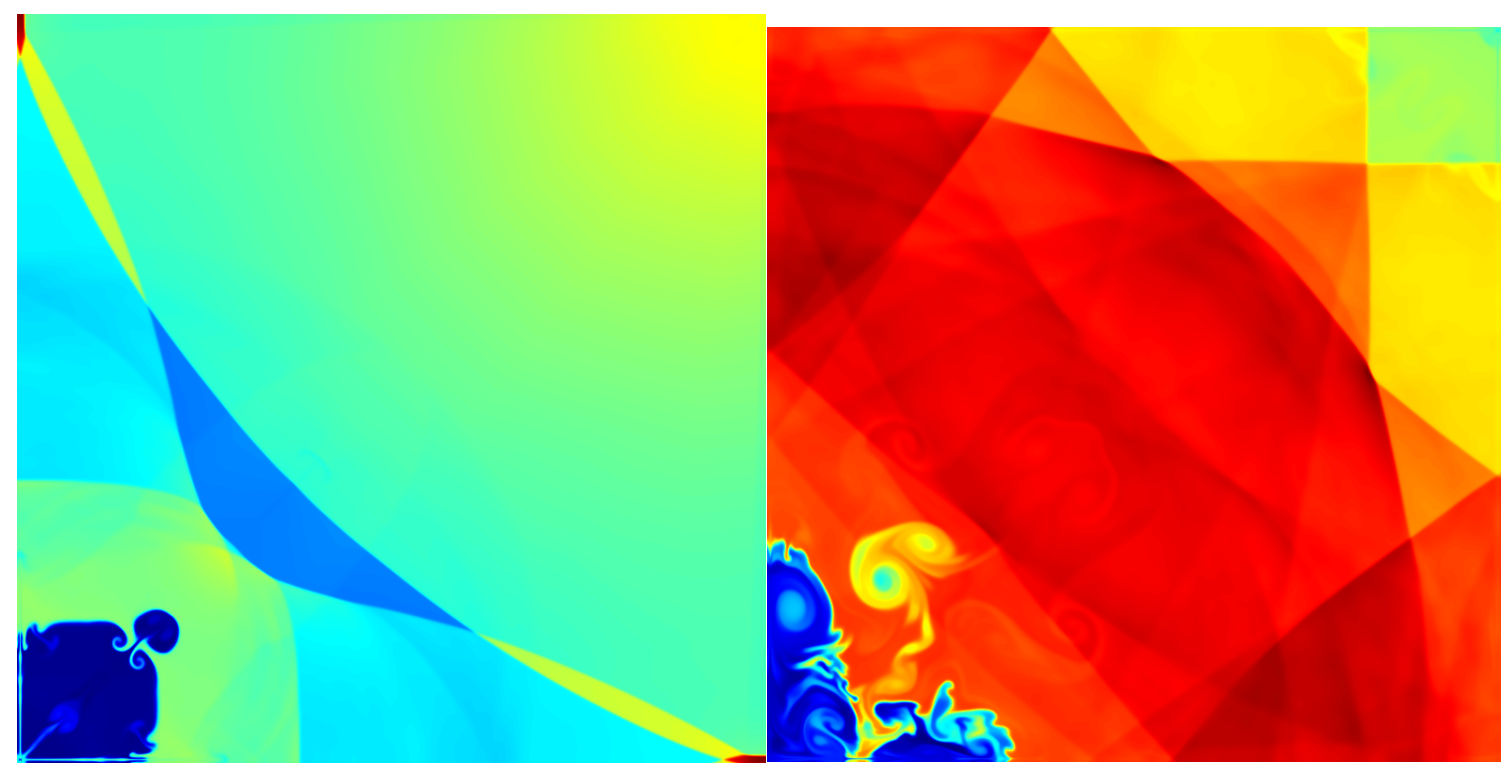

Figure 9: GPU-Imogen's simulation of the implosion test at $t=0.6$ (left) and $t=3.9$ (right). Resolution of $800 x 800$ with density color plot shown. Note that, at the early stage, diagonal symmetry has not yet been visibly broken, but over time, errors accumulate, and the jet deflects away from its diagonal path.

\section{iii. Time-Evolved Behavior}

When released, a shock rushes into the low-density region in the bottom left corner, and reflects off of the left and bottom edges simultaneously. The high-pressure fluid flowing along the edges of the grid then meets in the corner, squeezing out a jet that travels along the diagonal from bottom left to upper right. As this jet travels along the diagonal, GPU-Imogen begins to accumulate errors that cause the jet to distort more and more over time. Liska and Wendroff compare the performance of several different solvers on the implosion test, some of which preserve symmetry and some of which fail to do so. We observe that GPU-Imogen performs similarly to the JT solver in terms of diffusivity, but fails to preserve symmetry to an extent comparable to VH1. Schemes that are directionally unsplit will preserve the symmetry along the diagonal in this test; however, these schemes can be much more complicated to implement. Every hydrodynamics program has strengths and weaknesses, so it is impractical to seek a 'perfect' code, making these symmetry errors tolerable in light of the strengths of HLLC. 


\section{2b Rayleigh-Taylor Instability Test}

\section{i. Background}

The Rayleigh-Taylor Instability (RTI) is a phenomenon that can occur when a heavier fluid sits on top of a lighter fluid under the influence of gravity. In our case, we utilized GPU-Imogen's constant gravity field feature.

\section{ii. Initial Conditions}

For our test, we used a $400 \times 800$ grid. We gave the top half a density of 2, and the bottom half a density of 1 , and placed a small sinusoidal momentum perturbation at the interface. This perturbation is defined by

$$
y=.5+.01^{*}\left(1+\cos \left(2 p i^{*} x\right)\right)
$$

\section{iii. Time-Evolved Behavior}

When released, the heavy fluid will attempt to fall through the lighter fluid, but cannot do so uniformly, because the lighter fluid must be pushed out of the way. Small scale fluctuations on the boundary between fluids will become unstable and self-amplify over time.
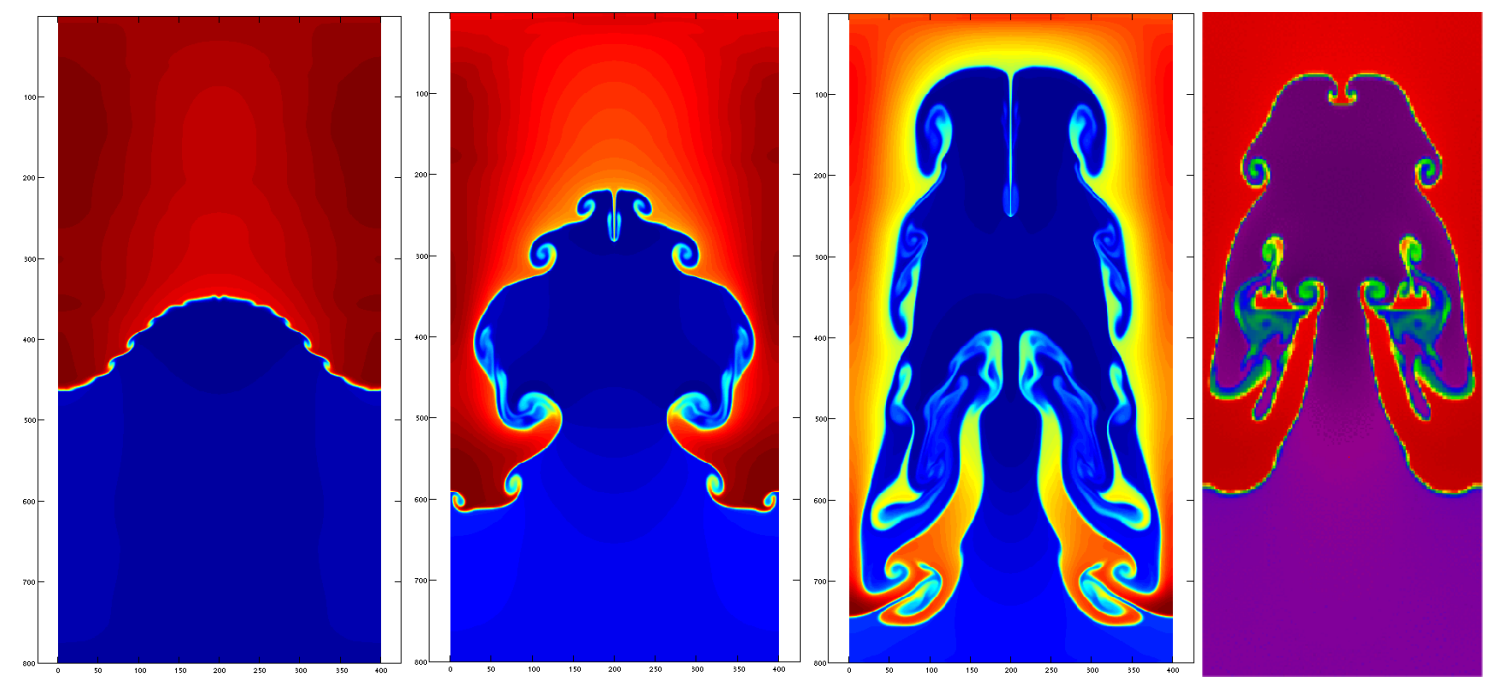

Figure 10: RTI at $\mathrm{T}=2$ (left), $\mathrm{T}=3$ (left middle) and $\mathrm{T}=4$ (right middle) at $400 \times 800$. Athena's solution to RTI at $\mathrm{T}=8.5$ at $200 \times 400$ is on the right.

The RTI is a good indicator of the diffusivity of a scheme, since these two fluids are separated by a contact discontinuity. The sharpness of our stationary contacts is no surprise, but we see some diffusion in regions of local vorticity, or rotational motion. This is because HLLC is best at preserving stationary contacts. Within regions of vorticity, such as the spiral forming in 
panel 2 of Figure 10, contacts are in constant motion in multiple directions, so HLLC's contact preservation worsens. Overall, GPU-Imogen handles this RTI comparably to other top codes.

\section{2c Richtmyer-Meshkov Instability Test}

\section{i. Background}

The Richtmyer-Meshkov instability (RMI) occurs when a shock wave passes through a nonuniform fluid interface. Any small perturbations in the flatness of the interface will cause the shock to refract around it. Since the interface is not a straight line, but a curve, the shock will refract by different amounts at each point along the interface. Thus, the rotational motion at each point on the interface will be different. Specifically, the local rotation on either side of any peak on the interface will spin in opposite directions, amplifying the velocity of any fluid caught between those fields. This extrudes a jet from the peak, which moves in a direction opposite the shockwave's motion.

\section{ii. Initial Conditions}

For our test, we used a $400 x 800$ grid with coordinates $(0,1) \mathrm{x}(0,2)$ where fluid with a density of 5 sits below the line $y=.15$. We added a single sinusoidal perturbation on the interface, and placed a subsonic incident wave at Mach 0.66 just above the perturbation.

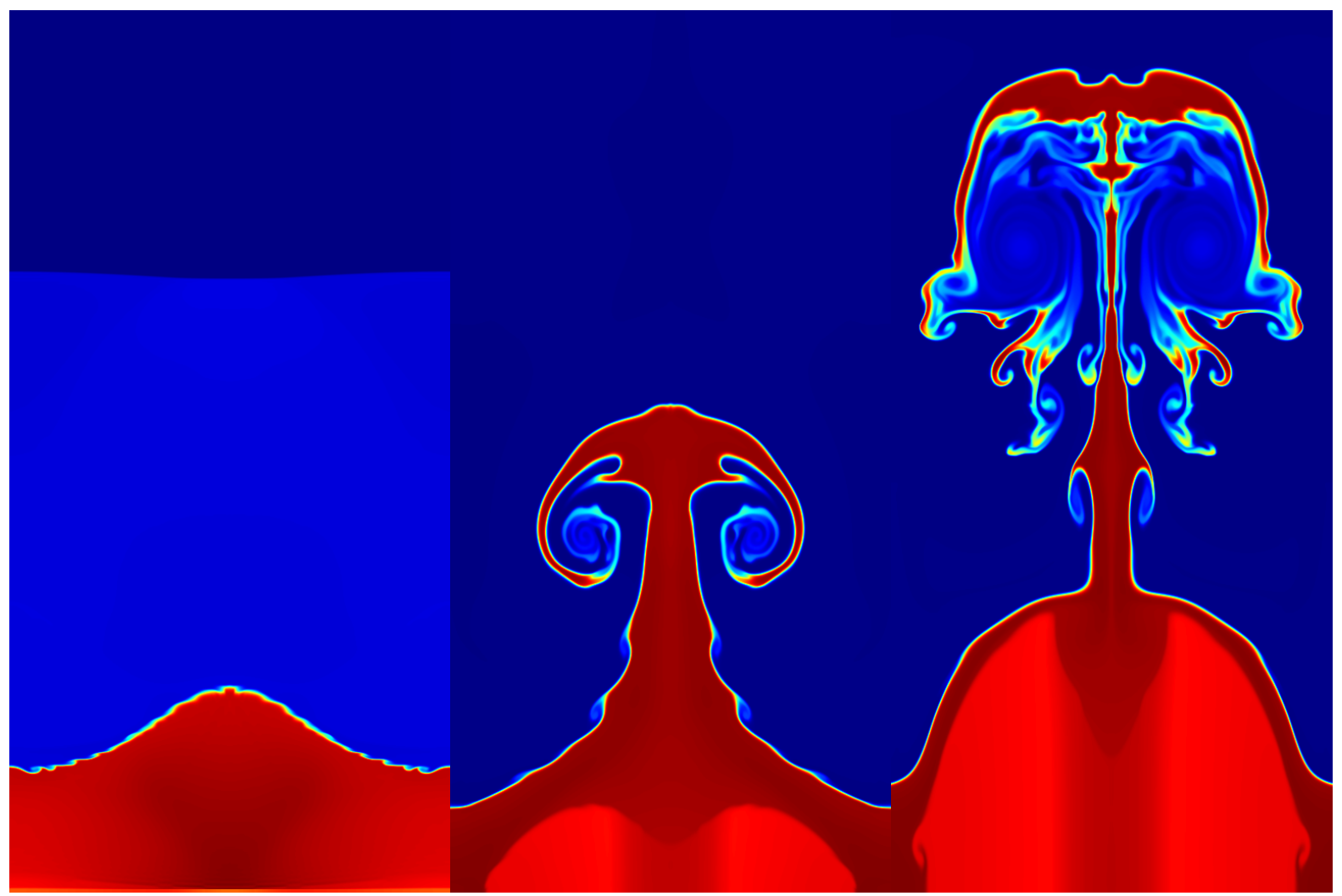

Figure 11: $\mathrm{RMI}$ at $\mathrm{T}=1$ (left), $\mathrm{T}=8$ (middle) and $\mathrm{T}=24$ (right) on a $400 x 800$ grid. 


\section{iii. Time-Evolved Behavior}

When released, the shock wave immediately refracts around the perturbation, causing it to deform into a jet. RMI is an interesting test to run, because at sufficiently high resolutions, we can begin to observe other fluid phenomena occurring at the interface between the light and heavy fluids. On the stem of the jet in Figure 11, we see the beginning of a Kelvin-Helmholtz instability, forming due to the relative speed of the heavy fluid with respect to the light fluid at that interface. GPU-Imogen properly simulates this phenomenon.

\subsection{THREE-DIMENSIONAL TESTS}

\section{3a Vortex Ring}

\section{i. Background}

A vortex ring is a self-propagating toroidal vortex that travels along the normal to the plane of the ring. Examples of vortex rings include smoke rings made by human smokers, mushroom clouds formed by nuclear detonations, and bubble rings made by dolphins.

\section{ii. Initial Conditions}

To form our vortex ring, we created a thin cylinder of fluid moving through a stationary fluid along the normal to its circular plane. The cylinder does not need to have any other special properties besides this momentum. This replicates the conditions that would be present if an experimenter used a syringe to inject fluid into a stationary medium. 


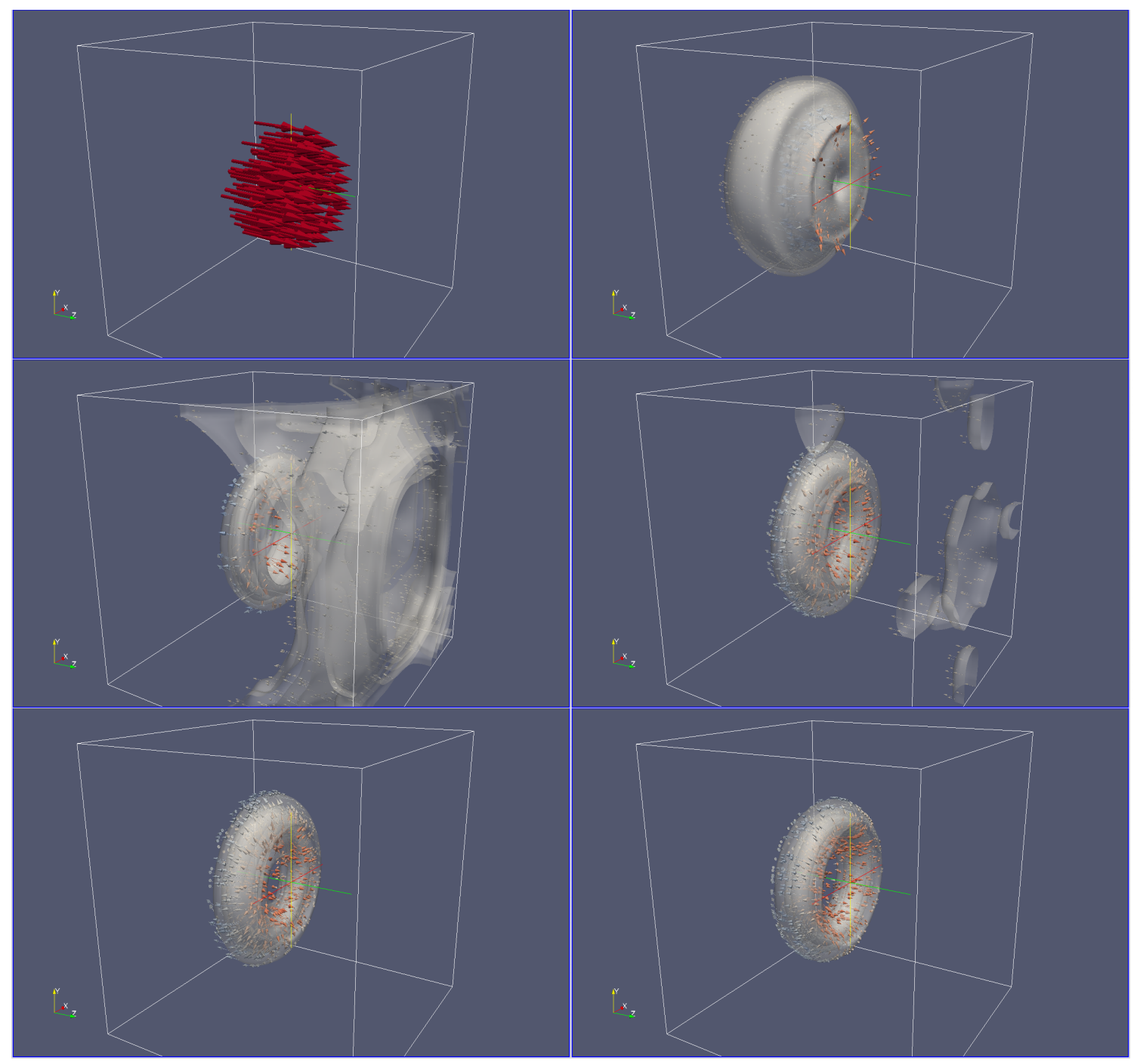

Figure 12: Formation of a vortex ring from a moving cylinder on a 100x100x100 grid. Frames taken at times $\mathrm{T}=0, .12, .67, .94,1.35$, and 2.73. Shown are density isosurfaces and velocity arrows. Isosurfaces are drawn at density values of .978, .984, .990, and .997.

\section{iii. Time-Evolved Behavior}

As this cylinder travels, fluid at its surface experiences friction, causing its outer layers to peel away from front to back, creating vorticity (local spinning) at its surface. As it travels, this vorticity self-perpetuates, deforming the cylinder into a torus that maintains this rotational motion. If left undisturbed, this vortex will propagate in the direction of the cylinder's original momentum. This demonstrates GPU-Imogen's ability to simulate three dimensional problems.

\section{ERROR ANALYSIS}

GPU-Imogen features a full self-test routine that runs various tests to check that the fluid schemes are working properly. It also conducts error convergence analysis. For problems with 
derived (exact) solutions, such as the Sod Shock Tube and simple bulk fluid transport (advection), the self-test automatically runs tests at increasingly refined grid resolutions to examine exactly how quickly the approximate solution converges to the derived solution. We would refer to this speed as the convergence order, which should align with the order of the scheme. The piecewise linear reconstruction used by GPU-Imogen can be verified to be secondorder accurate from this test.

GPU-Imogen measures error using L2 norms. These refer to the cumulative error across all cells, evaluated by

$$
\mathrm{L} 2=\frac{1}{\sqrt{\mathrm{N}}} \sqrt{\sum_{i}^{\mathrm{N}} \mathrm{E}(i)^{2}}
$$

where

$$
E(i)=F_{\text {Approximate }}(i)-F_{\text {Exact }}(i)
$$

is the difference between the approximate solution and the exact derived solution at each cell index i. $\mathrm{N}$ refers to the total number of cells on the grid, often called the grid resolution. Normally, the L2 norm is preferred over the L1 norm as a measure of convergence, since compared to the L1 norm, it places less importance on the few outliers that have significantly more error than the rest of the grid.

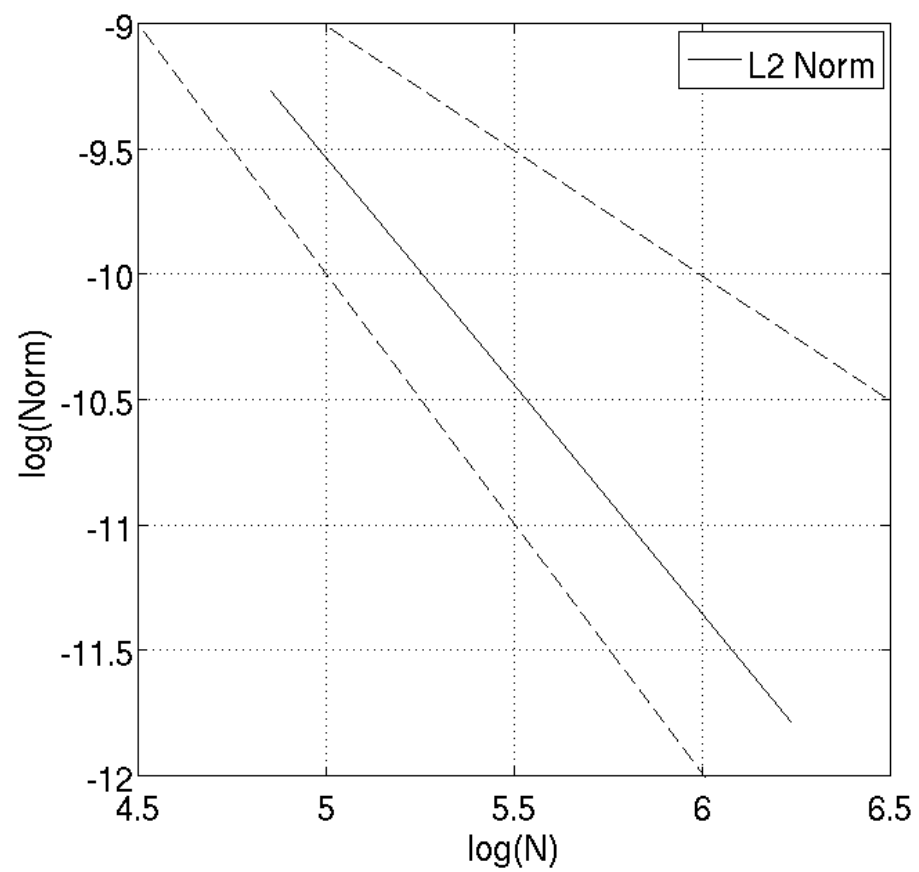

Figure 13: L2 norm for a simple, smooth fluid advection test. The dashed lines are reference lines with slopes of -1 and -2 . 
Figure 13 shows that the convergence order of GPU-Imogen's fluid scheme on the smooth advection problem is 2, as measured by the L2 norm. This confirms that the piecewise linear reconstruction scheme it uses is indeed second-order.

In some cases, advanced low-order schemes like HLLC can be more accurate per computation time than high-order schemes. This can be true in problems containing discontinuities, where all non-front-tracking codes are necessarily (formally at least) first order. To demonstrate this, we run convergence tests on the Sod Shock Tube, which contains several discontinuities.

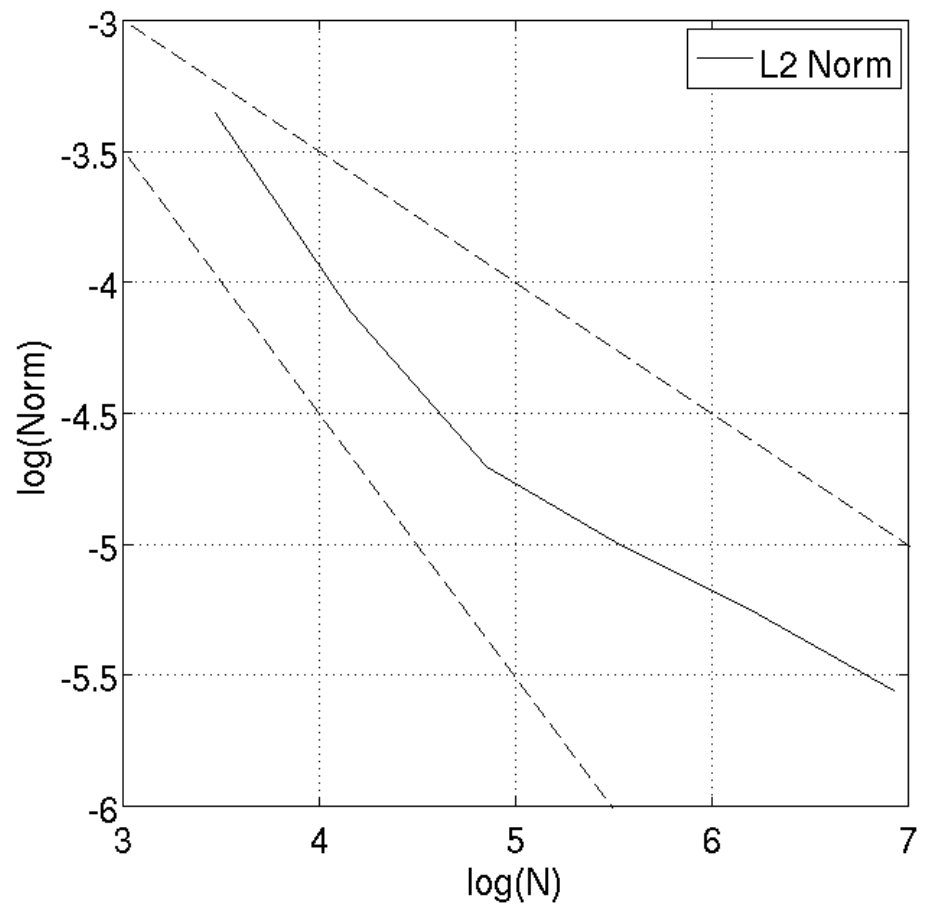

Figure 14: L2 norm for the Sod Shock tube problem. Dashed lines are reference lines with slopes of -0.5 and -1 .

In Figure 14, note that the slope of the L2 line is piecewise. The kinks in this line show the critical resolution at which large features become fully resolved. Beyond those resolutions, the approximation converges at a slower rate. But more significantly, the convergence rate here never reaches second-order. This is because the error in the position of a discontinuity is first order, so any code more accurate than first-order will be wasting its effort on such problems, as the error in the discontinuity will disturb any accuracy that may have been maintained by the higher-order scheme. This would mean that, since higher-order schemes require more computation, one could increase efficiency in such situations by switching to an advanced lowerorder scheme on a higher resolution.

It is fortunate that we have exact derived solutions to these particular problems, as it allows these types of quantitative analysis to give rigorous feedback on the performance of CFD codes. Without exact derived solutions, conversations about error and convergence become 
speculative. This makes tests like the Sod Shock tube and advection tests highly valuable to the CFD community.

\section{CONCLUDING REMARKS}

The point of this paper is to present the astrophysical hydrodynamic code GPU-Imogen, and to explore its features. We have shown through our benchmark tests that GPU-Imogen is robust and accurate. We have shown that HLLC is adept at capturing contact discontinuities, which allows us to resolve sharp interfaces on tests. We have also presented how GPU-Imogen is scalable to large GPU clusters, and how the use of MATLAB at surface level is user friendly. In conclusion, GPU-Imogen is a strong choice as an astrophysical CFD code.

\section{FUTURE DIRECTIONS}

We focused on running standard benchmark tests on GPU-Imogen to demonstrate its robustness. A next step is to run more subtle real world problems. One such problem is stellar accretion, where matter spirals in towards a star and is deposited at the surface. An eventual project would be to investigate ways to extend the existing HLLC scheme to include magnetism without having to scrap the scheme altogether. Researchers have been making breakthroughs in extending HLLC to include magnetism as recently as June of $2015 .{ }^{26}$ This would allow us to maintain the robustness and efficiency of GPU-Imogen while broadening the scope of possible experiments to the field of MHD.

\section{ENDNOTES}

1. M. N. Lemaster, J. M. Stone, T. A. Gardiner, "Effect of the Coriolis Force on the Hydrodynamics of Colliding-Wind Binaries," The Astrophysical Journal 662, 582 (2007).

2. Y. Shen, J. M. Stone, T. A. Gardiner, "Three-dimensional Compressible Hydrodynamic Simulations of Vortices in Disks," The Astrophysical Journal 653, 513 (2006).

3. M. Shin, J. M. Stone, G. F. Snyder, "The Magnetohydrodynamics of Shock-Cloud Interaction in Three Dimensions," The Astrophysical Journal 680, 336 (2008).

4. R. Dong, J. M. Stone, "Buoyant Bubbles in Intracluster Gas: Effects of Magnetic Fields and Anisotropic Viscosity," The Astrophysical Journal 704, 1309 (2009).

5. A. V. Kravtsov, Ph. D Thesis, New Mexico State University, 2000.

6. B. W. O’Shea, "Introducing Enzo, an AMR Cosmology Application," arXiv preprint astro-ph/0403044 (2004).

7. M. Gonzalez, E. Audit, P. Huynh, "HERACLES: a three-dimensional radiation hydrodynamics code," A\&A 464, 429 (2007). 
8. J. M. Stone, T. A. Gardiner, P. Teuben, J. F. Hawley, J. B. Simon, "Athena: a new code for astrophysical MHD," The Astrophysical Journal Supplement Series 178, 137 (2008).

9. U. Ziegler, "Self-gravitational adaptive mesh magnetohydrodynamics with the NIRVANA code," A\&A 435, 385 (2005).

10. J. C. Hayes et al, "Simulating Radiating and Magnetized Flows in Multiple Dimensions with ZEUS-MP," The Astrophysical Journal Supplement Series 165, 188 (2006).

11. S. Jin, Z. Xin, "The relaxation schemes for systems of conservation laws in arbitrary space dimensions," Communications on Pure and Applied Mathematics 48, 235 (1995).

12. S. Ernst, Ph.D Thesis, University of Oregon, 2011.

13. J. N. Imamura, E. Keever, "Imogen: a parallel 3D fluid and MHD code for GPUs," Proceedings of the 27th international ACM conference on International conference on supercomputing (ICS '13), 479 (2013).

14. E. F. Toro, M. Spruce, W. Speare, "Restoration of the contact surface in the HLLRiemann solver," Shock Waves 4, 25 (1994).

15. S. K. Godunov, "A difference scheme for numerical computation of discontinuous solution of hyperbolic equation," Mathematicheskii Sbornik 47, 271 (1959).

16. P. K. Sweby, "High resolution schemes using flux-limiters for hyperbolic conservation laws," SIAM Journal on Numerical Analysis 21, 995 (1984).

17. A. Harten, P. D. Lax, B. van Leer, "On upstream differencing and Godunov-type schemes for hyperbolic conservation laws," SIAM Review 25, 35 (1983).

18. P. Batten, N. Clarke, C. Lambert, D. M. Causon, "On the Choice of Wavespeeds for the HLLC Riemann Solver," SIAM Journal on Scientific Computing 18, 1553 (2006).

19. P. L. Roe, "Approximate Riemann Solvers, Parameter Vectors, and Difference Schemes," Journal of Computational Physics 43, 357 (1981).

20. Einfeldt et al, "On Godunov-Type Methods near Low Densities," Journal of Computational Physics 92, 273 (1991).

21. G. Strang, "On the construction and comparison of different splitting schemes," SIAM Journal on Numerical Analysis 5, 506 (1968).

22. G. A. Sod, "A survey of several finite difference methods for systems of nonlinear hyperbolic conservation laws," Journal of Computational Physics 27, 1 (1978).

23. C. Shu, S. Osher, "Efficient Implementation of Essentially Non-Oscillatory ShockCapturing Schemes, II," Journal of Computational Physics 83, 32 (1989). 
24. W. Hui, P. Li, Z. Li, "A unified coordinate system for solving the two-dimensional euler equations," Journal of Computational Physics 153, 596 (1999).

25. R. Liska, B. Wendroff, "Comparison of Several Difference Schemes on 1D and 2D Test Problems for the Euler Equations," SIAM Journal on Scientific Computing archive 25, 995 (2003).

26. X. Guo, "An extended HLLC Riemann solver for the magneto-hydrodynamics including strong internal magnetic field," Journal of Computational Physics 290, 352 (2015).

\section{ACKNOWLEDGEMENTS}

This research would not have been possible without the continual mentorship, dedication and availability of Erik Keever. We also want to thank Professor James Imamura for the use of his lab and mentorship. 